Florida International University

FIU Digital Commons

$3-5-2020$

\title{
Mechanical Properties of Permanent Foaming Fixatives for Deactivation \& Decommissioning Activities
}

Tristan Maximilian Simoes-Ponce

Florida International University, tsimo011@fiu.edu

Follow this and additional works at: https://digitalcommons.fiu.edu/etd

Part of the Applied Mechanics Commons, Energy Systems Commons, and the Other Mechanical Engineering Commons

\section{Recommended Citation}

Simoes-Ponce, Tristan Maximilian, "Mechanical Properties of Permanent Foaming Fixatives for Deactivation \& Decommissioning Activities" (2020). FIU Electronic Theses and Dissertations. 4439. https://digitalcommons.fiu.edu/etd/4439

This work is brought to you for free and open access by the University Graduate School at FIU Digital Commons. It has been accepted for inclusion in FIU Electronic Theses and Dissertations by an authorized administrator of FIU Digital Commons. For more information, please contact dcc@fiu.edu. 


\title{
FLORIDA INTERNATIONAL UNIVERSITY
}

\author{
Miami, Florida
}

\section{MECHANICAL PROPERTIES OF PERMANENT FOAMING FIXATIVES FOR DEACTIVATION \& DECOMMISSIONING (D\&D) ACTIVITIES}

\author{
A thesis submitted in partial fulfillment of \\ the requirements for the degree of \\ MASTER OF SCIENCE \\ in \\ MECHANICAL ENGINEERING \\ by \\ Tristan Simoes-Ponce
}


To: Dean John L. Volakis

College of Engineering and Computing

This thesis, written by Tristan Simoes-Ponce, and entitled Mechanical Properties of Permanent Foaming Fixatives for Deactivation \& Decommissioning (D\&D) Activities, having been approved in respect to style and intellectual content, is referred to you for judgment.

We have read this thesis and recommend that it be approved.

$\begin{array}{r}\text { Leonel Lagos } \\ \hline \text { Cesar Levy } \\ \hline \text { Bames Connor Nicholson } \\ \hline \text { Benjamin Boesl, Major Professor }\end{array}$

Date of Defense: March 5, 2020

The thesis of Tristan Simoes-Ponce is approved.

Dean John L. Volakis College of Engineering and Computing

Andrés G. Gil

Vice President for Research and Economic Development and Dean of the University Graduate School

Florida International University, 2020 


\title{
ABSTRACT OF THE THESIS \\ MECHANICAL PROPERTIES OF PERMANENT FOAMING FIXATIVES FOR DEACTIVATION \& DECOMMISSIONING (D\&D) ACTIVITIES
}

\author{
by
}

Tristan Simoes-Ponce

Florida International University, 2020

Miami, Florida

\section{Professor Benjamin Boesl, Major Professor}

The Department of Energy is investigating fixative technologies that encapsulate and/or immobilize residual contamination in voids during deactivation and decommissioning (D\&D). These technologies must have adequate mechanical and adhesion properties to withstand seismic activity that may occur. One solution is the implementation of polyurethane foams used as permanent foaming fixatives (PFF), specifically intumescent foams that contain expandable graphite, making them fire resistant when exposed to extreme heat conditions.

Tensile, compression, seismic, and tensile adhesion testing was done on six commercial-off-the-self polyurethane foams to determine if the expandable graphite and other filler intumescent technologies improve its mechanical limits. It was found the expandable graphite loading allowed intumescent foam to have the highest tensile and compressive stresses of the six tested foams, with better adhesion on rougher surfaces than smoother surfaces. Shear adhesion testing showed a near-fit linear relationship with surface area and no dependency on volume. Seismic stressor testing showed adhesion decreased by $19.8 \%$ compared to the control. 


\section{TABLE OF CONTENTS}

CHAPTER

PAGE

CHAPTER I - INTRODUCTION ..................................................................... 1

1.1 Problem Statement ................................................................................. 1

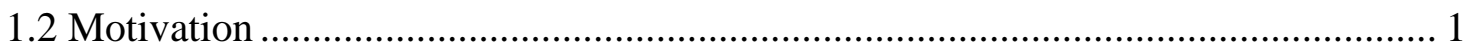

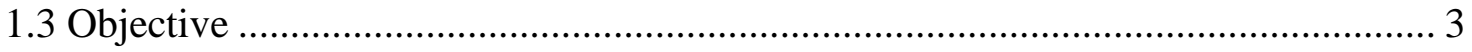

CHAPTER II - LITERATURE REVIEW ........................................................ 5

2.1 Background of Polyurethanes ....................................................................... 5

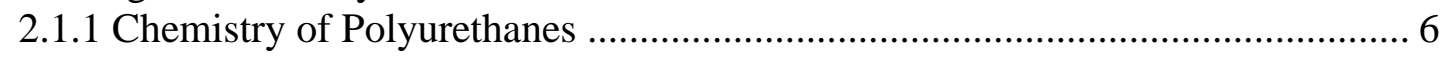

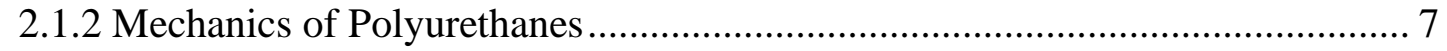

2.1.3 Adhesion Mechanisms of Polyurethanes........................................................ 11

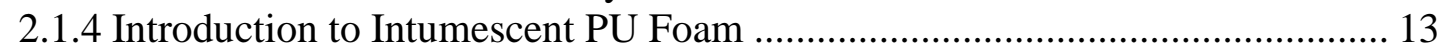

2.2 Previous Mechanical Testing on Polyurethane Foams ........................................ 14

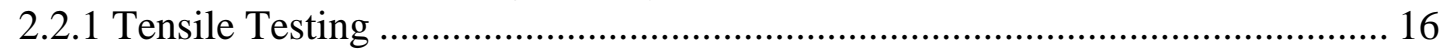

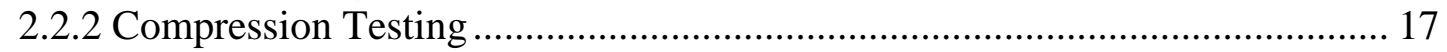

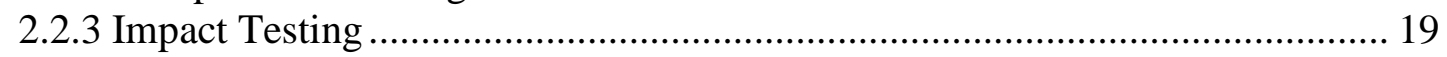

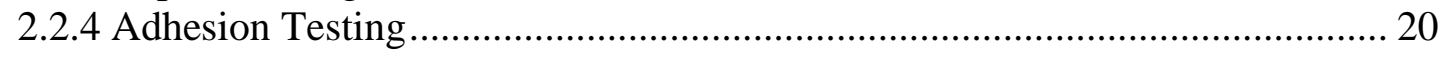

2.3 Radiological Shielding Tests by SRNL ........................................................ 21

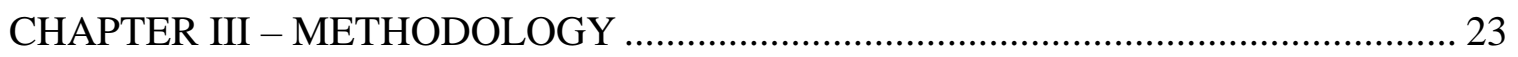

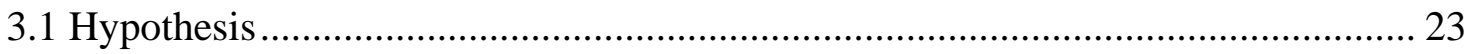

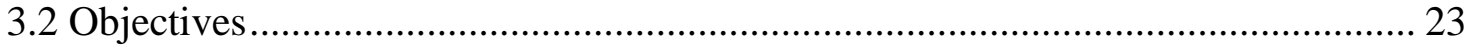

3.2.1 Objective 1 - Effects of Filler on Mechanical Performance ........................... 24

3.2.2 Objective 2 - Adhesion Characterization ..................................................... 24

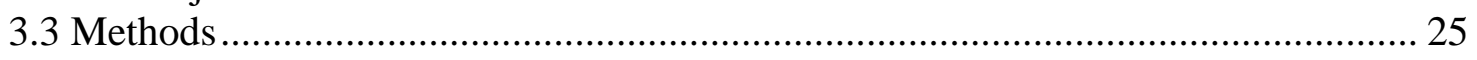

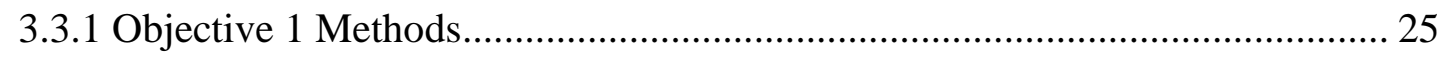

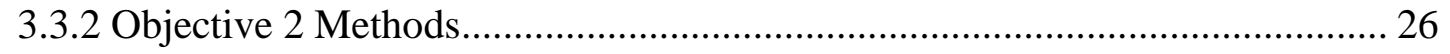

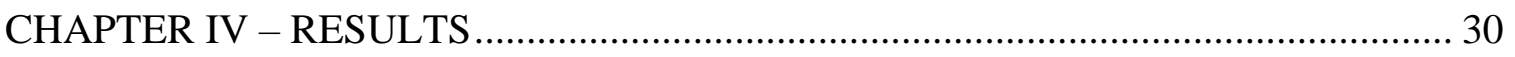

4.1 Objective 1 - Effects of Filler on Mechanical Performance .................................. 30

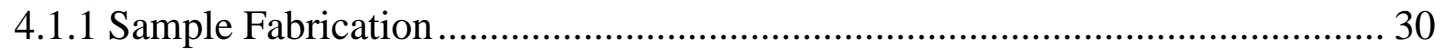

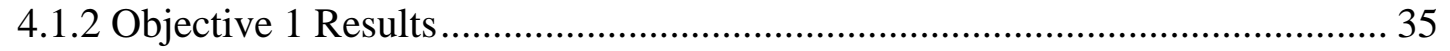

4.2 Objective 2 - Adhesion Characterization .......................................................... 44

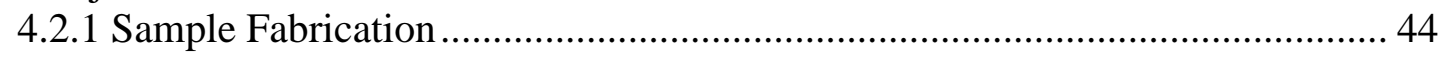

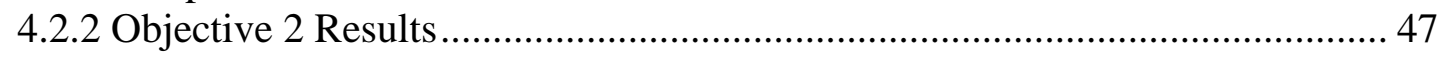

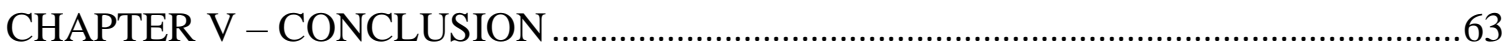

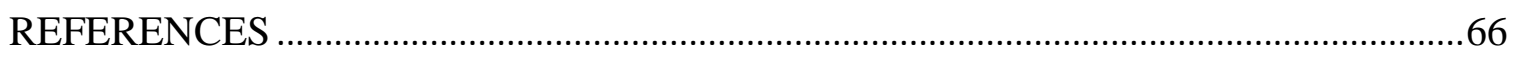




\section{$\underline{\text { LIST OF TABLES }}$}

TABLE

PAGE

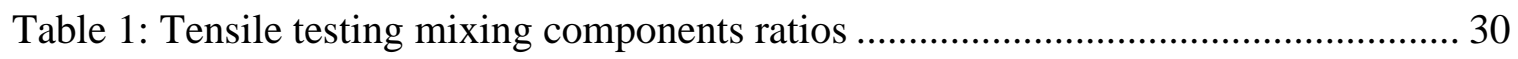

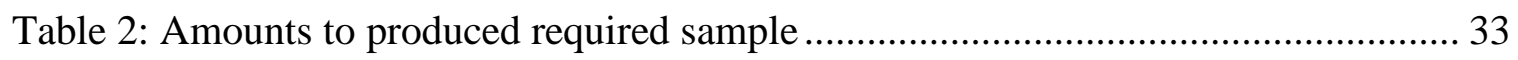

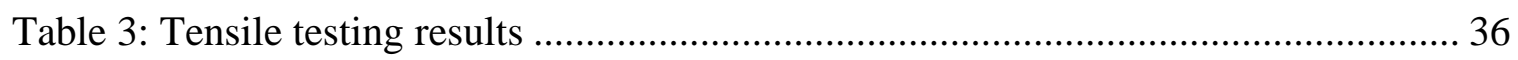

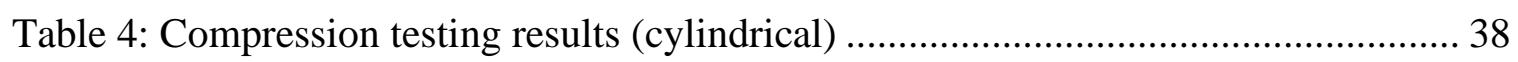

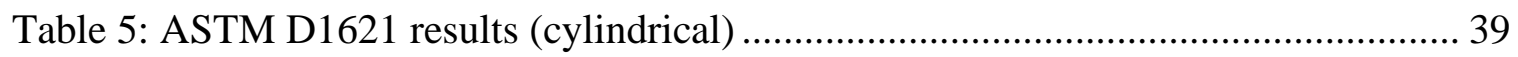

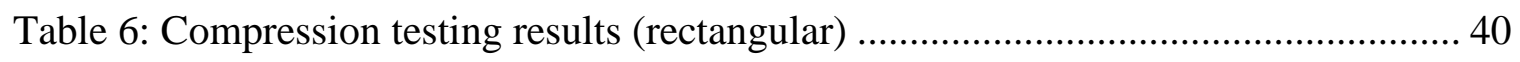

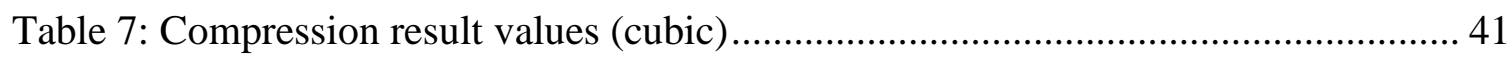

Table 8: Adhesion testing mixing amounts of parts ................................................. 44

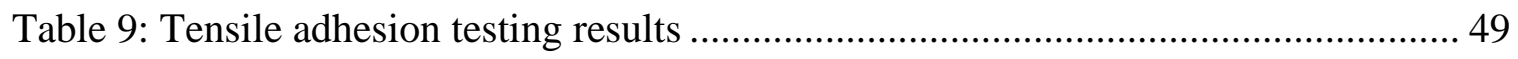

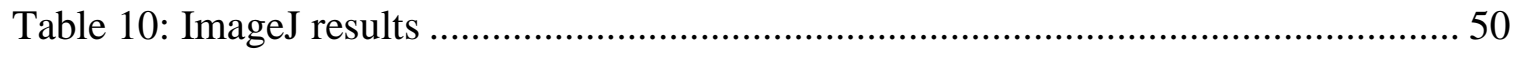

Table 11: Peak loads and temps (November testing) ................................................ 55 


\section{$\underline{\text { LIST OF FIGURES }}$}

FIGURE

PAGE

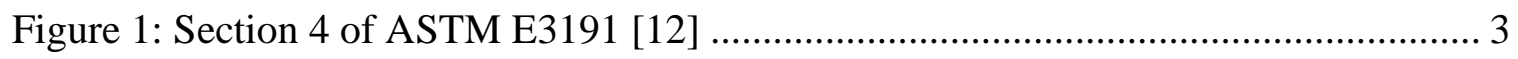

Figure 2: Section 5 of ASTM E3911 [12] ................................................................. 4

Figure 3: (a) Worldwide PU consumption forecasted up to 2020 [15]; (b) Global

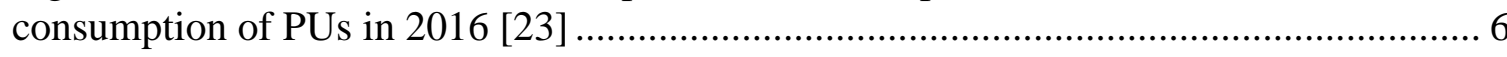

Figure 4: (a) PU chemical reaction equation; (b) water interacting with isocyanate

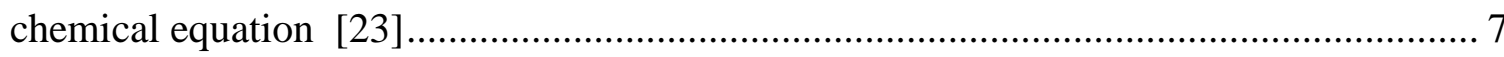

Figure 5: (a) Open-celled PU foam; (b) closed-celled PU foam [36] ............................. 9

Figure 6: Examples of different foam cell shapes: (a) tetrahedron, (b) triangular prism, (c) rectangular prism, (d) hexagonal prism, (e) octahedron, (f) rhombic dodecahedron, (g) pentagonal dodecahedron, (h) tetrakaicahedron, (i) icosahedron [36] ....................... 10

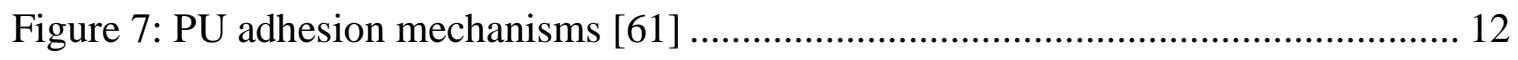

Figure 8: Micrographs displaying incremental EG loading in PU matrix [67] ............... 14

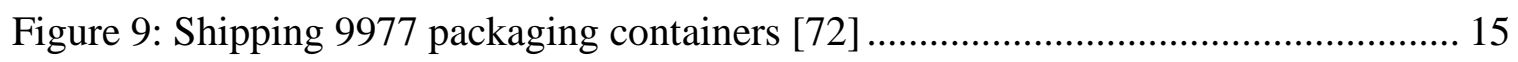

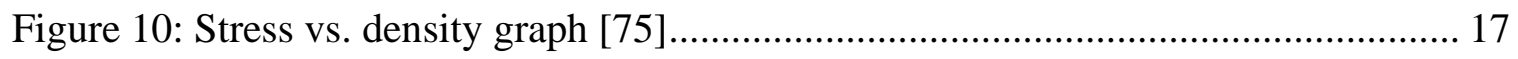

Figure 11: (a) Effects of increasing temperature in compression; (b) effects of

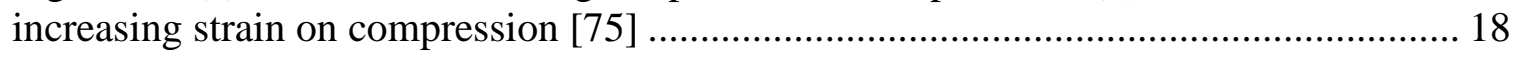

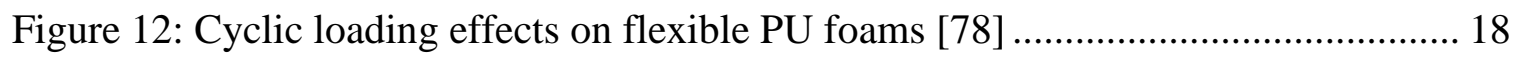

Figure 13: Energy absorption vs. density graph [79] .......................................... 19

Figure 14: (a) Adhesion graph; (b) different adhesion failure mechanisms [83] ............ 21

Figure 15: Effect of climate on adhesion graph [83] ............................................ 21

Figure 16. SRNL radiation shielding testing with a $10 \mathrm{~cm}$ distance between the source

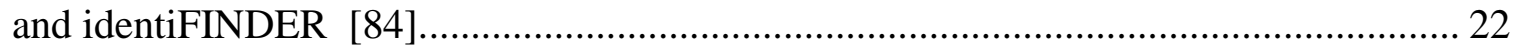

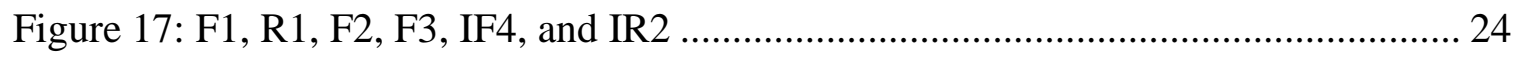


Figure 18: Shear adhesion experimental design

Figure 19: (a) Rigid 3D mold; (b) I-R2 cured in mold; (c) I-R2 excess shaven off ......... 31

Figure 20: (a) Flexible 3D mold; (b) foam cured in mold; (c) foam extracted................. 32

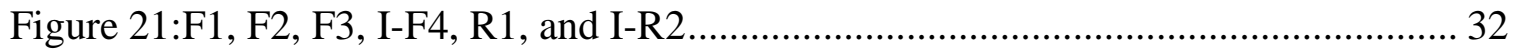

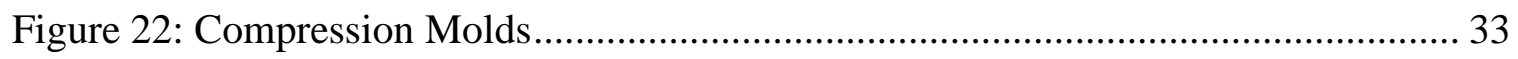

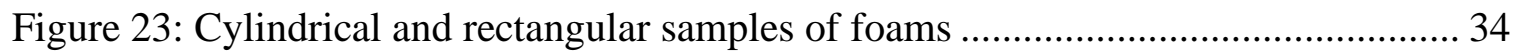

Figure 24: Cubic samples: R1 (left) and I-R2 (right) ............................................ 34

Figure 25: SEM samples: F1, R1, F2, F3, R1, I-F4 and I-R2 ................................... 34

Figure 26: (a) Flexible foam flexing; (b) rupturing during tensile testing....................... 35

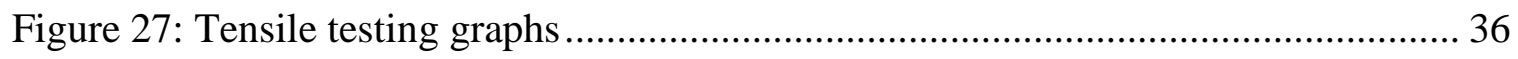

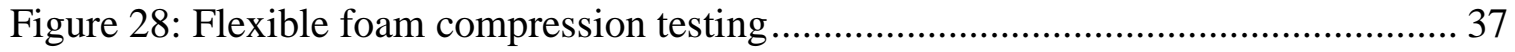

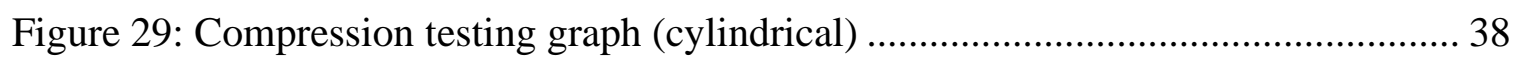

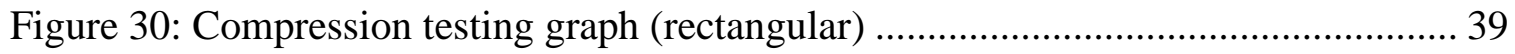

Figure 31: Compression testing results (cubic) …................................................ 41

Figure 32: Compression testing on different cubic concrete specimens [96] ................. 42

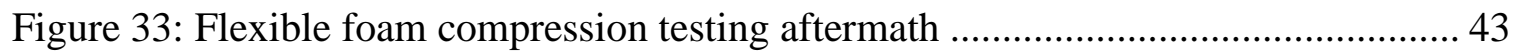

Figure 34: (a) Intumescent foam; (b) rigid foam; (c) flexible foam ............................ 43

Figure 35: (a) Foam curing in 3D mold; (b) foam excess outside of mold; (c) foam

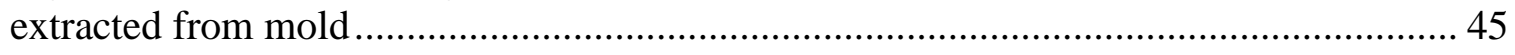

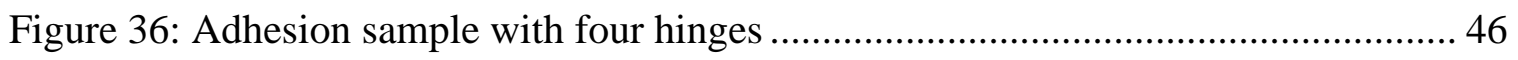

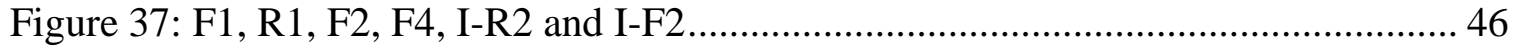

Figure 38: (a) Different volumes of pipe encapsulated with R1 and I-R2 foam;

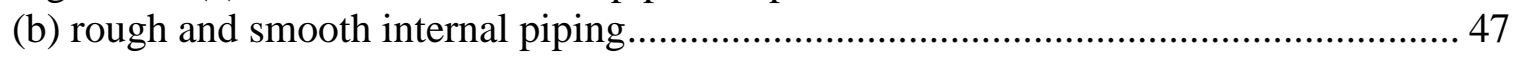

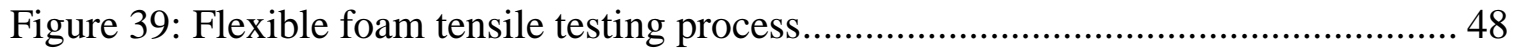




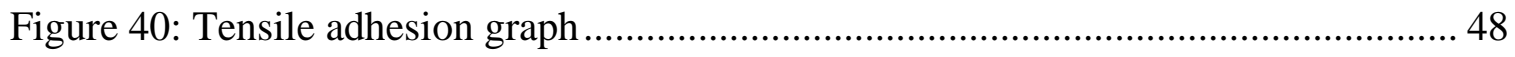

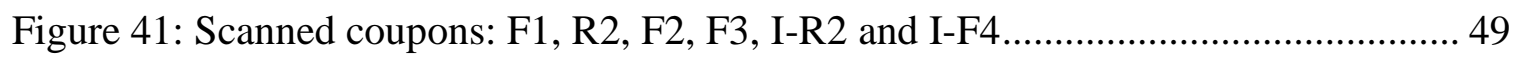

Figure 42: (a) Intumescent foam; (b) rigid non-intumescent foam; (c) non-intumescent

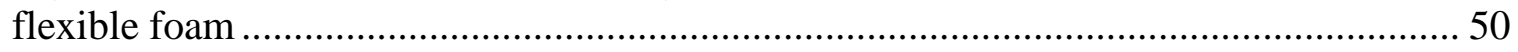

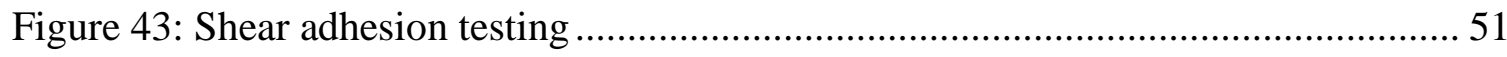

Figure 44: September adhesion testing on I-R2 foams ......................................... 52

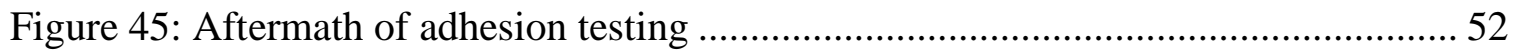

Figure 46: (a) P40 grit inside pipe; (b) roughing up pipe; (c) using a level to ensure

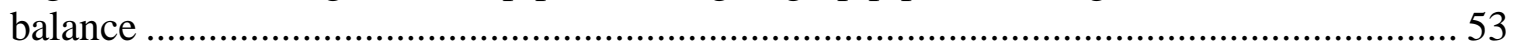

Figure 47: A: Foam before curing; B: foam after curing ........................................ 54

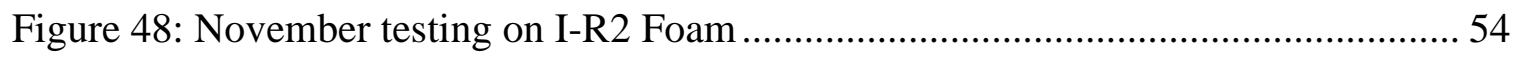

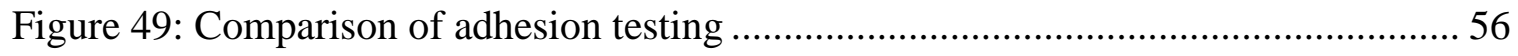

Figure 50:(a) 3D bucket piece, (b) sample inside of bucket piece................................ 57

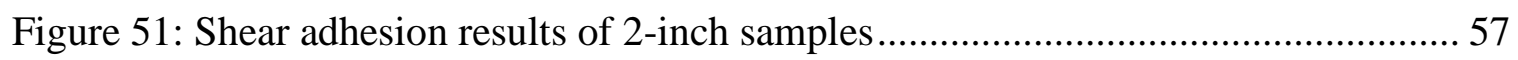

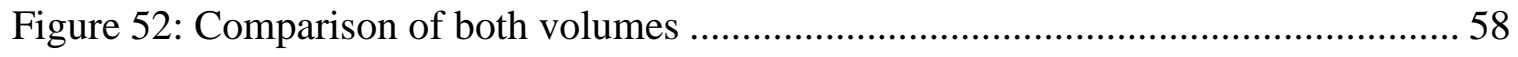

Figure 53: Comparison of both 4 -inch diameter volumes ........................................ 59

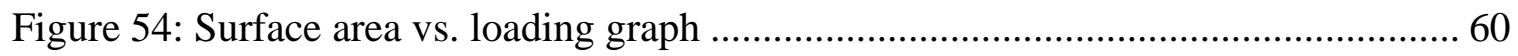

Figure 55: (a) Water submersion; (b) drop test; (c) muffle furnace ............................ 61

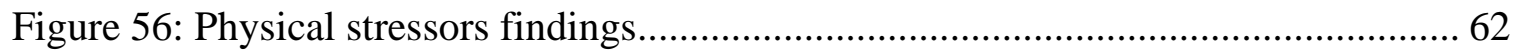




\section{CHAPTER I - INTRODUCTION}

\subsection{Problem Statement}

There is a high operational requirement across the Department of Energy's Office of Environmental Management (DOE-EM) complex for a fixative that can immobilize residual contamination and/or encapsulate three-dimensional void volumes (pipes, glove boxes, drums, etc.) during deactivation and decommissioning (D\&D) activities. DOE sites such as Hanford [1] and Idaho National Laboratory [2] can benefit from this technology since both sites contain hundreds of miles of contaminated piping. Savannah River Site (SRS) can also implement this technology since it contains multiple contaminated gloveboxes [3] and hot cells [4] with equipment that cannot be readily removed. Application of this fixative must be simple, cost-effective, and safe in order to ensure worker's safety.

Basis of Interim Operation (BIO) documents postulate contingency scenarios involving seismic and thermal activity that can occur at DOE sites during D\&D. These events insinuate that current and future fixative technologies must have sufficient mechanical and adhesion properties to withstand earthquakes, blunt trauma, free fall, etc. in order to prevent a potential release of residual contamination [5]. The likelihood of these events remain high due to many DOE facilities remaining dormant for around 60 years before completion of the final disposition stages [6].

\subsection{Motivation}

The relevancy of immobilizing residual contamination cannot be taken lightly. Gross decontamination is the process of removal of radiological contamination by physical 
means and is usually implemented first during the cleanup process [7]. It is very common after gross decontamination efforts for sites to remain dormant for multiple years before the final disposition stages. During this timeframe, loose contamination could potentially be mobile. This is especially relevant for facilities where high amounts of radioactive dust exist. A fixative can be applied to immobilize any airborne contamination [8]. Whatever fixative technology is chosen for implementation must have excellent long-term adhesion capabilities in order to immobilize residual contamination.

Release of residual contamination is an issue that has recently been broadcasted nationwide by media outlets. Towards the end of 2018, radioactive dust was found in communities around Hanford Nuclear Site, Rocky Flats and Los Alamos National Laboratory [9]. Microscopic particles of plutonium, thorium, and uranium were found in household dust, automotive air cleaners, and hiking trails. These particles present hazards that can exceed lifelong doses and can make areas around sites uninhabitable. Also occurring in 2018, cleanup missions at Hanford were stopped after plutonium dust was released from a building during demolition activities, became airborne, and coated nearby workers' cars. Some of this material may have been deposited in the Columbia River, which would cause a nationwide catastrophe depending on the amount released to the water[10]. The recent disaster that contaminated $35 \%$ of the area at the Waste Isolation Pilot Plant (WIPP) in 2014 was a result of using organic zeolite to protect nuclear waste tanks. The organic zeolite should have been replaced by a stronger, less volatile material that could have prevented one of the most expensive nuclear accidents in U.S. history with recovery costs nearing 2 billion dollars [11]. 


\subsection{Objective}

Discussions with representatives from the Savannah River National Laboratory (SRNL) have led to a possible solution that satisfies these operational requirements by implementing commercial-off-the-shelf (COTS) closed-celled polyurethane (PU) foams as permanent foaming fixatives (PFF). American Society for Testing and Materials (ASTM) E3191: Standard Specification for Permanent Foaming Fixatives Used to Mitigate Spread of Radioactive Contamination was recently developed for the intended use of this technology. Figure 1 defines the attributes of a permanent foaming fixative (PFF) is per ASTM E3191 [12].

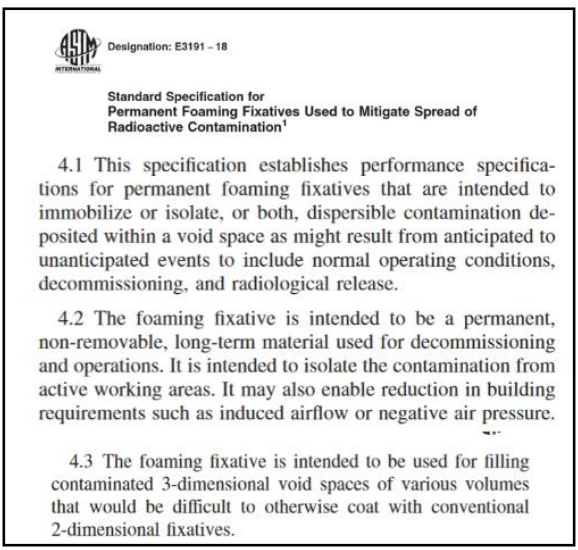

Figure 1: Section 4 of ASTM E3191: Standard Specification for Permanent Foaming Fixatives Used to Mitigate Spread of Radioactive Contamination [12]

It is intended for this research to lead to more substantive advancements in the concept of PFFs to improve safety in D\&D activities across the entire DOE-EM complex. It is the intent of the work presented in this thesis to better identify and define operational parameters for PFFs, and to be considered as a reference for updating Section 5 of ASTM 3191 which details mechanical properties of PFFs (Figure 2). 


5. Mechanlcal Properties
5.1 The foaming fixative shall be compatible with at least
one of the following conventional or remote application
systems:
5.1 .1 spraying,
5.1 .2 complete pouring, or
5.1 .3 incremental pouring.
5.2 The foaming fixative shall have suflicient mechanical
properties to withstand long-term wear associated with inci-
dental impact, abrasion, or vibration that are likely to cause
loss of containment of the isolated contaminant.
5.3 The foaming fixative should be readily applied within
the desired void space without significant preparation
(cleaning, sanding, primer layer, etc.). This does not supersede
a facilities decision for gross decontamination prior to appli-
cation of the foaming fixative.
5.4 The foaming fixative should have sufficient mechanical
properties to withstand contingency events such as earthquakes
as outlined in a facilities' safety design basis document.

Figure 2: Section 5 of ASTM E3911: Standard Specification for Permanent Foaming Fixatives Used to Mitigate Spread of Radioactive Contamination [12] 


\section{CHAPTER II - LITERATURE REVIEW}

\subsection{Background of Polyurethanes}

The first ever urethane was fabricated in 1849 by Wurtz [13]. The polyurethane industry was revolutionized by the invention of the diisocyanate polyaddition technique by Bayer in 1937. Polyurethanes became relevant during World War II as a replacement for rubber due to rubber becoming scarce. Over the next couple of decades, PUs have become one of the most researched and valuable materials in the world [14].

Polyurethanes are versatile polymeric materials whose properties can be altered by manipulation of the fabrication process [15]. Desired results can be achieved by changing the amounts of diisocyanate, polyester diol, surfactants, catalysts, and blowing agents [16]. Polyurethanes display excellent mechanical strength, toughness, abrasion, corrosion and chemical resistance and low temperature resistance. Polyurethanes exhibit combined properties of metals (toughness) and rubber (elasticity), which makes them suitable replacements for other materials [17]. Polyurethanes are malleable materials which allows for them to be encapsulated in a variety of complex volumes by extrusion or injection molding [18]. Polyurethanes are primarily utilized in automotive, textiles, arts and craft, cushioning, structural support, and buoyancy industries [19]. The most common forms of PUs are thermoplastic PUs, flexible PUs, rigid PUs, waterborne, binders, coatings, adhesives, sealants, and elastomers [20]. Polyurethane foams can either be thermosetting or thermoplastic polymers. Thermoplastics can be recycled while thermosets are harder to recycle because they are heavily crosslinked, or chemically bonded together [21]. Polyurethane rigid foams have become the most heavily consumed commercialized version 
of polyurethanes within the past couple years due to its insulative properties and its ability to reduce outside noise (Figure $3 \mathrm{a}$ and $\mathrm{b}$ )[22].

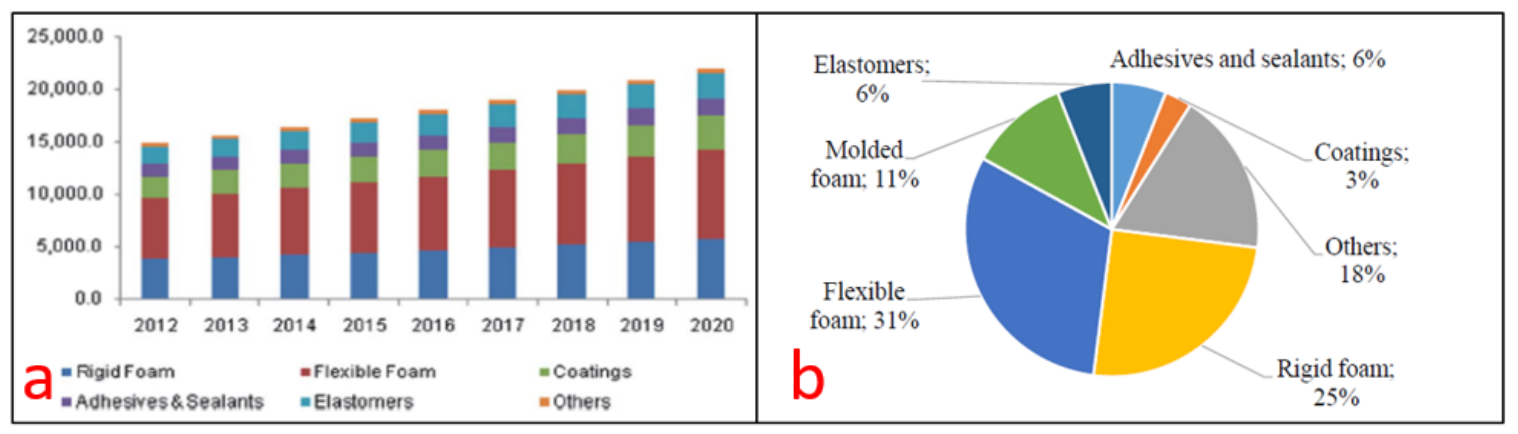

Figure 3: (a) Worldwide PU consumption forecasted up to 2020 [15]; (b) Global consumption of PUs in 2016 [23]

\subsubsection{Chemistry of Polyurethanes}

Polyurethanes are produced from an exothermic reaction between a polyester diol (an alcohol with two or more hydroxyl groups in a molecule) and a isocyanate (highly reactive and low molecular compound) (Figure 4a) [24]. Polyurethane's expansion capabilities depend on various processes that occur during the chemical reaction. Initially during the latent phase, the reactants are mixed, and polymerization occurs (reaction between isocyanate and polyol), which can last up to 30 seconds. Saturation is achieved when the blowing gas dissolves in this mixture and bubbles start to form [25]. Cell growth and expansion ensues when the chemical blowing agent, which is typically water, reacts with the isocyanate (Figure 4b) [23] and ends when steady-state is reached. Foam viscosity starts to increase, and all liquid constituents become solid. The cross-linking between the polyol and isocyanate solidify all the cell faces and walls, which gives the polymer its mechanical performance [26]. 


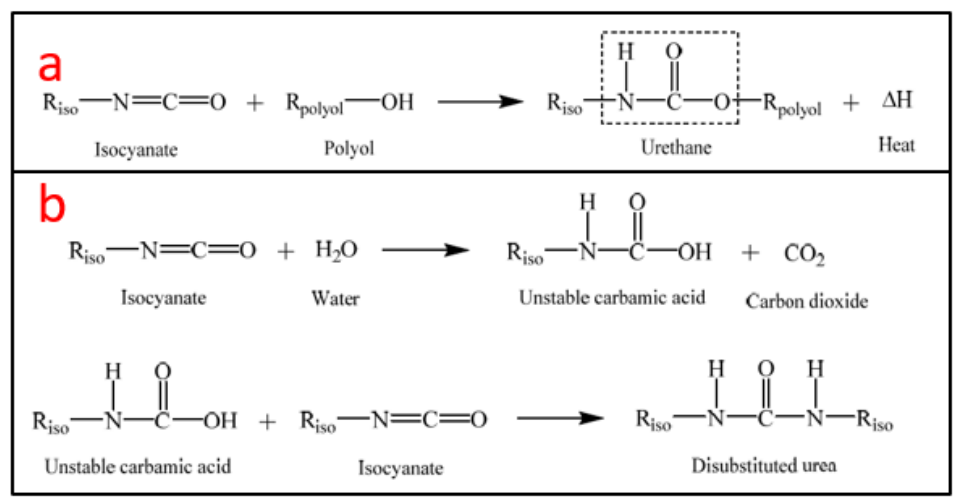

Figure 4: (a) PU chemical reaction equation; (b) water interacting with isocyanate chemical equation [23]

Surfactants and catalysts are reactants that are also implemented in the polymerization process. Surfactants used in PUs are copolymers that are composed of silicone backbone and poly grafts [27]. They lower the surface tension in order to promote creation of bubbles, stabilize cells, and can influence cell sizes and growth [28]. Catalysts promote the reaction between the isocyanate, polyols, and blowing agents. They are primarily responsible for influencing the expansion of cells [29]. Catalysts also monitor heat growth caused by the isocyanate. The exothermic reaction is vital in determining the density and other properties of PUs. Catalysts, like tertiary amines (compounds that contain a lone nitrogen atom), speed up the expansion process with recorded curing temperatures of $130-140{ }^{\circ} \mathrm{C}$ in the middle of the PU. This causes the viscosity of the fluid to become very high within a couple seconds which prohibits further pouring of other reactants [30].

\subsubsection{Mechanics of Polyurethanes}

Manipulating the fabrication results can alter the mechanical performance of PUs [31]. Both flexible and rigid PU foams have similar chemistry, but what distinguishes both are the amounts of reactants involved [32]. Changing the functionality of the polyol without 
changing the molecular weight can increase the foam hardness while reducing other properties like tensile strength, tear strength and elongation [24]. Increasing the molecular weight of the polyol can induce the opposite effect [24]. The isocyanate molecule dictates reactivity of the chemical reaction taken place. Different isocyanate yields different results. Aromatic isocyanate can produce higher glass transition temperatures, modulus and tensile strength, but can negatively affect elongation and impact properties [33]. Aliphatic isocyanates produce rubbery materials with enhanced elastic properties [34]. Higher isocyanate content can produce harder segments, which make the foam rigid [35]. The higher isocyanate amounts yield higher cross-linking which makes the atoms closer together in contrast to flexible PU foams [33].

Polyurethane foams consist of three-dimensional networks of cells at the microstructure level that dictate macrostructure performance [36]. There are two types of categorizing PUs: open-celled and closed-celled (Figure 5). Open-celled foams allow the passage of air because these cells are not closed unlike closed-celled foams [37]. Open celled foams are sound resistant while closed-celled foams are water resistant. Open celled foams cells sizes can alter the rate of which air can enter because when compressed, the air will escape. The viscosity of the air induces mechanical work which is all dependent on the rate of compression, or strain [38]. Gas has low mechanical strength, since open-celled foams contain the most gas they exhibit weaker mechanical properties than closed-celled foams [21]. Closed-celled foams' edges can both bend, extend and contract, while the thin membrane that closes each cell can stretch, which increases the cell-wall stiffness and elastic moduli. If the membrane does not fail, the entrapped air also enhances the mechanical performance [39]. 


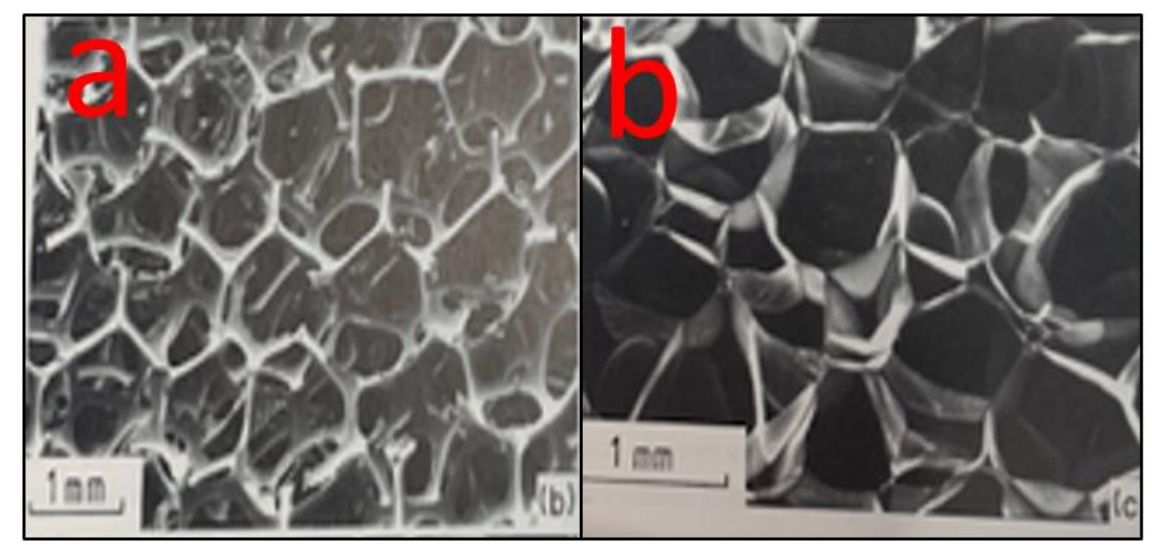

Figure 5: (a) Open-celled PU foam; (b) closed-celled PU foam [36]

Another microscale property that can affect the mechanics is the relative density [40]. It describes the void fraction of the cellular network and it is the ratio of the density of the foam to that of the bulk material of which the foam is made up [41]. Increasing the relative density can enhance Young's Modulus, and plastic collapse stress [42]. Equation 1 shows the equation for relative density $\left(\rho_{f} / \rho_{s}\right)$.

$$
\frac{P_{f}}{P_{s}}=C\left(\frac{\rho_{f}}{\rho_{s}}\right)^{n}
$$

$\mathrm{N}$ ranges from 1 to 2 and a value of 2 represents an open-celled foam. Other values relate to closed-celled foams that can undergo stretching and struts while bending. $\mathrm{C}$ is a constant, $\mathrm{P}$ represents any mechanical property and $\rho$ is the density. The subscripts $\mathrm{f}$ and $\mathrm{s}$ relate to the properties of a fully dense solid and the foam [43].

The cell shape is a vital attribute that can dictate mechanical performance [44]. Cells of PU foams elongate in the direction of rise which makes the material anisotropic [45]. Equation 2 shows the anisotropy ratio, R, and is the ratio of the unit cell parallel (h) and perpendicular to the direction of elongation (1) [43].

$$
R=\frac{h}{l}
$$


Equation 1 then becomes Equation 3 when incorporating Equation 2. According to Equation 3, the mechanical properties linearly increase in the direction of expansion and decreases in other directions.

$$
\frac{P_{f}}{P_{s}}=C\left(\frac{\rho_{f}}{\rho_{s}}\right)^{n} * f(R)
$$

Cell shapes also play a role in mechanical performance and are influenced by surface tension at the interface and competitive cell growth. A bigger cell will be surrounded by smaller cell due to the pressure difference during expansion. 3D cells consist of different geometric shapes that each contain different number of vertices, contact neighbors, intersections, connectivity, and edges (Figure 6) [36]. All these features can influence the relative density as well as contributing to different of constants for stress calculations. Monoclinic materials require 13 constants to compute stresses using Hooke's law, which is defined as the stress equaling to Young's modulus times strain, while orthotropic requires 9 [46].

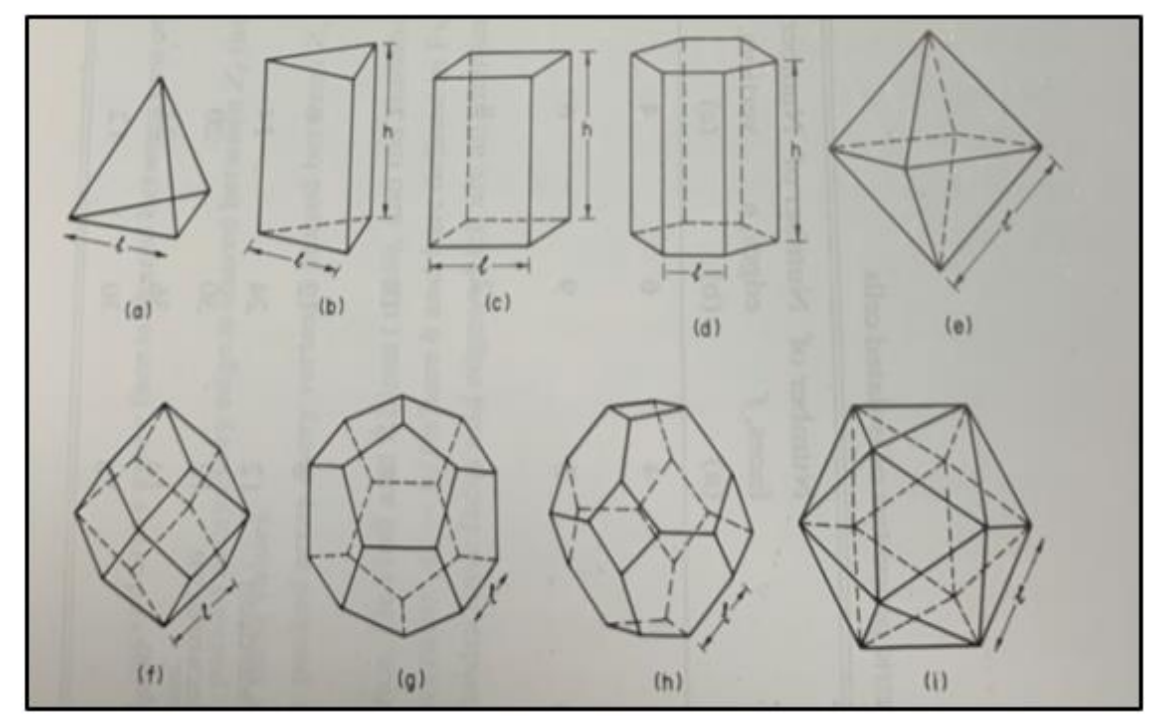

Figure 6: Examples of different foam cell shapes: (a) tetrahedron, (b) triangular prism, (c) rectangular prism, (d) hexagonal prism, (e) octahedron, (f) rhombic dodecahedron, (g) pentagonal dodecahedron, (h) tetrakaicahedron, (i) icosahedron [36] 


\subsubsection{Adhesion Mechanisms of Polyurethanes}

Adhesion is defined as the molecular interaction at an interface between two or more dissimilar materials. Polyurethane foams are being investigated for their adhesive potential to adhere onto adherends (i.e. substrates, surfaces, etc.), such as stainless steel in DOE facilities [47]. Polymer-metal hybrids are sought after especially in the aerospace and automobile industries where high performances and light components are desired [48]. The overall objective for this hybrid is to achieve strength, durability, impact resistance, and abrasion [49]. Factors that influence adhesion joint strength are amount of moisture, types of environment, materials and mechanical stress [50].

There are multiple ways of adhesion to occur for dissimilar materials in polymerhybrids. The most common is adhesive bonding/direct bonding [51]. This bonding relies heavily on the surface roughness of the adherend to allow for mechanical interlocking [52]. Mechanical interlocking depends on the number of cavities and pores on an adherend's surface [53]. An adherend's roughness affects the strength of bonded joints due to the increased contact area cavities and pores induce [54] . A high-surface roughness area may increase stress concentration and reduce joint adhesion strength due to the adhesive being unable to penetrate wholesomely into voids [55]. Adhesion reactivity depends heavily on the isocyanate chemical instead of the polyol. The isocyanate molecule is difunctional meaning there are two molecules, which makes it more reactive than a polyol [56]. The primary physical-chemical reaction occurs via covalent bond between the isocyanate group and the iron oxide layer of the stainless steel's surface [57]. Adhesion capabilities also depends on the amount of wettability the adhesive wets, or covers, on the adherend's surface. Complete wetting happens when the summation of surface energy of the liquid- 
vapor and solid-liquid interface is less than the energy of the surface energy of the solidvapor [58]. Electrostatic interactions occur when dissimilar materials interact and cause a net electrostatic charge due to electrostatic differences [59]. One other adhesion mechanism is the ability of the polymer chains to diffuse at the adhesive joint. The formation of new polymer chains to be made thru the adhesion interface requires two macromolecules have intimate contact [60]. Figure 7 illustrates all the different adhesion mechanisms that can occur [61].

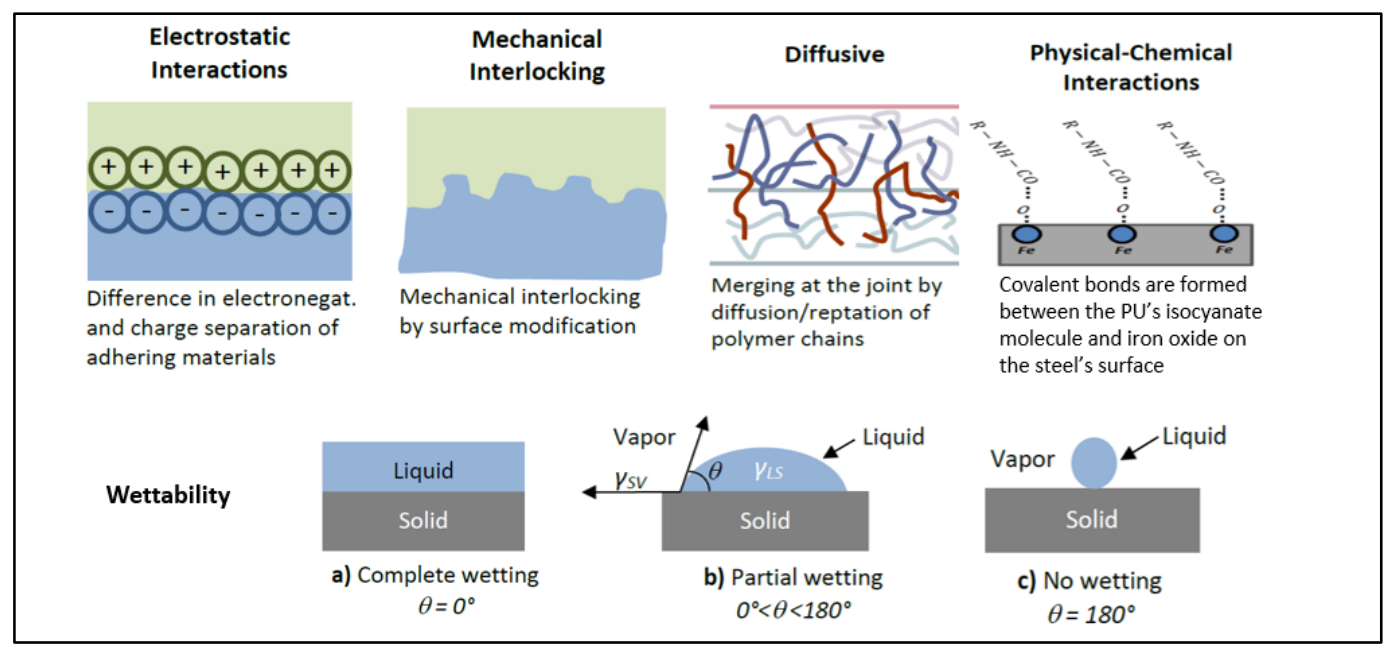

Figure 7: PU adhesion mechanisms [61]

There are three stages that occur during the adhesion of PU and a stainless-steel substrate. The first is known as the powder-coating process when negatively charged particles of the foam are attracted to the positively charged particles on the steel substrate by electrostatic interactions, followed by mechanical interlocking into available pores [59]. Cross-linking allows for polar and secondary interactions to occur, with covalent bonds being formed with the adherend [62]. The next stage is known as the over molding process. Polymer chains start to diffuse due to high temperatures. This process continues until temperatures stabilize and steady state is achieved [61]. 


\subsubsection{Introduction to Intumescent PU Foam}

Polyurethane foams, especially rigid PU foams, are severely flammable and can release carbon monoxide and hydrogen cyanide when exposed to thermal stressors [63]. Incorporating filler in the PU foam's matrix such as nano carbon-based particles, for example, expandable graphite (EG) can mitigate the transfer of heat and oxygen, thus increasing the thermal insulation [64]. When heated to temperatures around $572{ }^{\circ} \mathrm{F}$, EG melts into a viscous liquid and chemical reactions occur, causing fluids with low thermal conductivity that get trapped in solid bubbles. Acids begin to catalyze and dehydration occurs, leading to polymer aromatization and graphitization [65]. The phosphate molecule begins to cross-link and flammable gases and blowing agents begin the expansion phase. Expandable graphite then can increase its volume by hundreds of times its' initial volume and provide an insulating soft char layer. This process is known as intumescing and is used as passive fireproofing steel structures [66].

The EG loading affects the cell morphology as the cells appear to be initially spherical and then turn into polyhedral forms (Figure 8). It is seen with each loading of EG increase (from a to $\mathrm{b}$ to $\mathrm{c}$ to $\mathrm{d}$ ) in Figure 8, that unstable cell growth begins to occur. Cell collapse happens due to the cell walls rupturing amongst each other as evident in parts $\mathrm{c}$ and $\mathrm{d}$ in Figure 8. Higher loadings result in higher densities which is a function of higher crosslinking. Compression testing showed an increase in compression from 31.62 to 32.08 psi when testing samples with higher EG loading. Diethyl phosphate was used to regulate cell growth the EG loading induces [67]. 

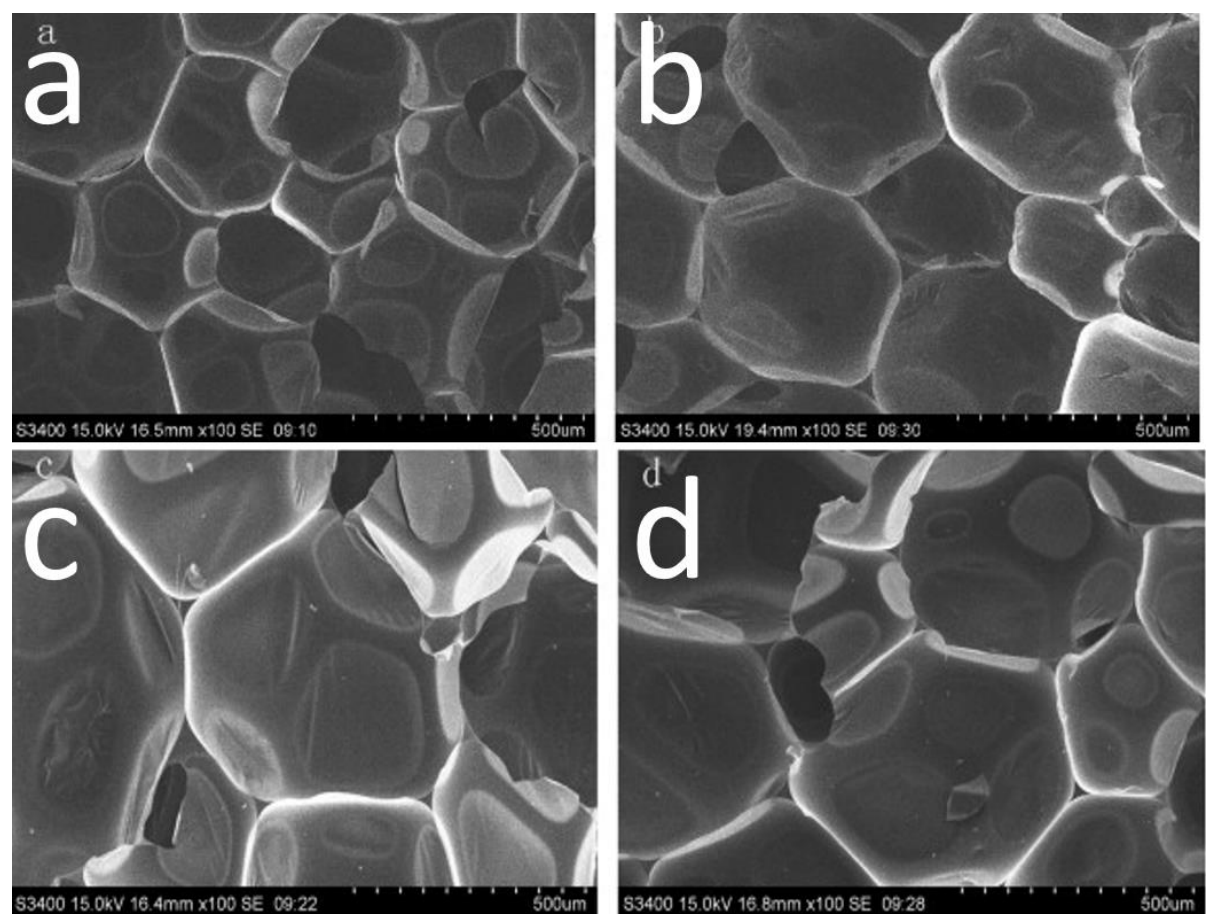

Figure 8: Micrographs displaying incremental EG loading in PU matrix [67]

Additional fillers in the PU matrix for intumescent technologies involve vinyl acetate. Vinyl acetate is used to control smoke and toxic emission during the intumescing process. These fillers form additional hydrogen bonds to steel substrate that can enhance adhesion capabilities. The hydrogen bonds reinforce the additional covalent bonding that is occuring between the isocyante and iron oxide layers [68].

\subsection{Previous Mechanical Testing on Polyurethane Foams}

Polyurethane foams, particularly rigid foams, have been used in the nuclear industry for over 48 years to protect radioactive sensitive cargo from impact [69]. Savannah River National Laboratory have been using rigid intumescent PU foams to help limit impact that can occur during transport of the 9977 Shipping Package, which houses different forms of uranium and plutonium (Figure 9). The maximum packaging limit it can support is $9.7 \mathrm{lbs}$. of plutonium or uranium. Mechanical testing on these PU foams showed 
the glass transition temperature was $278.6^{\circ} \mathrm{F}$, above which the foam was found to be more elastic [70]. The foam showed no degradation without any applied stresses around $150{ }^{\circ} \mathrm{F}$. The intumescing phase did not start until the ignition temperature $\left(600^{\circ} \mathrm{F}\right)$ was reached. The thermal properties of the foam were not affected by water submersion or humidity effects due it being closed-celled. Crush strength testing on the foam showed a $5 \%$ increase in the normal direction of expansion compared to testing in the parallel direction [71]. Dynamic crush testing on $15 \mathrm{lbs} . / \mathrm{ft}^{3} \mathrm{FR}-3700$ foam at temperatures of -18.4 to $75.2^{\circ} \mathrm{F}$ ensured delivery of acceptable results. Cooling down the foam with no external loading from high temperatures showed no effects on mechanical performance and aging studies by both Sandia National Laboratory (SNL) and General Plastics on 20-year-old foam samples showed no effects in crush strength [71].

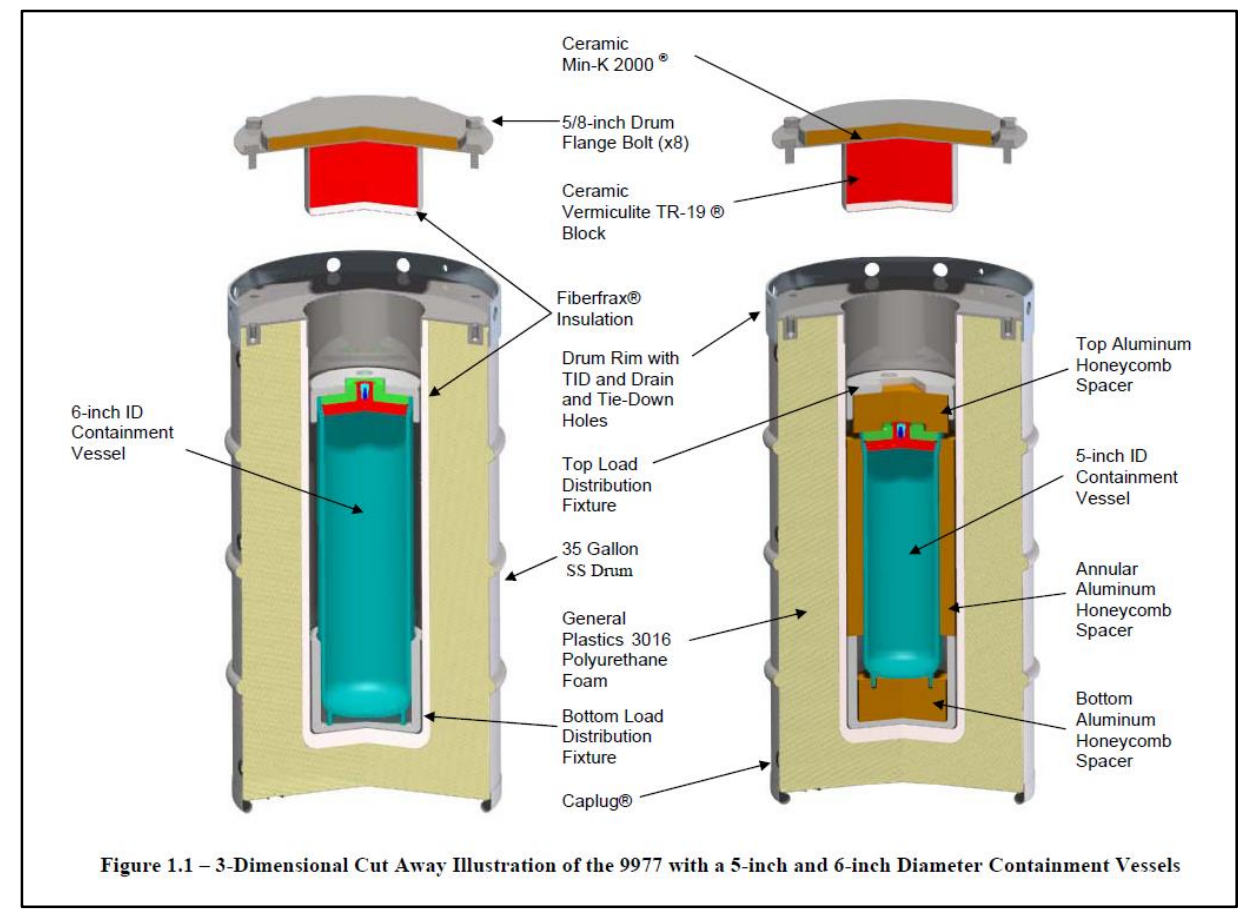

Figure 9: Shipping 9977 packaging containers [72] 
Savannah River National Laboratory also conducted a variety of impact testing on the 9977 shipping packages with the rigid intumescent PU foam inside motivated by Normal Conditions of Transport (NCT) and Hypothetical Accident Conditions (HAC) per the Department(s) of Transportation [72]. The impact testing ensured selection of materials in the package would not cause any chemical, galvanic, or any other reactions that might affect the packages performance [73]. Impact testing included free drop testing from 4 feet, which showed negligible surface damage and deformation. Crush testing utilized a 1750 lbf load placed on top of the package for $24 \mathrm{hrs}$. Vibration testing was performed on a large shake table to simulate truck transport and forklifting. The shipping 9977 package was also subjected to randomized vibrations to simulate 20,000 miles of shipping for over 20 hours. Puncture testing involved a steel cylinder of 13 lbs., (1.25 in. diameter) being dropped from a height of $3.28 \mathrm{ft} .(1 \mathrm{~m})$. Negligible damages were observed on the package's lid. Water spraying testing showed 13.6 lbs. of water entered the drum's cavity. Fourteen vent plugs helped prevent water from reaching the PU foam. Fire testing was done over 30 minutes of exposure at an average temperature of $2681{ }^{\circ} \mathrm{F}$. X-rays were taken before and after testing, and all post-testing data showed no loss of confinement occurred [73].

\subsubsection{Tensile Testing}

Rigid PU foams are heavily favored due to their high strength-to-weight ratios for low densities [74]. Sandia National Laboratory (SNL) conducted uniaxial tension tests for different density rigid PU foams under various temperatures. Tensile testing was performed only at 70 and $165.2^{\circ} \mathrm{F}$ at a strain rate of $10^{-2} \mathrm{~s}^{-1}$. Failure stress at $165.2^{\circ} \mathrm{F}$ was around 
$20 \%$ lower than the failure experienced at $21^{\circ} \mathrm{F}$ and strain was $14 \%$ more. SNL also proved that denser foams performed better in terms of tensile moduli and failure (Figure 10) [75].

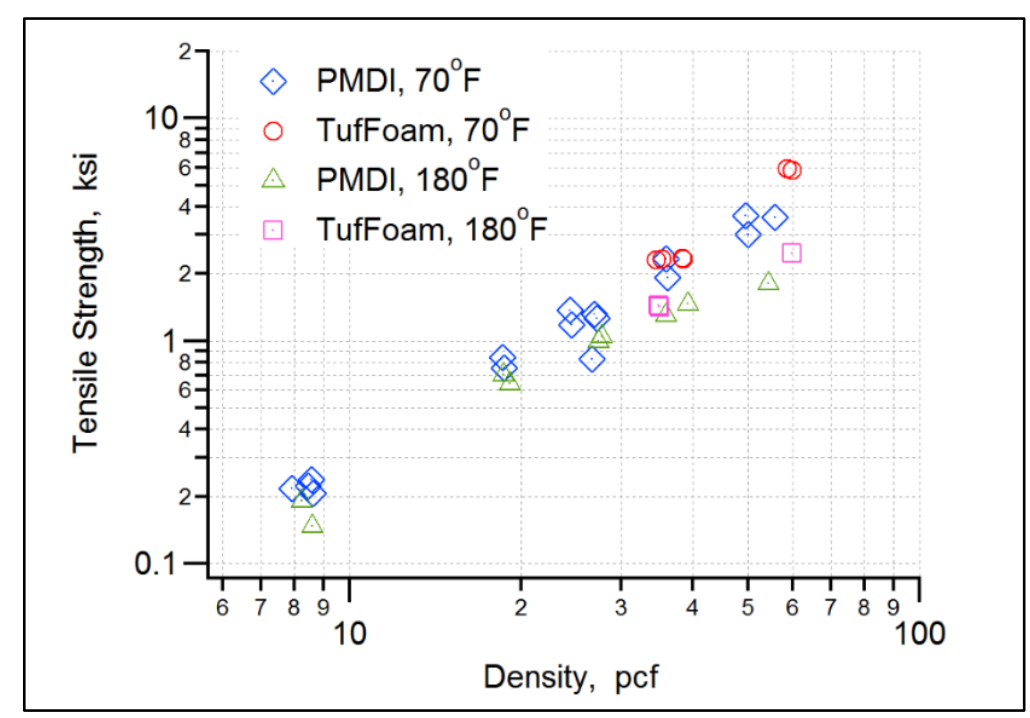

Figure 10: Stress vs. density graph [75]

\subsubsection{Compression Testing}

For compression testing, SNL complied with ASTM D695 and determined that a rigid polyurethane foam $\left(12 \mathrm{lbs} . / \mathrm{ft}^{3}\right)$ lost compressive strength and modulus with increasing temperature and strain rates (Figure 11) [75]. Another study by SNL on rigid foams undergoing uniaxial compression at various temperatures -85 to $356^{\circ} \mathrm{F}$ showed foams failed drastically when subjected to the coldest temperatures at small strain rates $\left(0.01 \mathrm{~s}^{-1}\right)$ [76]. Sandia National Laboratory deduced that the aspect ratio, ratio between height and diameter, did not affect the results drastically. The studies also showed that rigid urethane foams can be used before the urethane bonds decomposed around $287.6^{\circ} \mathrm{F}$ [77]. The rigid foams performance was also a function of density as the denser foams (26 lbs./ $\left./ \mathrm{ft}^{3}\right)$ performed better than the less dense foam $\left(4.5 \mathrm{lbs} . / \mathrm{ft}^{3}\right)$ [75]. 


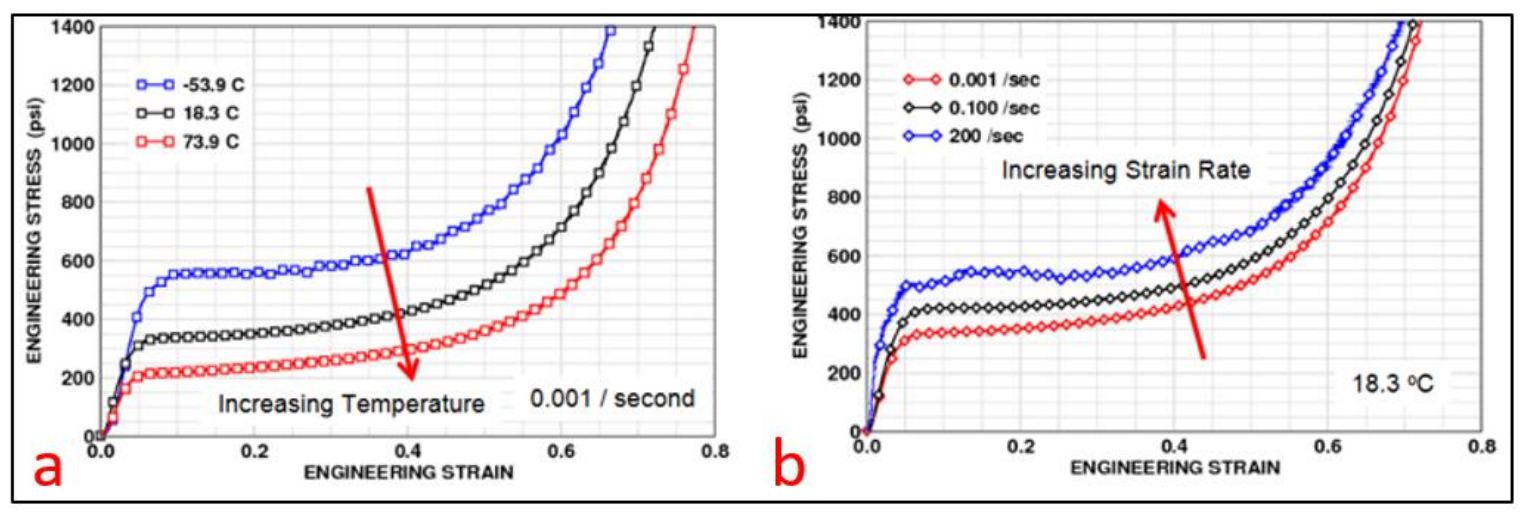

Figure 11: (a) Effect of increasing temperature in compression; (b) effects of increasing strain on compression [75]

Sandia National Laboratory has performed mechanical testing on flexible foams as well [78]. When cooled to temperatures below their glass transition temperatures -31 ${ }^{\circ} \mathrm{F}$, they behaved like rigid polyurethane foams and were able to plastically deform. SNL ultimately concluded that flexible foams would return to their original shape if operated at room temperature but if they experienced large loading, their performance would likely weaken afterwards (Figure 12) [78].

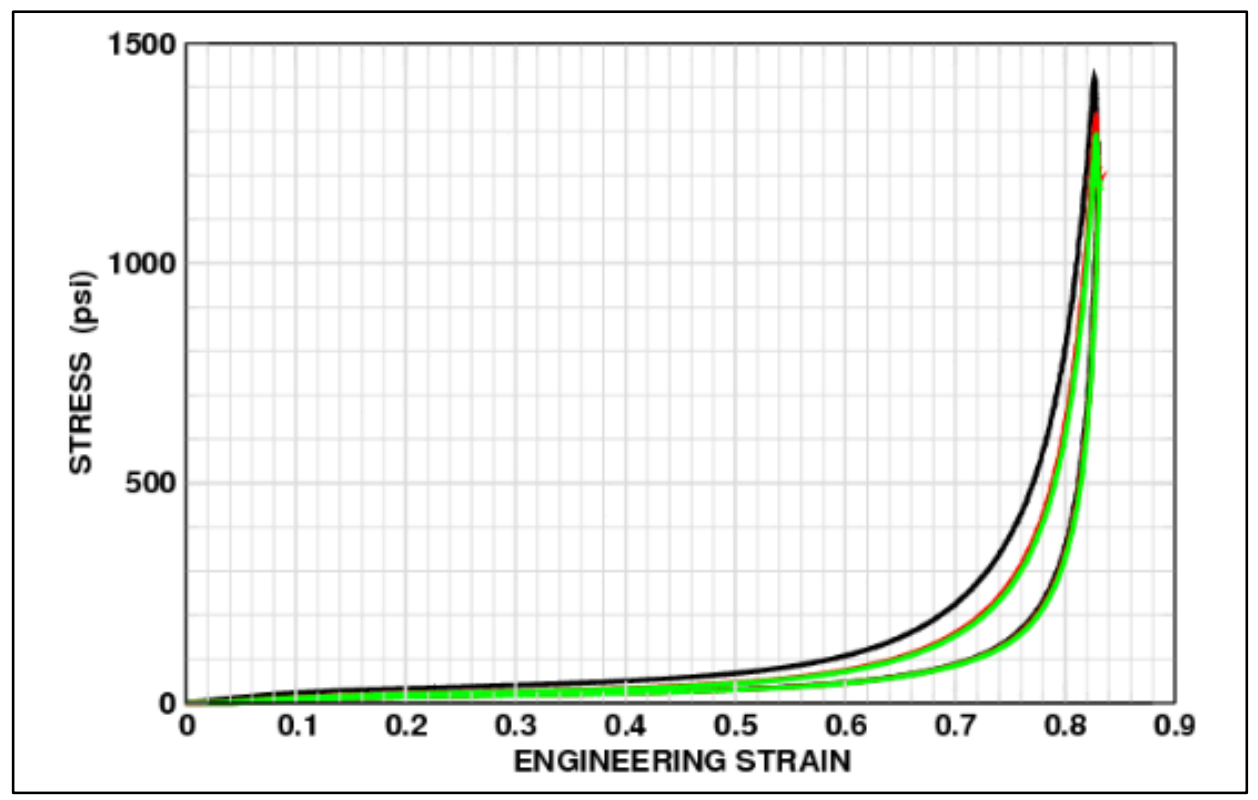

Figure 12: Cyclic loading effects on flexible PU foams [78] 


\subsubsection{Impact Testing}

Drop weight impact testing by SNL was performed on standing right circular cylinder foam specimens with geometries that were chosen to simulate in an operational environment that involved shock mitigation [79]. The strain rates used were $70 \mathrm{~s}^{-1}$ which caused all the specimens to fail prematurely. Increasing strain rates also produced increased stresses similarly to the compression testing results. Peak stresses occurred at 1 millisecond (ms) and impact contact lasted less than $4 \mathrm{~ms}$. Failure occurred around $60 \%$ of the peak stress of $6 \mathrm{MPa}$. SNL concluded results are geometry and density dependent and how the specimens are supported and impacted affected the results [80]. Figure 13 shows different density foams and their corresponding energy absorptions, from which SNL was able to conclude that an optimum foam density exists, in which energy absorption is at its peak [79].

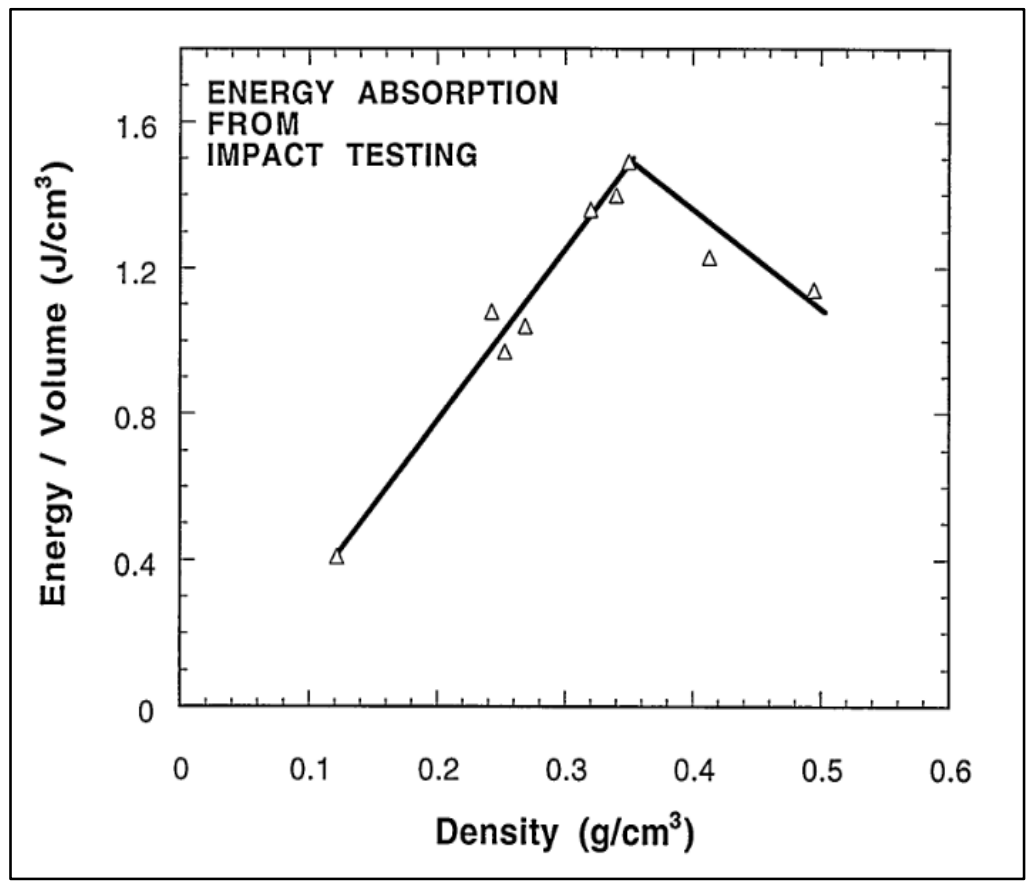

Figure 13: Energy absorption vs. density graph [79] 
Planar impact testing was performed by Ben Gurion University of the Negev with the intention to analyze the dynamic responses of PU foams [81]. Testing consisted of using a gas gun and Velocity interferometer system for any reflector (VISAR) monitoring to measure the impact velocity profiles ranging from 101575 to $1.429 \times 10^{6} \mathrm{in} / \mathrm{min}$ on the PU foam's surface. Results included compression stresses from 52.21 to 7396.92 psi with strain rates ranging from $4 \times 10^{3}-6 \times 10^{5} \mathrm{~s}^{-1}$. The foam started to crush around an impact velocity of $333071 \mathrm{in} / \mathrm{min}$ and a pressure of $464.12 \mathrm{psi}$. As density decreased, compressional loadings caused the shock and temperatures to increase [82]. Similar VISAR experiments were performed by Los Alamos on PU foams whose densities ranged from $0.012-0.032 \mathrm{lbs} . / \mathrm{in}^{3}$. The max velocity was $8503937 \mathrm{in} / \mathrm{min}$, with dissipation rates depending on the foam's densities. The shock input pressures ranged from 433662 to $1171906 \mathrm{psi}$, which also showed a dependency on density [82].

\subsubsection{Adhesion Testing}

A peel test was done by Mahmood at Martin-Luther University by cutting rectangular thermoplastic strips of $0.65 \mathrm{in}^{3}$ [83]. The test used a peel angle of $90^{\circ}$ at room temperature. The peeling rate used was $0.39 \mathrm{in} / \mathrm{in}$. The peel force $(\mathrm{N} / \mathrm{mm})$ was recorded to compute the max force required to peel the PU foam from the thermoplastic substrate. The peel forces were found to be 28.5-34.2 lbf/in. Increasing the roughness of the surface by $3.93 \times 10^{-8}$ in. caused a $1.96 \times 10^{-5}$ in. thickness increase of PU material which demonstrates the effect of mechanical interlocking. A cohesive failure occurred when the thermoplastic material was stronger than the peel force. Figure 14a shows the produced adhesion graph and Figure 14b displays different failure adhesion mechanisms [83]. 

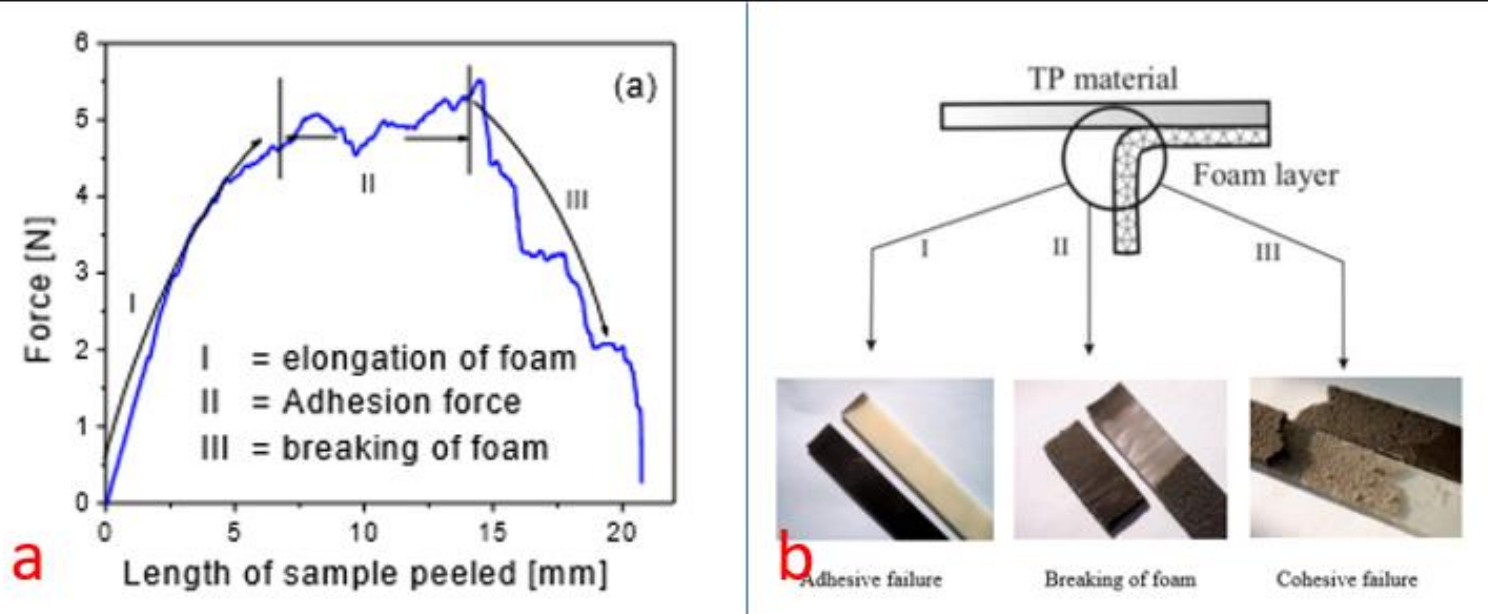

Figure 14: (a) Adhesion graph; (b) different adhesion failure mechanisms [83]

Different climate treatment without humidity drastically reduced the peel strength (Figure 15). The diffusion of water potentially caused adhesion failure due to it affecting the hydrogen bonding at the interface. This was achieved in testing without humidity. High humidity and high temperature also had similar effect but low temperatures did not [83].

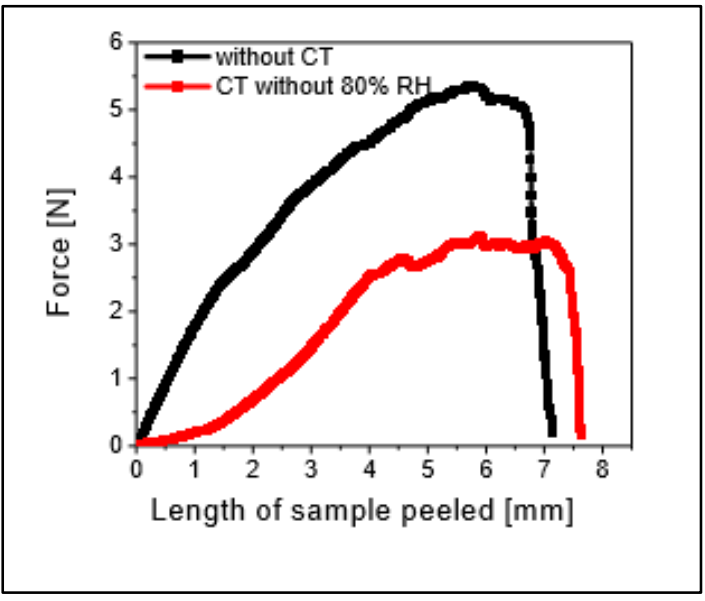

Figure 15: Effect of climate on adhesion graph [83]

\subsection{Radiological Shielding Tests by SRNL}

Scientists at Savannah River National Laboratory (SRNL) have recently been interested in conducting research and experiments on rigid and flexible polyurethane foams 
to determine their ability to immobilize radioactive contamination. Rigid foams are known for reducing energy costs and for being great insulation materials, while flexible foams are used in a wide variety of products such as bedding and shock absorbers due to their flexibility. Savannah River National Laboratory initiated testing on a wide variety of COTS foams to determine which properties would be deemed compatible with the safety basis requirements in a radioactive environment. The properties deemed relevant were the foaming characteristics, temperature profiles, and loading of high-density additives to shield gamma emitting isotopes such as Am-241, Cs-137, and Co-60.

Savannah River National Laboratory created and cured the following four foam samples with and without additives. All the foam samples were within about $\pm 5 \%$ of their expected expansion volume. Foams with the additives experienced a slight temperature difference compared to the unmodified foams. The temperature difference was within the margin of error, and all foams cooled to room temperature within 15 minutes. Using an identiFINDER, an experiment using the various additives was conducted by SRNL to test the foams' abilities to shield radiation. The results demonstrated the following effective shielding of the gamma isotopes with the highest density additives: $98 \%$ of Am-241, 16\% of Cs-137, and 9.5\% of Co-60 [84].

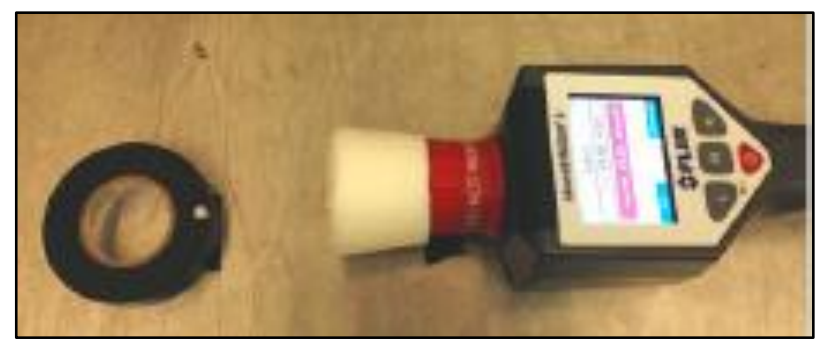

Figure 16. SRNL radiation shielding testing with a $10 \mathrm{~cm}$ distance between the source and identiFINDER [84]. 


\section{CHAPTER III - METHODOLOGY}

\subsection{Hypothesis}

There are two hypotheses that will be proven or refuted over the course of this thesis:

1. Commercial-off-the-shelf (COTS) intumescent polyurethane rigid foams will have better mechanical limits than non-intumescent commercial-off-the-shelf rigid foams due to the increased and consistent cell size and relative density the expandable graphite loading, or other fillers induces.

2. Commercial-off-the-shelf rigid polyurethane foams will have better adhesion than non-rigid commercial-off-the-shelf foams due to higher cross-linking, slower curing times, and higher reactivity due to high isocyanate content. Commercial-offthe-shelf intumescent rigid foams may have better adhesion than non-intumescent commercial-off-the-shelf rigid foams due to having extra fillers like vinyl acetate that form additional hydrogen bonds.

\subsection{Objectives}

The following objectives will support both hypotheses stated in the previous sections with the main interest of updating Section 5 of ASTM E3919. 6 COTS PU foams will be tested (Figure 17). There will be a combination of flexible, rigid, and intumescent

PU foams. The naming convention will be as follows: I denotes intumescence, F denotes flexible, and $\mathrm{R}$ denotes rigid. 


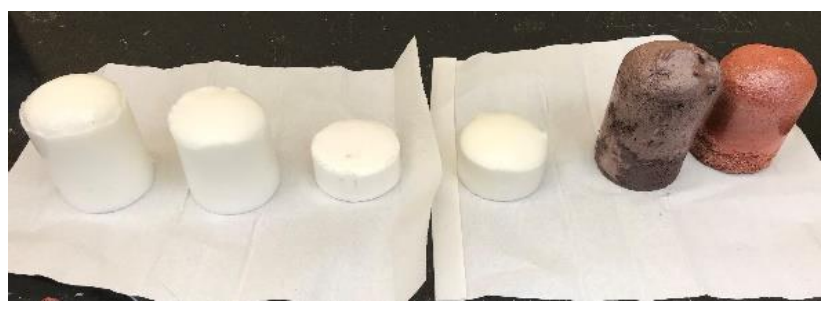

Figure 17: F1, R1, F2, F3, IF4, and IR2

\subsubsection{Objective 1 - Effects of Filler on Mechanical Performance}

This objective will identify the mechanical properties of the 6 COTS PU foams to down-select the best one to be used as a PFF. The goal is to determine if the EG loading in intumescent rigid PU foam will improve its mechanical performance. This can also potentially provide a metrics of success chart to which future PU foams may be compared. Section 5.2 of ASTM E3191 relates to this objective and states the following:

"The foaming fixative shall have sufficient mechanical properties to withstand long-term wear associated with incidental impact, abrasion, or vibration that are likely to cause loss of containment of the isolated contaminant."

\subsubsection{Objective 2 - Adhesion Characterization}

This objective will consist of adhesion testing to determine which will be the best candidates of the 6 COTS PU foams to be used as a PFF. The first stage will consist of a simple tensile adhesion testing. The second phase will consist of encapsulating an operational volume (pipe) with the two most adhesive PU foams from the previous testing. The remainder of the work under this objective will consist of applying various physical stressors to the PFF encapsulated in a 304 stainless steel pipe. Adhesion testing will be performed after to determine impact effect on adhesion. This will be an important indicator if the PFF can immobilize residual contamination in a radioactive environment while experiencing stresses as referenced in Section 5.4. Safety Basis of Interim Operations 
(SBIO) documents will be heavily referenced as well as having discussions with SRNL representatives to determine realistic seismic stressors that can occur at DOE sites. This objective is motivated by Section 5.4 of ASTM E3191, which states the following:

"The foaming fixative should have sufficient mechanical properties to withstand contingency events such as earthquakes as outlined in a facilities' safety design basis document."

\subsection{Methods}

The following methods will be used to help satisfy both objectives.

\subsubsection{Objective 1 Methods}

The following will outline the several sections of Objective 1. All testing methods are inspired by rigid PU foam testing performed at the Institut Teknologi Sepuluh Nopember [85]

\subsubsection{Tensile Testing}

Residual contamination can be trapped inside the PFF and tension may cause subsequent release of the residual contamination due to induced delamination. Tensile testing will be performed to characterize the foam's mechanical properties that involve Young's Modulus, strain, peak stress and peak load. These properties can be calculated by analyzing the produced stress-strain curves. An MTS Systems Corporation (MTS) Criterion 43 Tensile Tester was utilized for this task. The standards to be considered are ASTM D3574-E Flexible Cellular Materials - Slab, Bonded, and Molded Urethane Foams (flexible) [86] and ASTM D1623 Tensile and Tensile Adhesion Properties of Rigid Cellular Plastics (rigid) [87]. ASTM D3574-E specifies a pull rate of $20 \mathrm{in} / \mathrm{min}$ while ASTM D1623 states to use a pull-rate of $0.05 \mathrm{in} / \mathrm{min}$. 


\subsubsection{Compression Testing}

Residual contamination may be trapped inside permanent foaming fixative and any static loading can cause a release of the contamination. Compression testing will be performed to characterize the foam's mechanical properties that characterizes compression stress, compression strain, compression modulus and maximum compression modulus. An MTS Criterion 43 Tensile Tester will be utilized for this task. The standards that will be utilized are ASTM 3574-C Flexible Cellular Materials - Slab, Bonded, and Molded Urethane Foams (flexible) and ASTM D1621 Compressive Properties of Rigid Cellular Plastics (rigid) [88]. ASTM 3574-C for the flexible foams states to pre-flex the foams twice at a rate of $10 \mathrm{in} / \mathrm{min}$ and then compress the foam for $2 \mathrm{in} / \mathrm{min}$ and dwell for a minute. ASTM D1621 states to compress the rigid foam at a rate of $10 \%$ of its initial thickness until the foam is compressed $13 \%$ of its original thickness. Testing will stop if the rigid foam reaches this strain criteria or until it reaches the load limit of the MTS which was set to 8992.35 lbf.

\subsubsection{Cell Size Evaluation}

After completion of mechanical testing, scanning electron microscopy (SEM) will be utilized to evaluate the cell sizes of each of the PU foam samples. This can help compare cell sizes to the results obtained from mechanical testing since cell sizes influences mechanical properties.

\subsubsection{Objective 2 Methods}

The following methods will be done in support of satisfying objective two. 


\subsubsection{Tensile Adhesion Testing}

Adhesion capabilities will ultimately decide whether a permanent foaming fixative can immobilize residual contamination. Any sort of incidental impact can cause the foam to delaminate from the substrate thereby releasing residual contamination. ASTM D1623: Test Method for Tensile and Tensile Adhesion Properties of Rigid Cellular Plastics will be used to conduct adhesion testing.

Using the MTS Criterion Series 43 Tensile Tester, the tensile adhesion strength will be calculated to see the amount of force or stress required to pull the foam off the 304 Stainless Steel substrate in 3 to 6 minutes. ASTM D1623 suggests using a rate of pull of $.05 \mathrm{in} / \mathrm{min}$ for each inch of test section gauge length. The 304 stainless steel coupons will be 2 inches by 2 inches by .125 inch thickness so each PU foams' dimensions will be 2 inch by 2 inch by 2 inch, making the rate of pull $1 \mathrm{in} / \mathrm{min}$ per the standard.

\subsubsection{Adhesion Interface Evaluation}

After completion of tensile adhesion testing, SEM will be used on the same 1 in. tall pipe samples to evaluate the adhesion interface of each of the 6 COTS PU foams to help further down-select the best suitable candidates. Each PU foam cures at different rates, which may influence how well each adheres to the pipe wall. Blowing agent eruptions, entrapped air, and pipe frictions are other factors can influence adhesion [89].

\subsubsection{Shear Adhesion Testing}

Shear adhesion testing will be done to compare the adhesion loads required to compress the 2 best permanent foaming fixative off an operational volume, which is a 304stainless steel pipe. If the permanent foaming fixative leaves material in the internal walls 
of the pipe, it will be concluded that the shear strength will be less the adhesive strength. The opposite can be said if the permanent foaming fixative does not leave any material then the shear strength will be greater than the adhesion strength. The pipe samples will be 4 in. in internal diameter and 4 in. in length. Two samples will be made in total for preliminary testing. Testing will also be done on different internal roughness pipe samples to confirm that the primary adhesion mechanism is mechanical interlocking for PU foams. The two best foaming candidates of the tensile adhesion testing will be the foams used for experimentation.

Figure 18 shows a cross-sectional view of how the permanent foaming fixative will be compressed out of the 304 stainless steel pipe and the dimensions of all components involved. An MTS 43 Criterion tensile tester will be used with compression plates. Component 1 of Figure 18 will have a diameter of 3.5 in. and a height of 6 in. Component 2 will have a height of $4 \mathrm{in}$., an inner diameter (ID) of $4 \mathrm{in}$, and an outer diameter of $4.5 \mathrm{in}$. Component 3 will have a height of 6 in., an inner diameter of 4.25 in, an outer diameter of 5.5 in., and a counter bore diameter of 4.5 in. with a depth of 1.5 in. All components will be made from 304 stainless steel. 


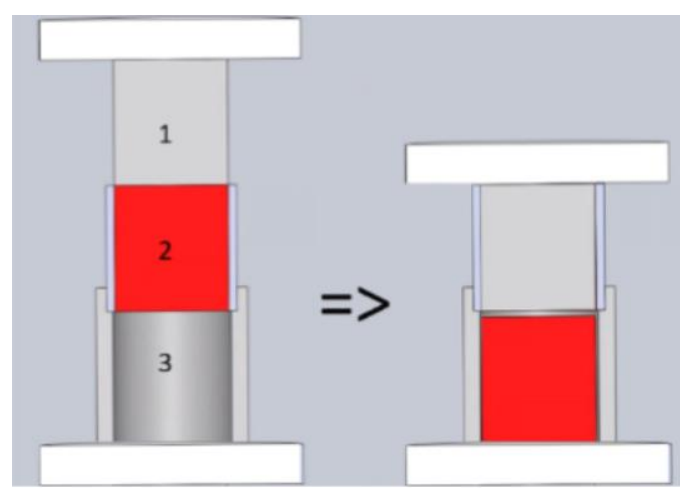

Figure 18: Shear adhesion experimental design

Once determining the default adhesion loads required to compress the PFF is completed, conducting physical stressors on pipes will be done to evaluate effect on adhesion. Testing protocols will comply with Normal Conditions of Transport [72] and Hypothetical accident conditions described in the United States Nuclear Regulatory Commission (NRC). These seismic stressors will involve drop test, water submersion and extreme heat conditions [90]. Drop testing will be performed at heights of 4, 8, and $12 \mathrm{ft}$. Water submersion will be accomplished at a water depth of $3 \mathrm{ft}$. and submerged for 8,12 , and 24 hrs. Extreme heat conditions will be evaluated by placing the samples in a muffle furnace at a temperature of $1475^{\circ} \mathrm{F}$ for 30 minutes. 


\section{CHAPTER IV - RESULTS}

\subsection{Objective 1 - Effects of Filler on Mechanical Performance}

The objective is to compare the mechanical limits of the 6 COTS PU foams to determine the effects of fillers. Four of the foams were non-intumescent and did not contain the fillers and EG the two intumescent foams had. One of the intumescent foams was rigid while the other was flexible. The goal was to show intumescent rigid foams will have the best mechanical limits due to the consistent cell sizes the EG loading induced.

\subsubsection{Sample Fabrication}

The following sections displays the sample fabrication for the tensile and compression testing. The SEM samples' fabrication process was also documented.

\subsubsection{Tensile Testing Sample Fabrication}

Table 1 shows how much of each component was used to develop the tensile testing samples. The intumescent foams were not included because there is no fixed amount to apply them due to their rapid hardening and dispersing. Overcompensation of amounts of components were used to ensure quality performance.

Table 1: Tensile testing mixing components ratios

\begin{tabular}{|c|c|c|c|c|}
\hline \multicolumn{5}{|c|}{ Tensile Testing } \\
\hline Foam & Volume & A & B & Ratio \\
Identifier & $(\mathbf{m L})$ & $(\mathbf{m L})$ & $(\mathbf{m L})$ & $(\mathbf{A}: \mathbf{B})$ \\
\hline F1 & 50 & 10 & 10 & 1 \\
\hline R1 & 86 & 16 & 8 & 2 \\
\hline F2 & 50 & 12 & 24 & 0.5 \\
\hline
\end{tabular}




\begin{tabular}{l|l|l|l|l|} 
F3 & 50 & 11.5 & 13.5 & 0.85 \\
\hline
\end{tabular}

A mold was 3D printed for the rigid polyurethane foams with dimensions that comply with the Type B tensile dye of ASTM D1623 Tensile and Tensile Adhesion Properties of Rigid Cellular Plastics [87]. The mold was taped around all its edges and placed on wax paper to ensure the sample can be removed (Figure 19). Using the I-R2 foam dispenser gun, foam was poured inside the mold and the I-R2 foam cured and expanded within a minute. Once the foam started to expand, a 12-inch by 12-inch 304 stainless steel coupon was placed on top of the mold sandwiching the foam inside the mold. After 5 minutes passed, the large 304 stainless steel coupon was taken off and a saw was used to trim any excess foam from the top surface (Figure 19a-c). The foam was then extracted from the mold to produce the tensile testing sample.

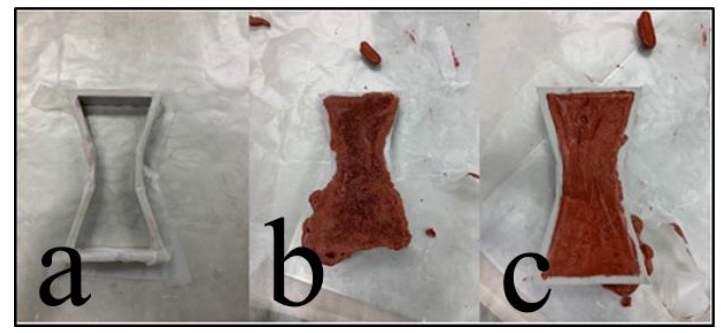

Figure 19: (a) Rigid 3D mold; (b) I-R2 cured in mold; (c) I-R2 excess shaven off

A total of five samples were produced. Two of the samples created will be used as test dummy samples due to imperfections and impurities. The other rigid foam documentation (R1) are shown in the Appendix. The same process was applied for the flexible foams using the amounts of both Part A and B prescribed in Table 1. The 3D mold used is shown in Figure 20a and complies with ASTM 3574 Flexible Cellular Materials - 
Slab, Bonded, and Molded Urethane Foams Test E dimensions [86]. Figure 20b and 20c also shows the process of curing and extraction from the mold.

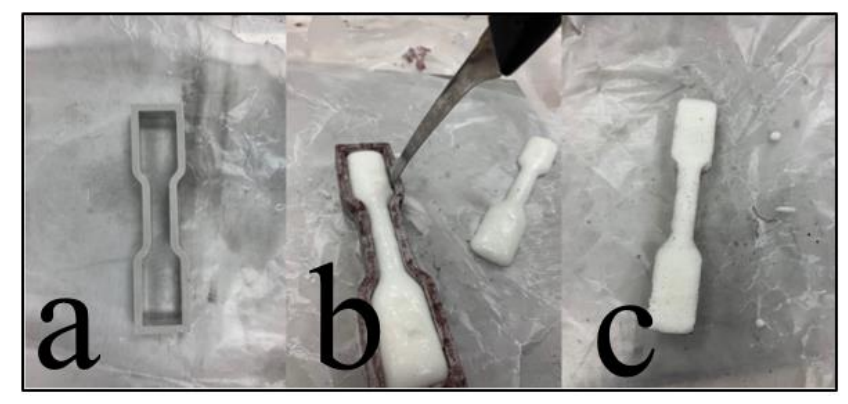

Figure 20: (a) Flexible 3D mold; (b) foam cured in mold; (c) foam extracted

A total of five samples were produced for F3. All of the other flexible foam documentation are shown in the Appendix. Figure 21 shows all the tensile testing foam samples of the 6 COTS PU foams.

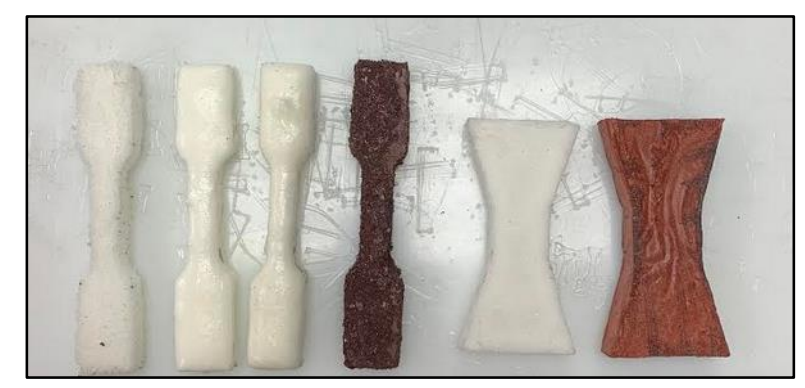

Figure 21: F1, F2, F3, I-F4, R1, and I-R2

\subsubsection{Compression Testing Sample Fabrication}

Table 2 shows how much of each component was used to develop the compression samples. The intumescent foams are not included because there is no fixed amount to apply them due to rapid hardening. Overcompensation of amounts of components were used to ensure quality performance. 
Table 2: Amounts to produced required sample

\begin{tabular}{|c|c|c|c|c|c|c|c|c|}
\hline \multirow{2}{*}{$\begin{array}{c}\text { Foam } \\
\text { Identifier }\end{array}$} & \multicolumn{4}{|c|}{ Compression (Cylinder) } & \multicolumn{3}{c|}{ Compression (Rectangular) } \\
\cline { 2 - 9 } & Volume & $\mathbf{A}$ & $\mathbf{B}$ & Ratio & Volume & $\mathbf{A}$ & $\mathbf{B}$ & Ratio \\
$(\mathbf{m L})$ & $(\mathbf{m L})$ & $(\mathbf{m L})$ & $(\mathrm{A}: \mathbf{B})$ & $(\mathbf{m L})$ & $(\mathbf{m L})$ & $(\mathbf{m L})$ & $(\mathbf{A : B})$ \\
\hline F1 & 102 & 7 & 7 & 1 & 65 & 5 & 5 & 1 \\
\hline R1 & 102 & 10 & 5 & 2 & 65 & 6 & 3 & 2 \\
\hline F2 & 102 & 12 & 24 & 0.5 & 65 & 9 & 18 & 0.5 \\
\hline F3 & 102 & 23.5 & 27.5 & 0.85 & 65 & 15 & 17.5 & 0.86 \\
\hline
\end{tabular}

Two molds (Figure 22) were used with the dimensions of each cavity in each mold complying with standards ASTM 3574-C (flexible) and ASTM D1621 Compressive Properties of Rigid Cellular Plastics (rigid) [88]. The area of each specimen were 3.87 in $^{2}$ with a height of .78 inches. Both rectangular and circular specimens will be considered to evaluate if geometry can influence the results.

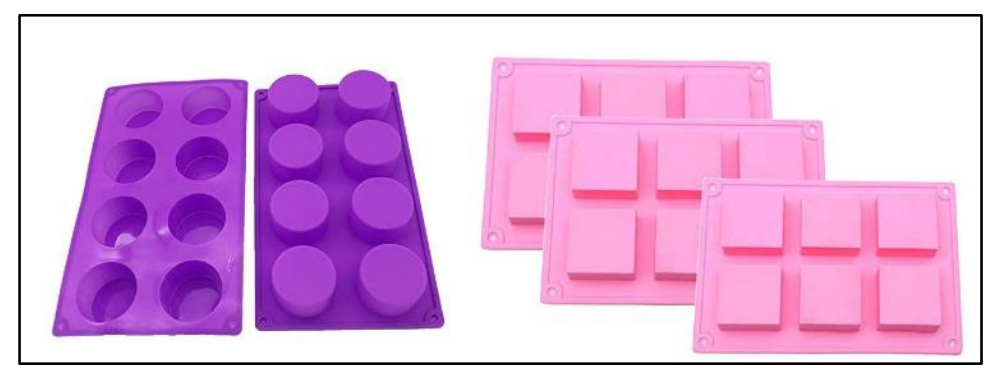

Figure 22: Compression molds

The same process was used for the intumescent foams, and any excess foam was shaved off. The other foams used the amounts in Table 2 and were mixed, poured, and allowed to cure overnight. Figure 23 shows all the foam samples in both rectangular and cylindrical form. 


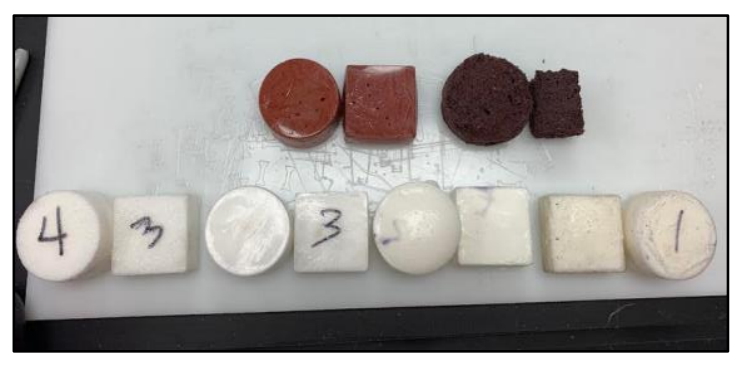

Figure 23: Cylindrical and rectangular samples of foams

Compression testing was also performed on the cubic samples after they were used for tensile adhesion testing. Figure 24 showcases the rigid foam samples (R1 and I-R2).

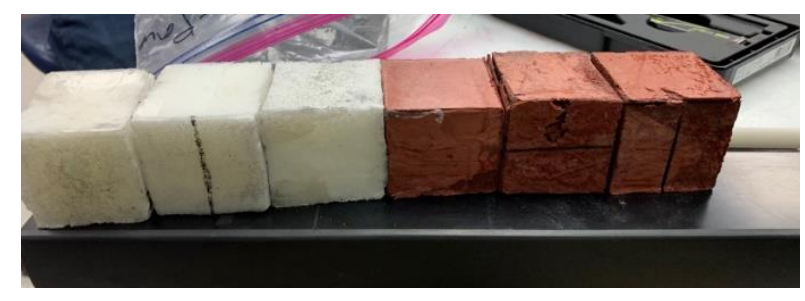

Figure 24: Cubic samples: R1 (left) and I-R2 (right)

\subsubsection{SEM Sample Fabrication}

Each PU foam was encapsulated in a 1-inch tall 304 stainless steel pipe with an inner diameter of 0.5 inches and outer diameter of 0.66 inches. The samples were gold coated to allow for the electrons to interact with the polymers. Figure 25 shows the 6 PU foam samples encapsulated. Different magnification factors will be used ranging 25-100x to obtain a realistic view on the cell sizes.

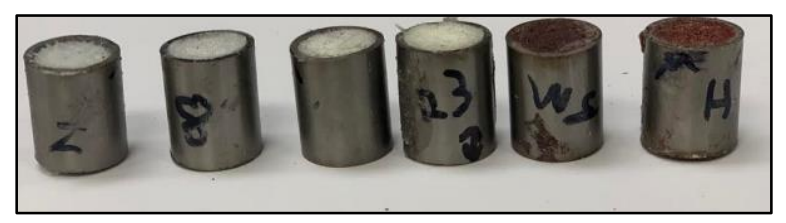

Figure 25: SEM samples: F1, R1, F2, F3, R1, I-F4 and I-R2 


\subsubsection{Objective 1 Results}

The section highlights the results and findings of all testing related to Objective 1 .

\subsubsection{Tensile Testing Results}

Figure 26 shows the process of tensile testing for a flexible foam. Flexible foams would typically elongate until sudden rupture occurred. No sign of permanent deformation occurred. Rigid foams displayed the opposite behavior as they did not stretch and exhibited minor permanent deformation before failure occurred. This is due to the higher crosslinking that allowed for the atoms to be permanently locked near each other [33]. The flexible foams had an average gauge length of $1.37 \mathrm{in.}$ and cross-sectional area of $0.1 \mathrm{in}^{2}$. The rigid foams had to be shaved down because they were too thick for the grips of the machine, and had an average gauge length of $1 \mathrm{in}$. and cross-sectional area of $0.35 \mathrm{in}^{2}$.

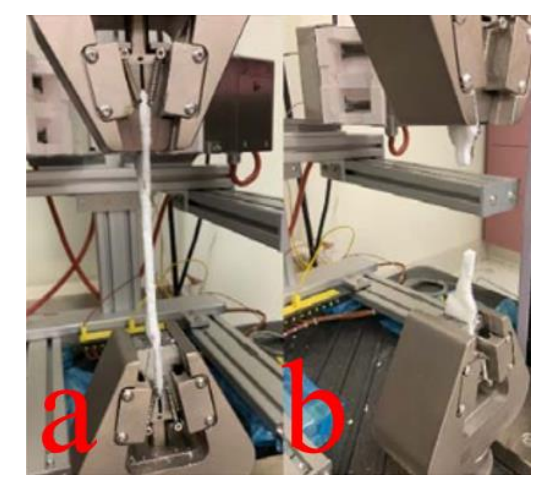

Figure 26: (a) Flexible foam flexing; (b) rupturing during tensile testing

Figure 27 displays the produced stress-strain curves, and shows the flexible foams stretched to approximately triple their length. The flexible foams behaved in an elasticbrittle fashion due to brittle fracture occurring at the end of the linear elasticity region [36]. The rigid foams had negligible strain and experienced the highest stresses and loadings, which can be desirable in an operational environment. The rigid foams behaved liked elastic-plastic materials since elastic yielding initially occurred then was followed by rapid 
stress increase due to cell wall re-alignment [91]. Most of the rigid foams failed once reaching the elastic limit portion of the stress-strain curve. The elastic moduli for I-R2 and R-1 foam were computed to be $5.34 \mathrm{ksi}$ and $3.09 \mathrm{ksi}$, respectively.

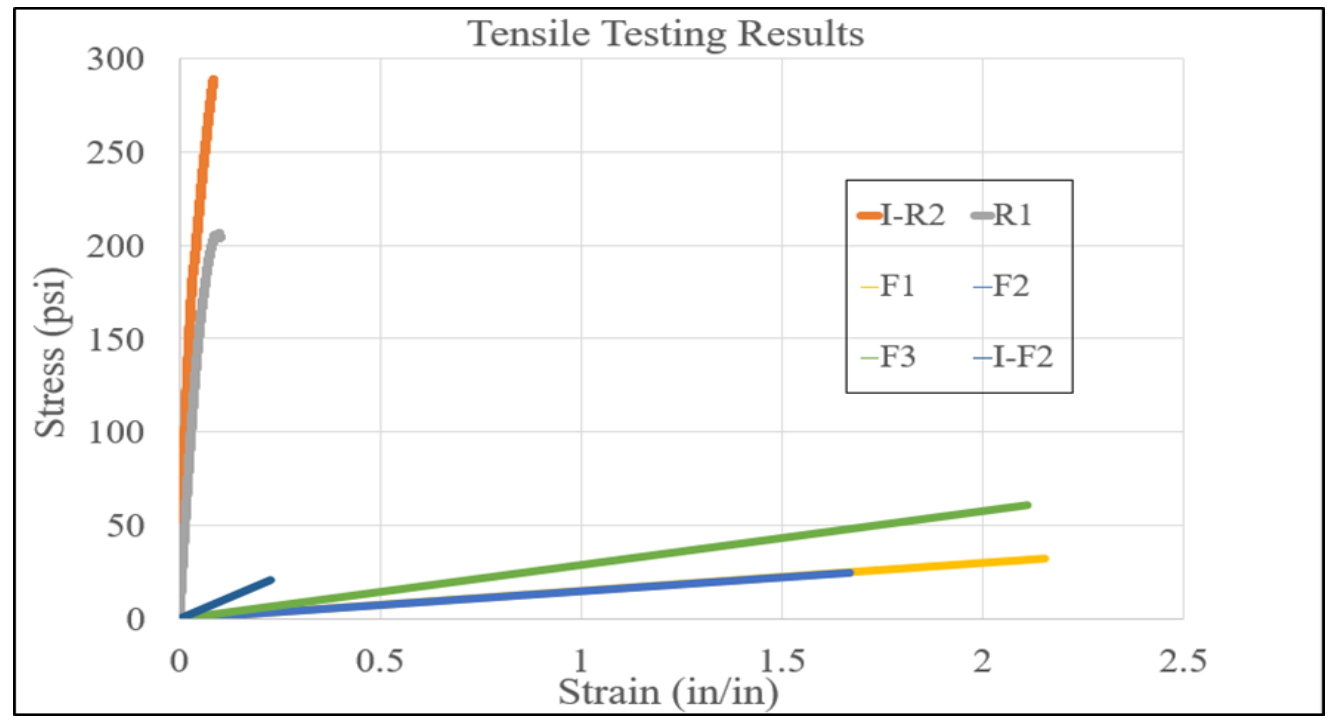

Figure 27: Tensile testing graphs

Both ASTM E3574 and D1623 state that one should calculate the stresses and loadings that occur at failure as well as the failure strain. The rigid foams, R-1 and IR-2, had the highest stresses of $73.99 \mathrm{psi}$ and $103.65 \mathrm{psi}$. The loadings that coincided with these stresses were $206.6 \mathrm{lbf}$ and $289.42 \mathrm{lbf}$, respectively. The flexible foams had the highest strain values with F-1 extending to $215 \%$ its original gauge length. Table 3 displays all findings from this test.

Table 3: Tensile testing results

\begin{tabular}{|c|c|c|c|}
\hline $\begin{array}{c}\text { Foam } \\
\text { Sample }\end{array}$ & Peak Load (lbf) & $\begin{array}{c}\text { Peak Stress } \\
(\mathbf{p s i})\end{array}$ & $\begin{array}{c}\text { Strain at } \\
\text { Break (in/in) }\end{array}$ \\
\hline F-1 & 4.84 & 32.24 & 2.15 \\
\hline F-2 & 3.70 & 24.63 & 1.67 \\
\hline F-3 & 9.13 & 60.85 & 2.11 \\
\hline IF-4 & 3.11 & 20.73 & 0.23 \\
\hline R-1 & 73.99 & 206.60 & $\mathbf{0 . 1 1}$ \\
\hline IR-2 & $\mathbf{1 0 3 . 6 5}$ & $\mathbf{2 8 9 . 4 2}$ & 0.12 \\
\hline
\end{tabular}




\subsubsection{Compression Testing Results}

Figure 28 illustrates the compression testing for a flexible foam cube.

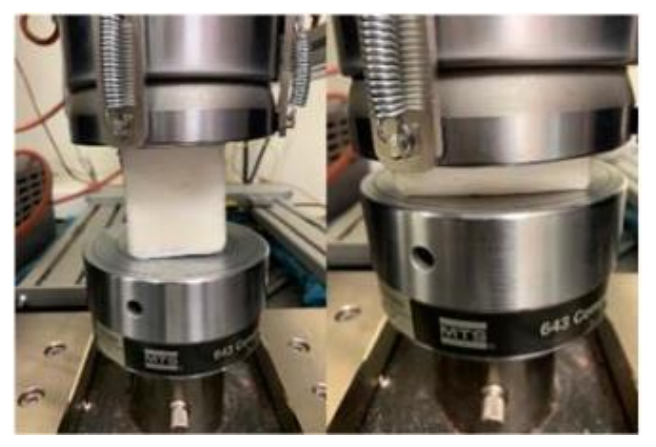

Figure 28: Flexible foam compression testing

Some of the dimensions for cylindrical and rectangular samples varied slightly and were calibrated appropriately so all the samples had the same dimensions. The rigid foams, I-R2 and R1, showed elastomeric behavior [91]. The rigid foams first experienced an initial elastic regime at low stresses, followed by a nearly plateau-like region where the loading was nearly constant until densification occurred, in which stresses rapidly increased. In the initial linear elastic part, the rigid foams were compressed uniformly due to membranes in the cell walls being deformed and internal fluids building pressure [36]. For the plateau part, they started to plastically deform as the cell walls were compressed together [14]. 


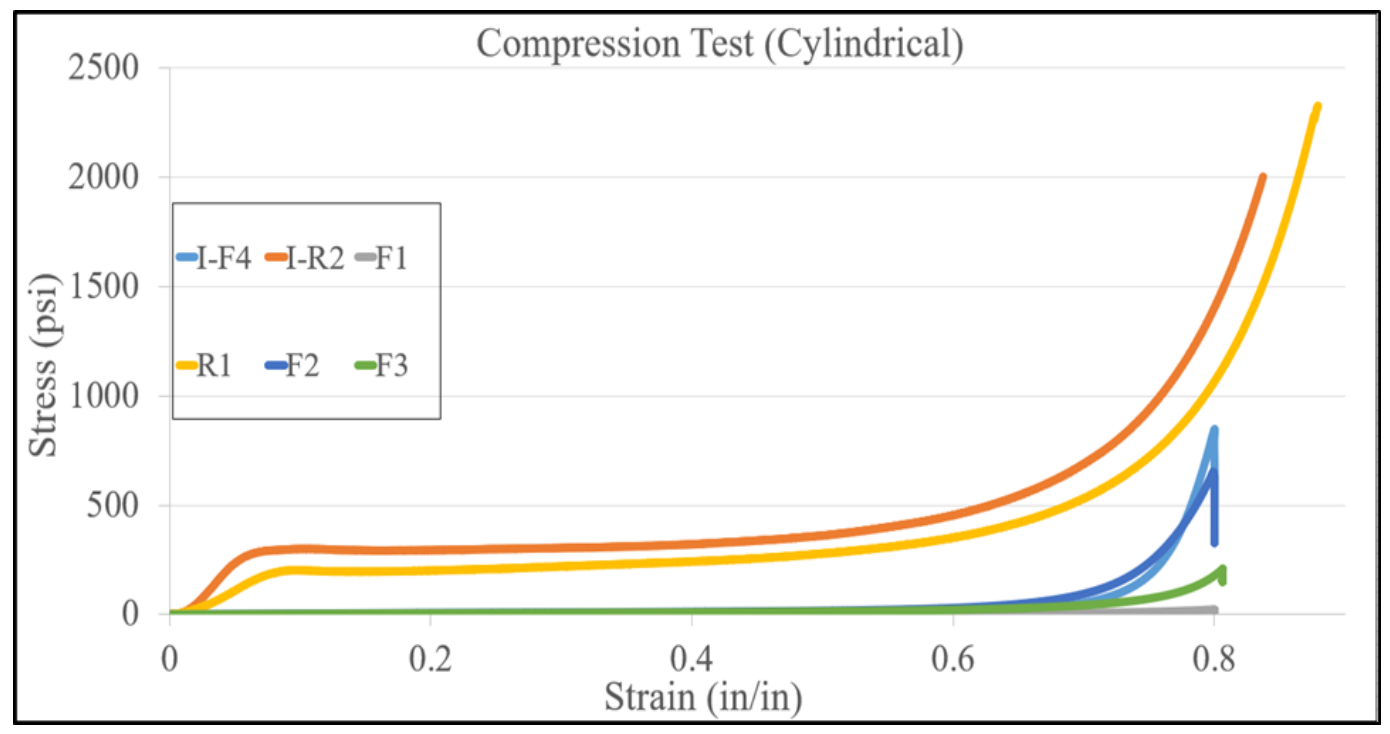

Figure 29: Compression testing graph (cylindrical)

Table 4 shows the results for all parameters that ASTM 35474-C requires. It only asked for values at $50 \%$ deflection, but $80 \%$ deflection values were also obtained. The rigid foams, R-1 and I-R2, performed better as evident in Table 4 and Figure 29 by achieving higher loading and stresses than flexible foams. The flexible foams became slightly shorter while the rigid foams were able to restore some thickness once uncompressed.

Table 4: Compression testing results (cylindrical)

\begin{tabular}{|c|c|c|c|c|c|c|}
\hline $\begin{array}{c}\text { Foam } \\
\text { Sample }\end{array}$ & $\begin{array}{c}\mathbf{5 0 \%} \\
\text { Deflection } \\
\text { Stress (psi) }\end{array}$ & $\begin{array}{c}\mathbf{5 0 \%} \\
\text { Deflection } \\
\text { Load (lbf) }\end{array}$ & $\begin{array}{c}\mathbf{8 0 \%} \\
\text { Deflection } \\
\text { Stress (psi) }\end{array}$ & $\begin{array}{c}\mathbf{8 0 \%} \\
\text { Deflection } \\
\text { Load (lbf) }\end{array}$ & $\begin{array}{c}\text { Thickness } \\
\text { Decrease } \\
\text { \% }\end{array}$ & $\begin{array}{c}\text { Final } \\
\text { Thickness } \\
\text { (in) }\end{array}$ \\
\hline F-1 & 2.77 & 10.67 & 22.59 & 86.92 & -0.15 & 0.79 \\
\hline F-2 & 17.00 & 65.40 & 637.69 & 2453.21 & 0.14 & 0.79 \\
\hline F-3 & 13.77 & 52.98 & 178.83 & 687.94 & 13.86 & 0.68 \\
\hline IF-4 & 3.75 & 14.43 & 845.83 & 3253.91 & 11.63 & 0.70 \\
\hline R-1 & 278.53 & 1071.49 & 1064.88 & 4096.61 & 71.75 & 0.22 \\
\hline IR-2 & $\mathbf{3 6 0 . 6 7}$ & $\mathbf{1 3 8 7 . 4 8}$ & $\mathbf{1 4 0 4 . 3 7}$ & $\mathbf{5 4 0 2 . 6 0}$ & 71.76 & 0.22 \\
\hline
\end{tabular}

Table 5 highlights the results that ASTM D1621 required. As previously stated, the three stages these rigid foams went through were the linear elastic region, plateau region, and densification. Anything that happened after the initial linear elastic region resulted in 
permanent deformation. The modulus computed, which is the measure of stiffness a material can exhibit before plastic deformation, was greater for the intumescent rigid foam than the non-intumescent rigid foam.

Table 5: ASTM D1621 results (cylindrical)

\begin{tabular}{|c|c|c|c|}
\hline $\begin{array}{c}\text { Rigid } \\
\text { Foam }\end{array}$ & $\begin{array}{c}\mathbf{1 0 \%} \\
\text { Stress } \\
(\mathbf{p s i})\end{array}$ & $\begin{array}{c}\mathbf{1 0 \%} \\
\text { Load } \\
\text { (lbf) }\end{array}$ & $\begin{array}{c}\text { Modulus } \\
(\mathbf{p s i})\end{array}$ \\
\hline R1 & 198.12 & 762.18 & 2103.95 \\
\hline I-R2 & $\mathbf{2 9 7 . 2 5}$ & $\mathbf{1 1 4 3 . 5 2}$ & $\mathbf{3 9 2 8 . 0 5}$ \\
\hline
\end{tabular}

Compression testing results for rectangular specimens were similar to the cylindrical findings. Figure 30 displays the produced stress-strain graph. Based on visual inspection, I-R2 and R1 foams had the best highest stress-strain curves amongst the other foam candidates. Besides the initial linear portion, the I-R2 foam had the best results once again.

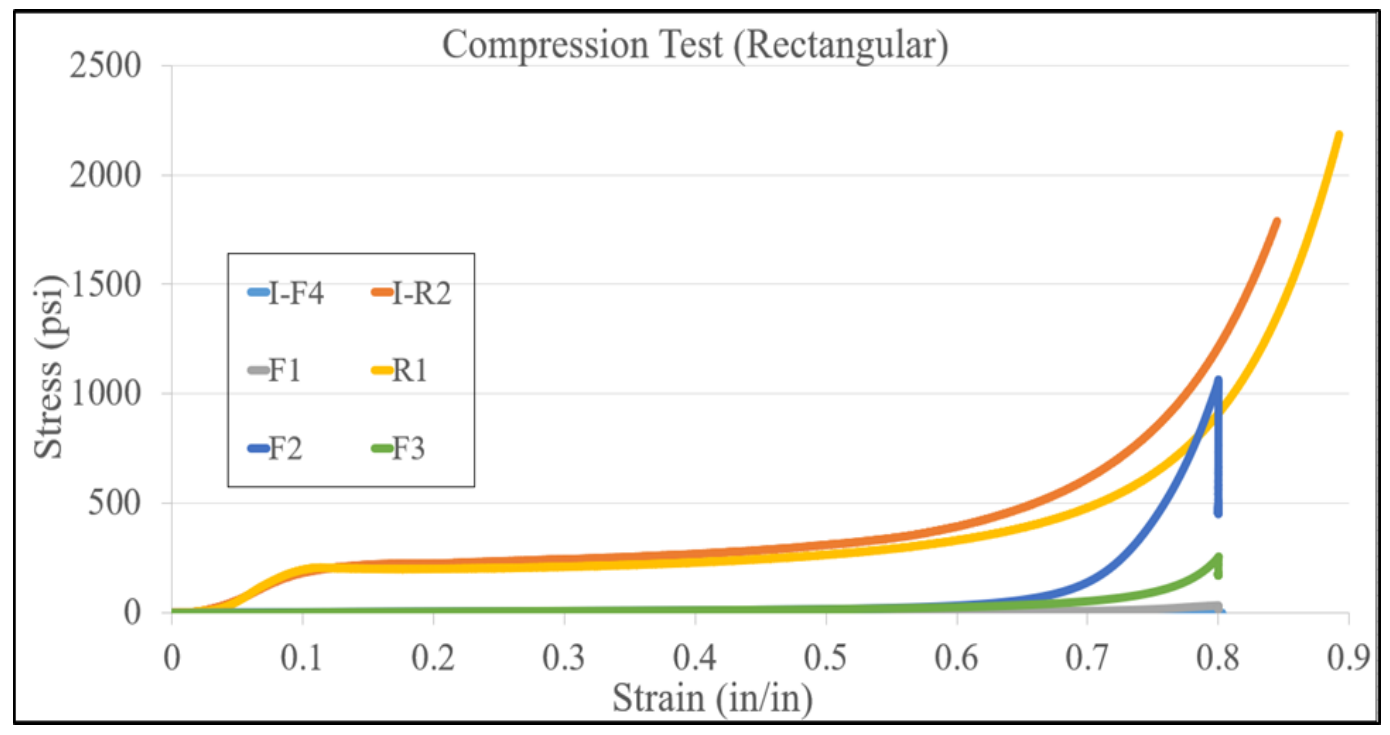

Figure 30: Compression testing graph (rectangular)

Table 6 confirms that the I-R2 foam had the best results. It had the highest stresses at $80 \%$ deflection of $1214.59 \mathrm{psi}$, which equated to $4672.54 \mathrm{lbf}$. The other rigid foam, R1, 
was the second best with a stress value of $911.10 \mathrm{psi}$ and $3505.02 \mathrm{lbf}$ at $80 \%$ deflection. The computed compression modulus ASTM D1621 was then calculated for the R1 and IR2 foams. The compression moduli for R1 and I-R2 were computed to be 1415.50 psi and $1553.82 \mathrm{psi}$, respectively. The values varied compared to the values computed in Table 4 , which may show an influence in geometry.

Table 6: Compression testing results (rectangular)

\begin{tabular}{|c|c|c|c|c|c|c|}
\hline $\begin{array}{c}\text { Foam } \\
\text { Sample }\end{array}$ & $\begin{array}{c}50 \% \\
\text { Deflection } \\
\text { Stress (psi) } \\
\end{array}$ & $\begin{array}{c}50 \% \\
\text { Deflection } \\
\text { Load (lbf) }\end{array}$ & $\begin{array}{c}\mathbf{8 0 \%} \\
\text { Deflection } \\
\text { Stress (psi) }\end{array}$ & $\begin{array}{c}\mathbf{8 0 \%} \\
\text { Deflection } \\
\text { Load (lbf) } \\
\end{array}$ & $\begin{array}{c}\text { Thickness } \\
\text { Decrease } \\
\%\end{array}$ & $\begin{array}{c}\text { Final } \\
\text { Thickness } \\
\text { (in) }\end{array}$ \\
\hline F-1 & 3.01 & 11.59 & 34.95 & 134.46 & 1.76 & 0.77 \\
\hline F-2 & 17.85 & 68.67 & 1063.59 & 4091.65 & 0.62 & 0.78 \\
\hline F-3 & 17.67 & 67.98 & 257.98 & 992.45 & 0.34 & 0.78 \\
\hline IF-4 & 0.01 & 0.03 & 0.12 & 0.47 & 15.50 & 0.67 \\
\hline $\mathrm{R}-1$ & 266.10 & 1023.67 & 911.10 & 3505.02 & 71.22 & 0.23 \\
\hline IR-2 & 311.41 & 1197.99 & 1214.59 & 4672.54 & 72.90 & 0.21 \\
\hline
\end{tabular}

Figure 31 shows the compression results for the cubic samples. The cubic samples were previously used for the adhesion testing, but none suffered structural degradation. All the cubic samples were 2 in. thick and had a cross-sectional area of $4 \mathrm{in}^{2}$ which satisfied both ASTM 3574-C and ASTM D1621 dimension requirements. The minimum thickness and cross-sectional areas for ASTM 3574-C are 0.78 in. and $3.87 \mathrm{in}^{2}$, respectively, while the minimum thickness and cross-sectional area for ASTM D1621 are 1 in. and $3.87 \mathrm{in}^{2}$, respectively. Upon visual inspection on Figure 31, R1 performed better than I-R2 in terms of stresses and strains. 


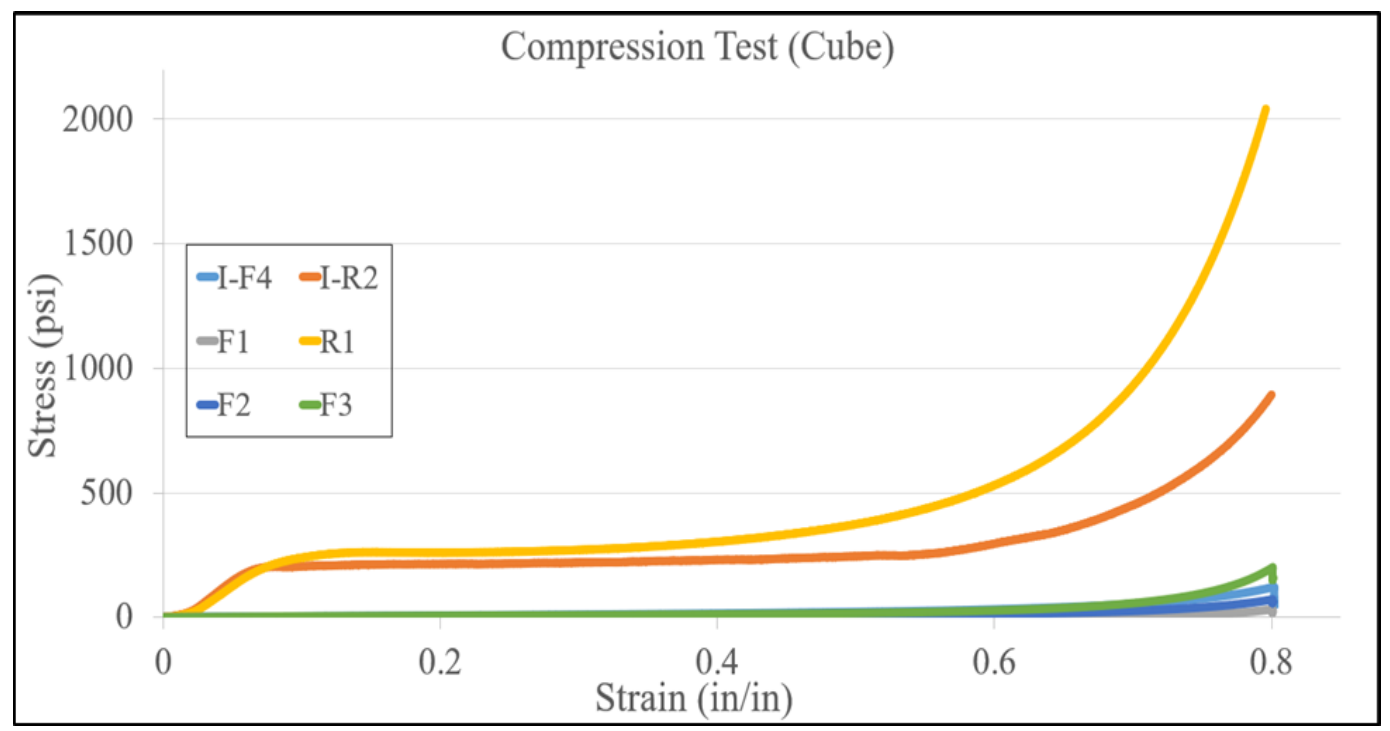

Figure 31: Compression testing results (cubic)

Table 6 shows that the R-1 foam performed better than the I-R2 foam. The I-R2 samples had significant cracking from tensile adhesion testing that could have affected the results.

Table 7: Compression result values (cubic)

\begin{tabular}{|c|c|c|c|c|c|c|}
\hline $\begin{array}{c}\text { Foam } \\
\text { Sample }\end{array}$ & $\begin{array}{c}\mathbf{5 0 \%} \\
\text { Deflection } \\
\text { Stress (psi) }\end{array}$ & $\begin{array}{c}50 \% \\
\text { Deflection } \\
\text { Load (lbf) }\end{array}$ & $\begin{array}{c}\mathbf{8 0 \%} \\
\text { Deflection } \\
\text { Stress (psi) }\end{array}$ & $\begin{array}{c}\mathbf{8 0 \%} \\
\text { Deflection } \\
\text { Load (lbf) }\end{array}$ & $\begin{array}{c}\text { Thickness } \\
\text { Decrease } \\
(\%)\end{array}$ & $\begin{array}{c}\text { Final } \\
\text { Thickness } \\
\text { (in) }\end{array}$ \\
\hline F-1 & 1.32 & 5.28 & 32.82 & 131.30 & 3.40 & 1.93 \\
\hline $\mathrm{F}-2$ & 8.08 & 32.30 & 72.08 & 288.33 & 1.24 & 1.97 \\
\hline F-3 & 16.97 & 67.87 & 201.38 & 805.50 & 1.29 & 1.97 \\
\hline IF-4 & 21.87 & 87.46 & 120.51 & 482.03 & 32.41 & 1.35 \\
\hline R-1 & 373.89 & 1495.57 & 2041.56 & 8166.24 & 68.42 & 0.63 \\
\hline IR-2 & 245.11 & 980.43 & 893.71 & 3574.84 & 74.75 & 0.50 \\
\hline
\end{tabular}

Compression testing on cylinder specimens gives more accurate results than cubic and rectangular specimens since the stress distribution is proportional to its geometry [92]. Shear stress is introduced as the platens compress the specimen's top surface. A cube and rectangular specimens' four unloading surfaces resist volumetric expansion, due to interference between load transferring mechanisms from the top to bottom surfaces. This 
effect causes more compressive strength. A factor of 0.8 is normally used to relate cylindrical and cubic compression strength, but this ratio increases when the aspect ratio (h/d) of the cylindrical samples is large [93]. An aspect ratio of 1 of a cylinder will be able to experience higher loadings than a cylinder that has an aspect ratio of 2 [94]. Due to the cubic samples being larger in height and in area than the rectangular and cylindrical samples, the data may not be comparable; so, the cylindrical findings will be used. Downscaling the cubic dimensions to have the same areas and heights as the other geometric specimens will yield higher stresses due to lesser contact area and larger interference in the load transferring mechanisms (Figure 32) [95].

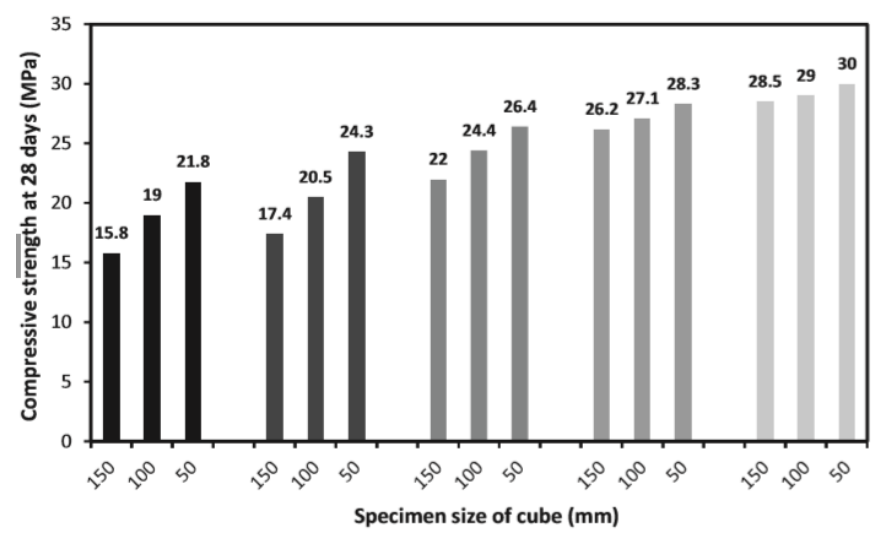

Figure 32: Compression testing on different cubic concrete specimens [96]

Overall, there is no criteria on what compression amount will cause the release of residual contamination, so overcompensation was used by assuming $80 \%$ deflection. All the rigid foams did not reach the $13 \%$ thickness due to the machine limit criteria being reached first $(9000 \mathrm{lbf})$. The flexible foams, however, showed degradation while preflexing, which could cause the release of residual contamination (Figure 33). The intumescent flexible foam, I-F4, did not return to its original height after preflexing which can cause additional concerns. 


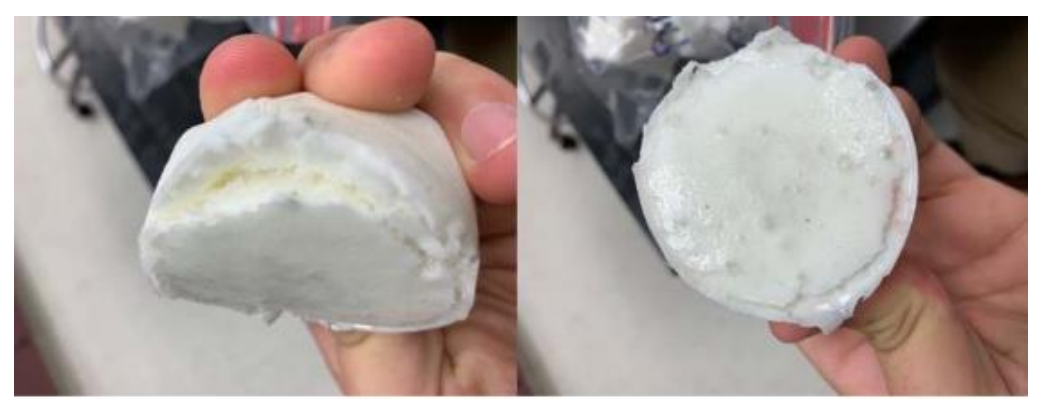

Figure 33: Flexible foam compression testing aftermath

\subsubsection{Cell Size Evaluation Results}

The SEM pipe samples had to be gold coated twice to prevent static charging on the sample surface. The samples were gold coated using a Pelco SC-7 auto sputter coater. Figure 34 shows all the foam's images at 50x magnification and was examined in the center of the top surface. This area is least likely to be affected by the shear stress the friction of the pipe wall's induce [89]. Intumescent foams had the most consistent cell sizes (Figure 34a) [4] while non-intumescent foams did not (Figure 34b-c). The smaller cells would collapse first under stress, causing failure in non-intumescent rigid foams. Smaller consistent spherical cell sizes and thicker cell walls are desired for better mechanical properties [97] which relates to the relative density of the foam [36]. The intumescent cell size diameter was roughly 0.019 in. while the non-intumescent rigid foam's was 0.035 in. The flexible foam's cell size diameter was approximated to be 0.009 in.

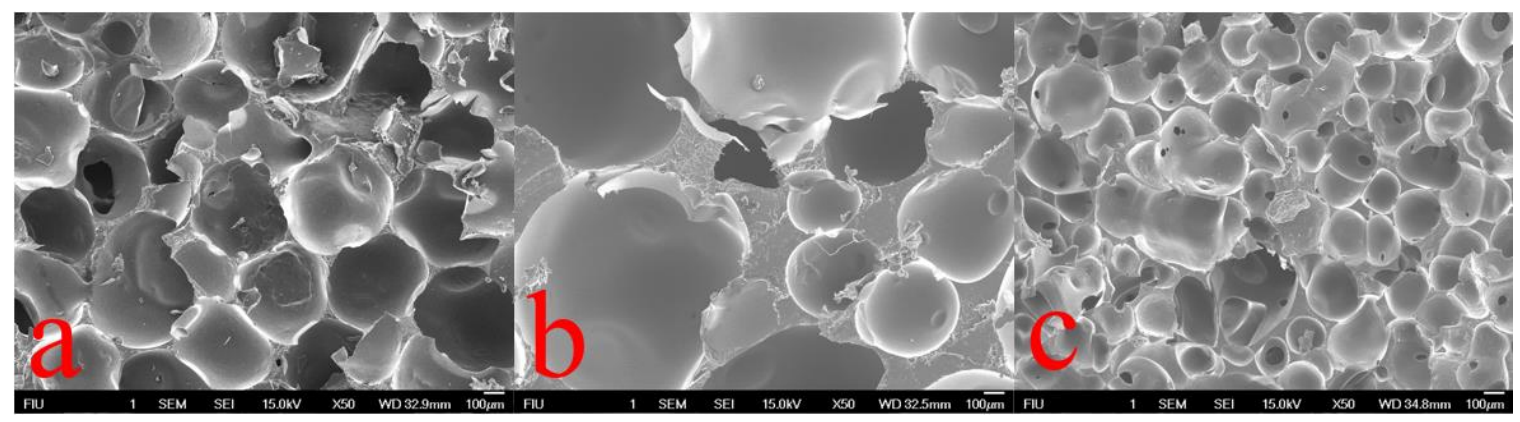

Figure 34: (a) Intumescent foam; (b) rigid foam; (c) flexible foam 


\subsection{Objective 2 - Adhesion Characterization}

The objective is to compare the mechanical limits of the 6 COTS PU foams to determine the effects of fillers. Four of the foams were non-intumescent and did not contain the fillers and EG the two intumescent foams had. One of the intumescent foams was rigid while the other was flexible. The goal was to show intumescent rigid foams will have the best mechanical limits due to the consistent cell sizes the EG loading induced.

\subsubsection{Sample Fabrication}

The following sections displays the sample fabrication for the tensile adhesion and shear adhesion testing samples. The SEM samples' fabrication process was also documented.

\subsubsection{Tensile Adhesion Testing Sample Fabrication}

Table 8 shows how much of each component was used to develop the adhesion tensile testing samples. The intumescent foams are not included because there is no fixed amount to apply due to rapid hardening. Overcompensation of amounts of components were used to ensure quality performance.

Table 8: Adhesion testing mixing amounts of parts

\begin{tabular}{|c|c|c|c|c|}
\hline \multicolumn{5}{|c|}{ Adhesion (Tension) } \\
\hline Foam & Volume & A & B & Ratio \\
Identifier & (mL) & $(\mathbf{m L})$ & $(\mathbf{m L})$ & $(\mathbf{A}: \mathbf{B})$ \\
\hline F1 & 131 & 15 & 15 & 1 \\
\hline R1 & 131 & 20 & 10 & 2 \\
\hline F2 & 131 & 16 & 32 & 0.5 \\
\hline
\end{tabular}




\begin{tabular}{|l|l|l|l|l|} 
F3 & 131 & 35 & 41 & 0.85 \\
\hline
\end{tabular}

A mold was 3D printed with dimensions that complied with Type $\mathrm{C}$ specimens in ASTM D1623. The inner dimensions of the rectangular mold were 2.25 inches by 2 inches by 2 inch. The two 304 stainless steel coupons would be placed on the inner walls of the mold while the foam would be dispersed and cured between them (Figure 35). The same process for the tensile testing die was applied as the mold was placed on top of wax paper and a larger 304 stainless steel coupon was used to prevent the foam from pouring out of the mold for the intumescent foams. The other non-intumescent foams used the required amounts as highlighted in Table 8. Once the foams cured and hardened inside the mold, it was extracted from the mold.

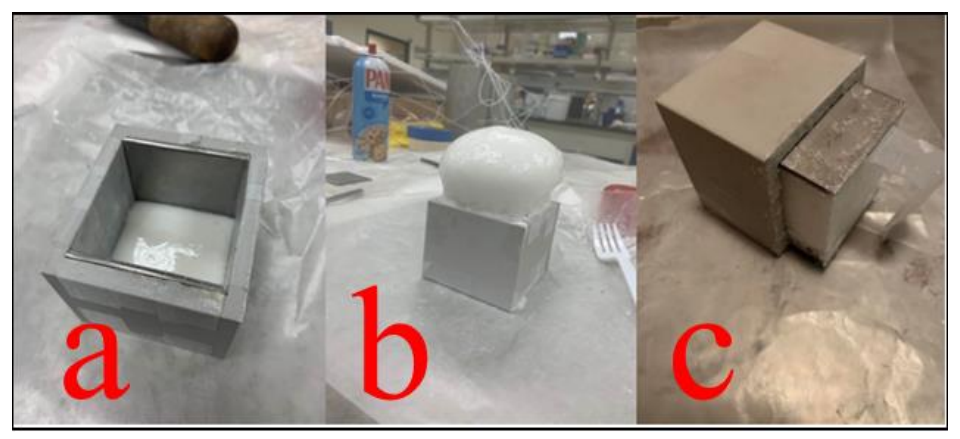

Figure 35: (a) Foam curing in 3D mold; (b) foam excess outside of mold; (c) foam extracted from mold

A total of three samples were produced of each type of PU foam. For the tensile testing machine to grip the adhesion sample, some sort of attachment had to be applied for the machine to grip. Hinges were selected as the sample-machine interface, and to ensure the shear strength of the glue used to attach the hinges to the samples was greater than the tensile strength, the outer surfaces of the coupons were sanded thoroughly with 120 grit 
sand paper to increase the surface energy. The hinges were sanded as well and then were attached using Loctite Super Glue Gel on the top and bottom surfaces as symmetrical as possible to ensure even stress distribution. The hinges were glued on the same axis to prevent any shearing and were left overnight to cure (Figure 36).

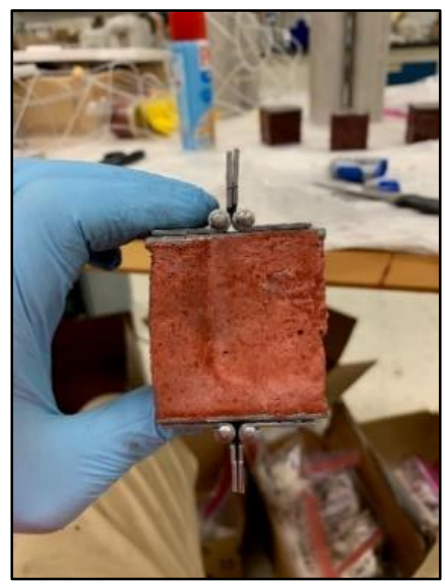

Figure 36: Adhesion sample with four hinges

Preliminary testing was done to ensure the super glue would be strong enough to withstand the pulling. A pull rate of 0.1 inches per minute was used to pull the top 304 stainless steel coupon off the I-R2 foam. The testing proved successful, so the rest of the PU foams were made in this manner (Figure 37).

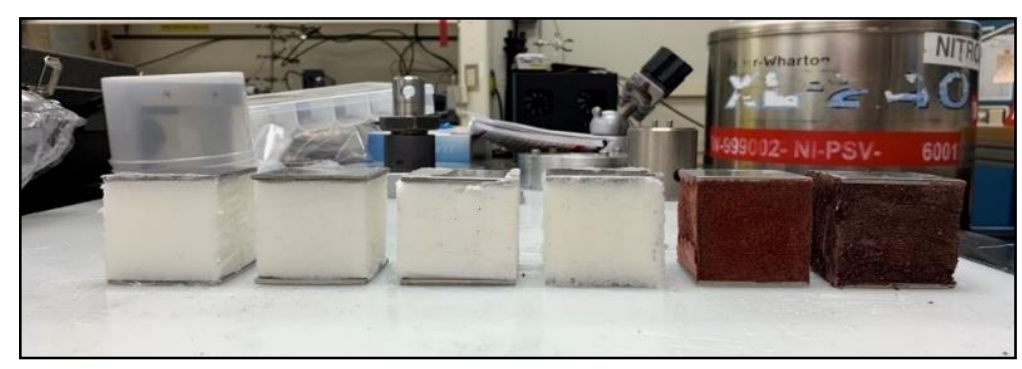

Figure 37: F1, R1, F2, F4, I-R2 and I-F2 


\subsubsection{SEM Sample Fabrication}

The same samples produced in section 4.1.1.3 were used to evaluate the adhesion interface.

\subsubsection{Shear Adhesion Testing Sample Fabrication}

Volumes of 50 and 100 in $^{3}$ were tested to determine the effects on adhesion. Testing was also be done on both internal smooth and rough pipe to determine the impact of mechanical interlocking. Figure 38 shows the R1 and I-R2 foam encapsulated in both 50 and $100 \mathrm{in}^{3}$ volumes.

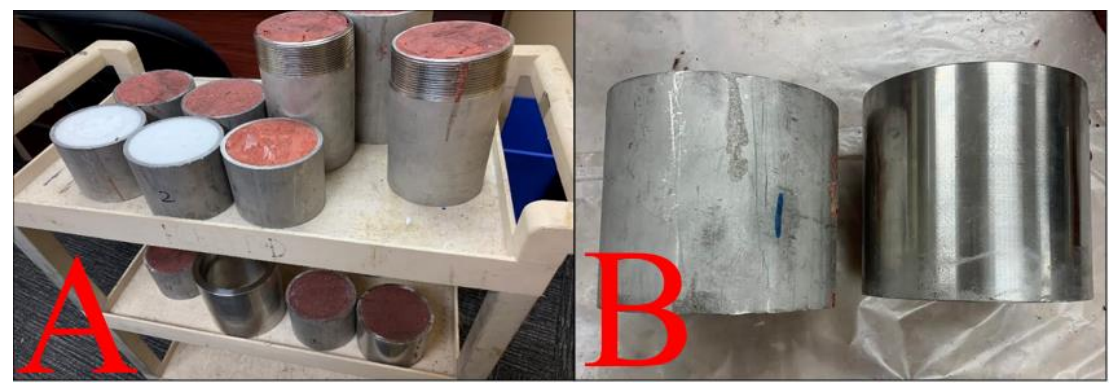

Figure 38: (a) Different volumes of pipe encapsulated with R1 and I-R2 foam; (b) rough and smooth internal piping

\subsubsection{Objective 2 Results}

\subsubsection{Tensile Adhesion Testing Results}

Figure 39 illustrates the process of adhesion testing for a flexible foam. Flexible foams also stretched the most compared to rigid foams before the stainless-steel coupon delaminated. 


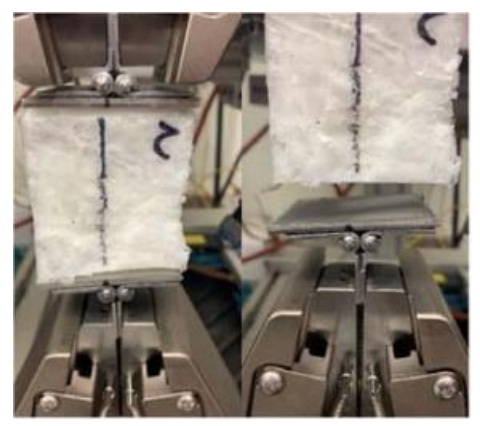

Figure 39: Flexible foam tensile testing process

Figure 40 illustrates the results of adhesion testing. The noisy data for the flexible foams is due to using a load cell that can go up to $8992 \mathrm{lbf}$. The rigid foams experienced higher stresses (13.3 psi) before failure while the flexible foams experienced higher strains (25.4\%) before failure.

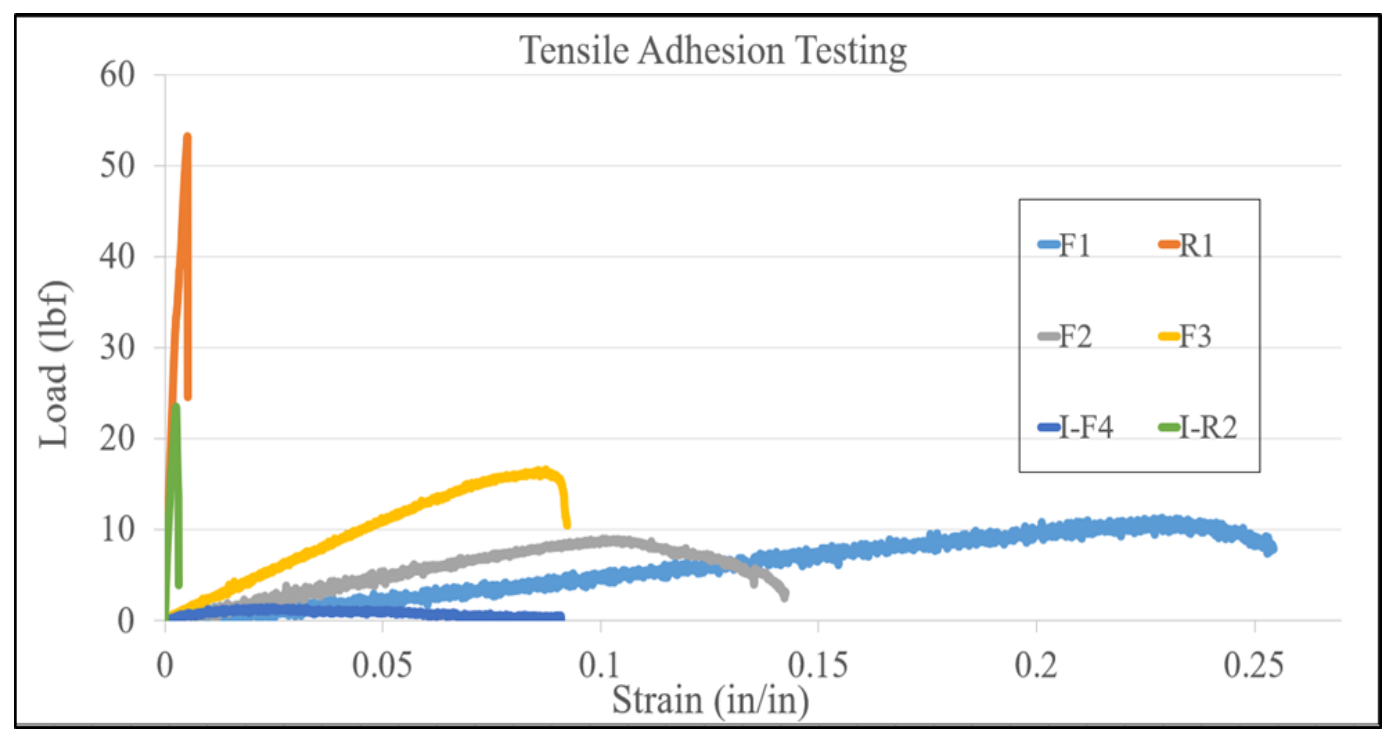

Figure 40: Tensile adhesion graph

Table 9 shows the results from this testing that ASTM D1623 requires. The results confirmed that the rigid polyurethane foams would be more suited to be used as permanent foaming fixatives due to their higher isocyanate content [56]. This allows for them to reach higher stresses before delamination occurs which can cause the release of residual contamination in an operational scenario. 
Table 9: Tensile adhesion testing results

\begin{tabular}{|c|c|c|c|}
\hline $\begin{array}{c}\text { Foam } \\
\text { Name }\end{array}$ & $\begin{array}{c}\text { Peak Stress } \\
\text { (psi) }\end{array}$ & $\begin{array}{c}\text { Peak load } \\
\text { (lbf) }\end{array}$ & $\begin{array}{c}\text { Strain at Break } \\
\text { (in/in) }\end{array}$ \\
\hline F1 & 2.82 & 11.29 & 0.254 \\
\hline F2 & 2.26 & 9.05 & 0.142 \\
\hline F3 & 4.17 & 16.67 & 0.092 \\
\hline I-F4 & 0.38 & 1.54 & 0.091 \\
\hline R1 & $\mathbf{1 3 . 3 0}$ & $\mathbf{5 3 . 1 8}$ & 0.005 \\
\hline I-R2 & 5.89 & 23.57 & $\mathbf{0 . 0 0 3}$ \\
\hline
\end{tabular}

ImageJ was used on images of the scanned surfaces of the stainless-steel coupons that were pulled off (Figure 41). Analysis of the surfaces helped show how much foam still adhered onto the coupon. For samples that had significant residue, the failure was due to shearing of the material rather than delamination as the failure mode.

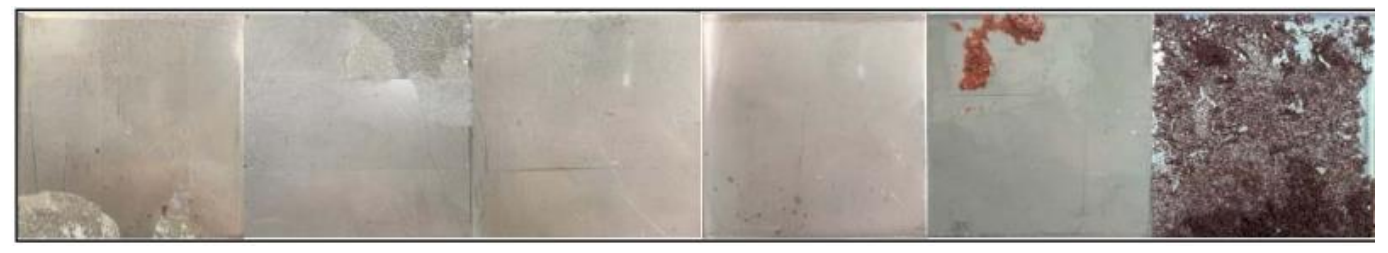

Figure 41: Scanned coupons: F1, R2, F2, F3, I-R2 and I-F4

Table 10 shows the ImageJ results and illustrates that the intumescent foam, I-F4, adhered the most to the surface $(61.45 \%)$. This is another advantage intumescent technology has over non-intumescent technology. R1 had better results than I-R2 due to slower curing times (20 min. compared to $1 \mathrm{~min}$ ). I-R2 has catalysts and surfactants like polyamide amine, which multiplied the polymer chains over a short period time. Upon further inspection of Figure 41, the stainless-steel plates were smooth and had no roughness. An adhesion study on intumescent coatings on steel substrate showed that the primary adhesion mechanism of intumescent technology is mechanical interlocking instead of wetting [64]. This can further explain why the R1 performed better than I-R2 in this test. 
Table 10: ImageJ results

\begin{tabular}{|c|c|c|}
\hline Foam & Average (\%) & Average $\left(\boldsymbol{i n}^{\mathbf{2}}\right)$ \\
\hline F-1 & 4.05 & 0.16 \\
\hline F-2 & 0.00 & 0.00 \\
\hline F-3 & 0.26 & 0.01 \\
\hline IF-4 & $\mathbf{6 1 . 4 5}$ & $\mathbf{2 . 4 6}$ \\
\hline R-1 & 7.38 & 0.3 \\
\hline I-R2 & 2.84 & 0.11 \\
\hline
\end{tabular}

\subsubsection{Adhesion Interface Evaluation}

Intumescent rigid foam left voids at the interface in the SEM pipe samples due to faster curing ( $1 \mathrm{~min}$ ) which is due to curing agents like polyamide amine. Most cells in the I-R2 sample did not collapse to shear stress around the interface. This was due to its stronger mechanical properties that the consistent cell sizes induced [97]. Non-intumescent rigid foam adhered well to the substrate due to slower curing times. The cells around the walls collapsed due to either shearing, blowing agents eruptions or entrapped air [89]. Flexible foams had the worst adhesion. Flexible foams left the largest voids due to the formation of carbon dioxide and urea which caused it to cure and expand quickly ( 2 min) [23]. The lesser crosslinking also made the flexible foams more vulnerable to shear stress, blowing agent eruptions and entrapped air [56].

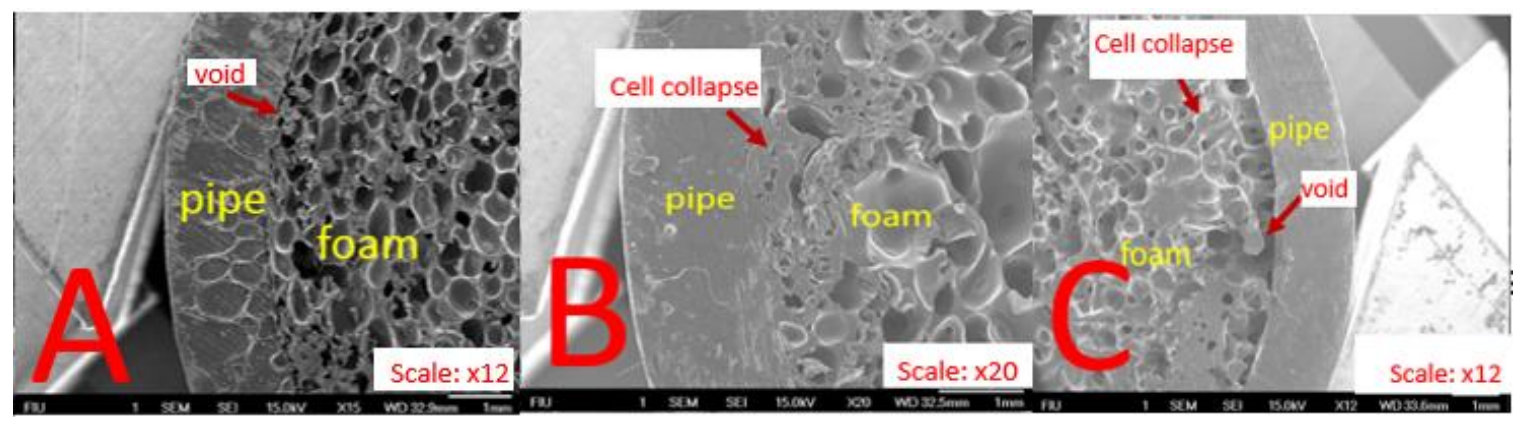

Figure 42: (a) Intumescent foam; (b) rigid non-intumescent foam; (c) non-intumescent flexible foam 


\subsubsection{Shear Adhesion Testing Results}

Figure 43 shows the experimental design Figure 28 proposed. The machine shop at SRNL machined the components to the dimensions prescribed in Figure 18. A rate of 0.4 inches per minute was used since this is $10 \%$ of the pipe's height. This procedure is not standardized, but followed some protocols described in ASTM D1621. The I-R2 and R1 foams were the foam of choice due to both displaying promising mechanical and adhesion performances.

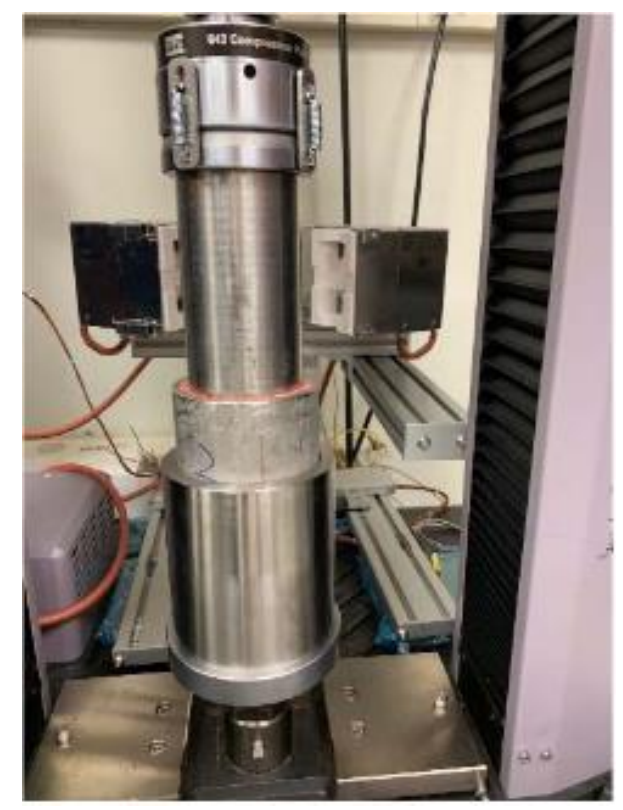

Figure 43: Shear adhesion testing

Figure 44 showcases the breaking loads of the I-R2 foam in the 4-inch diameter, 4inch-tall stainless-steel pipes $\left(50.24 \mathrm{in}^{3}\right)$. The data spread from $85 \mathrm{lbf}$. to almost $4000 \mathrm{lbf}$. Samples 7 and 10 were the samples that had smooth internal roughness that SNRL machined, which explains that the primary adhesion mechanism of the I-R2 is mechanical interlocking. 


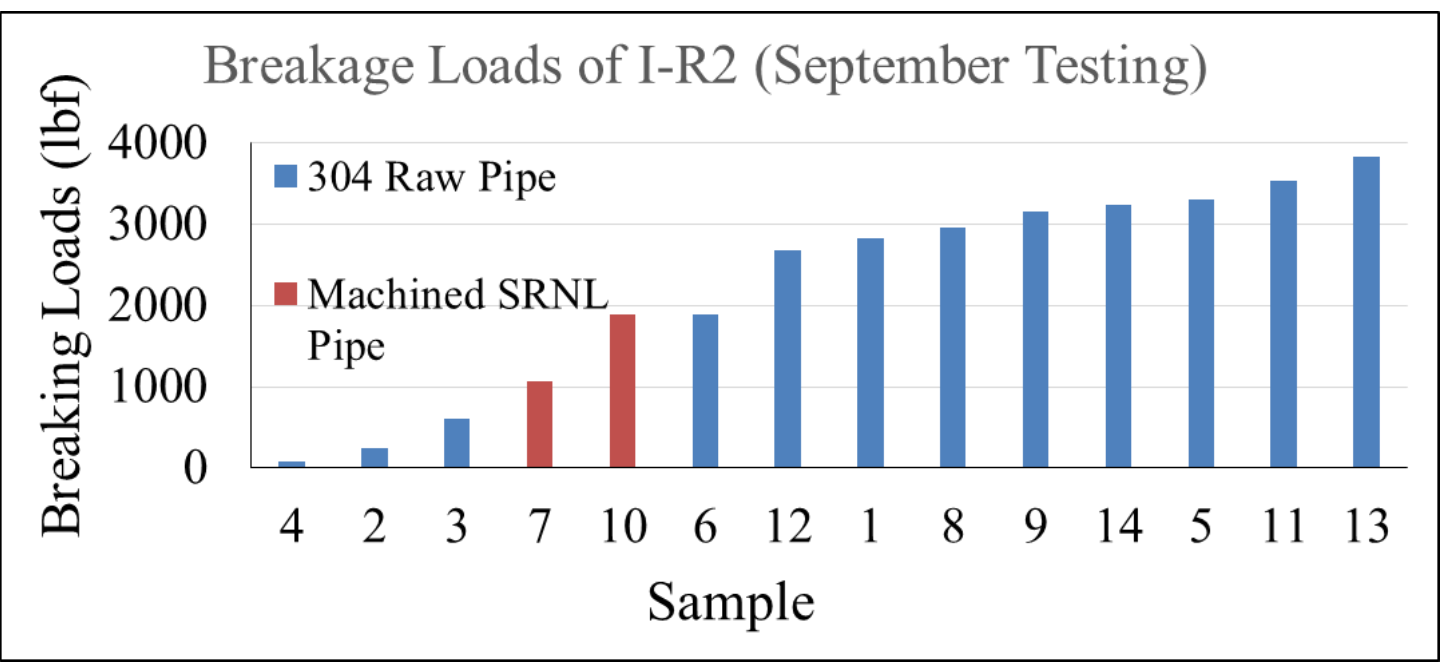

Figure 44: September adhesion testing on I-R2 foams

Figure 45 shows the pipe samples after shear adhesion testing. Samples 2, 3, and 4 left no foam material on the substrate and suffered adhesive failure [83]. The other samples suffered cohesive failure in which the adhesive strength was greater than the shear strength. The foam behaved as if it was in compression when this occurred. Samples 14, 5, and 11 also left minimal material on the wall but experienced larger loadings compared to samples 2,3 , and 4 .

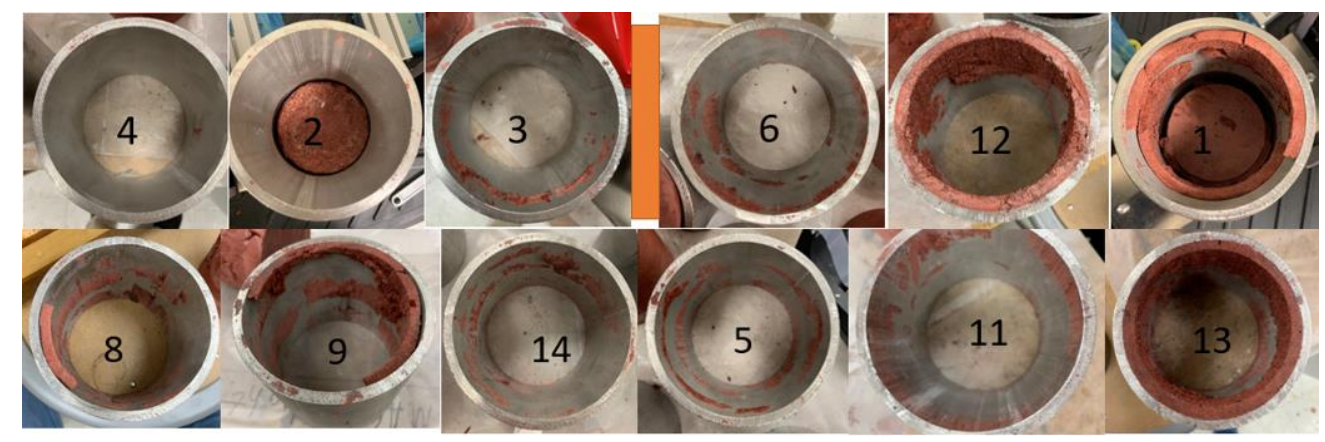

Figure 45: Aftermath of adhesion testing

Due to wide scatter of loads as shown in Figure 44, duplicate testing was performed to obtain better data. Samples 4, 2, and 3 were observed to be compressed from the bottom 
of the pipe, which could be why adhesive failure occurred. PU foams are anisotropic materials, which means the cells elongate parallel to the direction of rise [45]. This means that the top surface may have better mechanical properties than the bottom due to the higher densities and consistent cell sizes the elongation of cells causes[45] . Figure 46 shows how the roughness was normalized by grinding a default 80 grit sander on the internal surface of each pipe. A 40 grit was also used to roughen it up as well as a 120 grit to smoothen it.

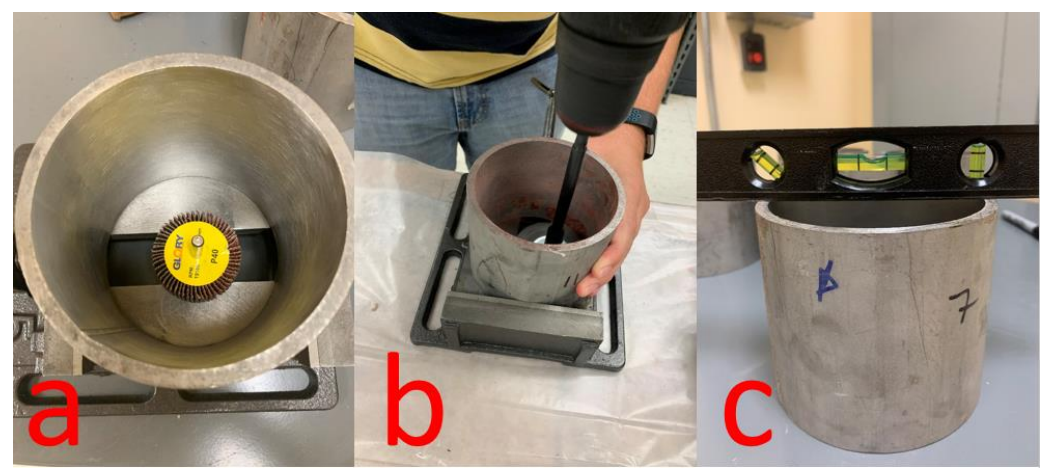

Figure 46: (a) P40 grit inside pipe; (b) roughing up pipe; (c) using a level to ensure balance

A forward-looking infrared radar (FLIR) thermal imaging camera was used to detect the maximum curing temperatures. Heat is one external stimuli that can affect the adhesion of adhesives [51]. All the samples curing temperatures were monitored in hopes of finding a correlation between adhesion and curing temperature. Figure 47 shows a FLIR image that was taken. The red colors highlights the hottest temperatures while the blue represents the coldest. 

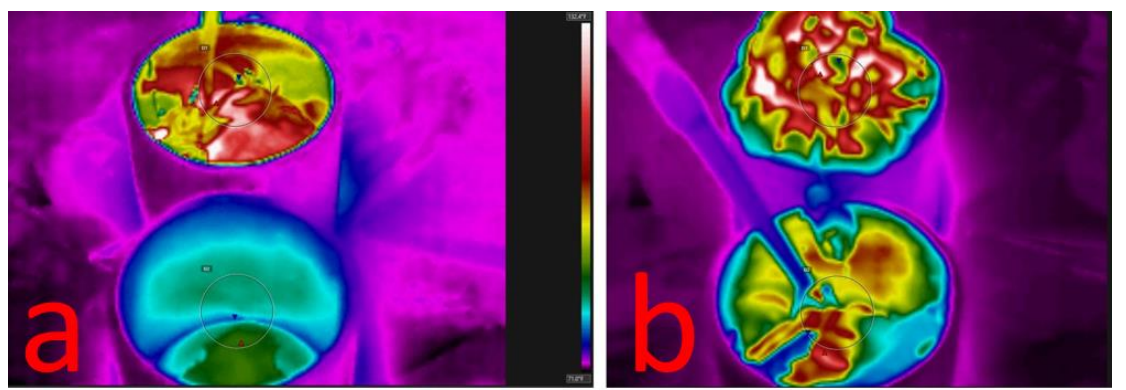

Figure 47: A: Foam before curing; B: foam after curing

Figure 48 displays the new breaking loads conducted with all samples being compressed from the top. The data looks more precise compared to Figure 44. The rough (P40) and smooth (P120) samples performed the best with breaking loads of almost 3500 lbfs. The smooth grit (P120) left rough marks internally, which explain why the I-R2 foam performed better in this case. The average breaking loading came out to be $2994.66 \pm$ $135.64 \mathrm{lbf}$.

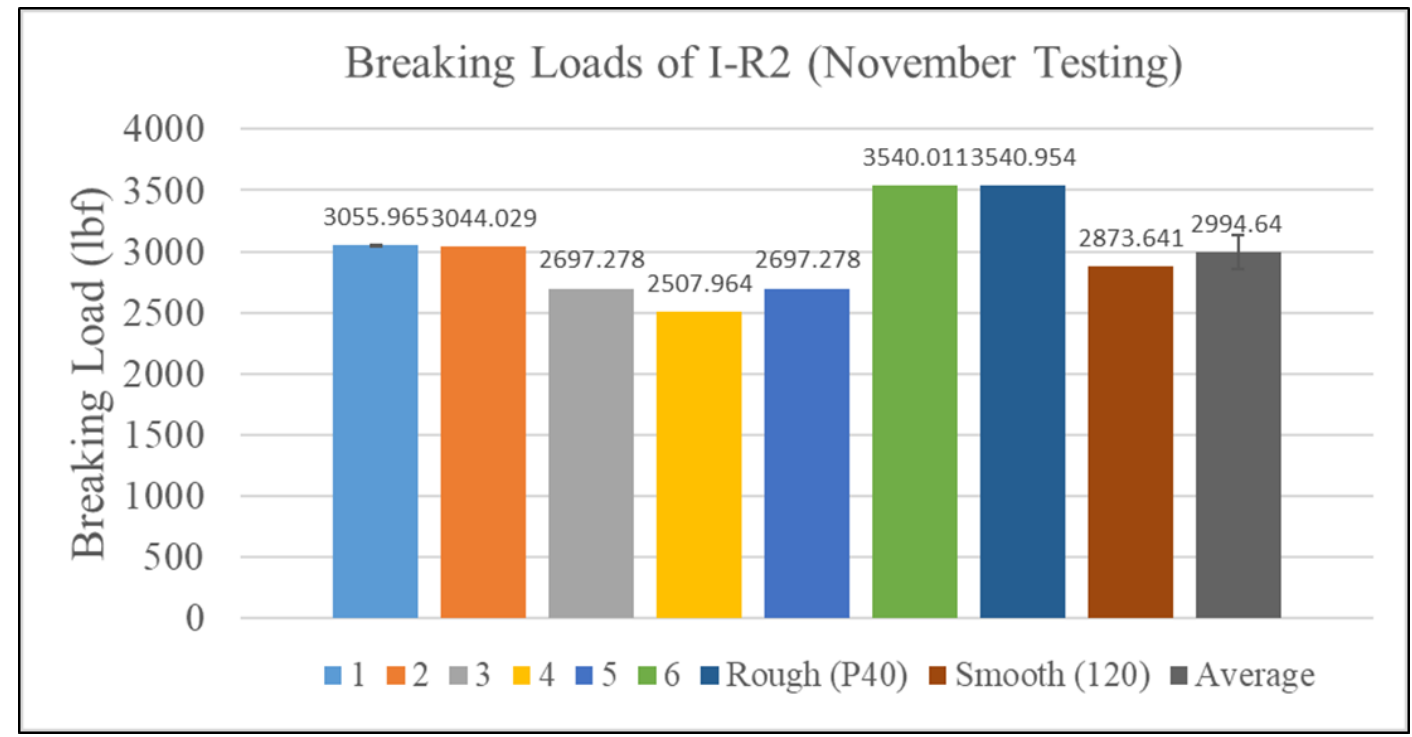

Figure 48: November testing on I-R2 Foam

Table 11 shows the peak loading and max curing temperatures. No correlation could be made with this information. The thought process was that the curing temperatures 
would affect the hardening process since heat is an external stimuli that can affect adhesion [61]. This could have potentially affected the mechanical interlocking process, but no relationship was able to be determined from these findings.

Table 11: Peak loads and temperatures (November testing)

\begin{tabular}{|c|c|c|c|c|c|c|c|c|}
\hline Sample & 1 & 2 & 3 & 4 & 5 & 6 & 7 & 8 \\
\hline Peak Load (lbf.) & 3055.97 & 3044.03 & 2697.28 & 2507.96 & 2697.28 & 3540.01 & 3540.95 & 2873.64 \\
\hline Peak Temp. $\left({ }^{\circ} \mathrm{C}\right)$ & 254.40 & 245.27 & 262.69 & 226.36 & 238.00 & 230.00 & 239.00 & 230.00 \\
\hline
\end{tabular}

An outlier test using Tukey fencing was then done to determine any outliers in the data in both Figures 44 and 48 . Samples 7 and 10 were eliminated due to being smoothly made from SRNL. The outlier test then was able to eliminate samples 2,3 , and 4 since they fell outside the lower limit. Figure 49 shows the new calculated average after the November testing with the outlier compared to the September testing. The results were computed by dividing the average loadings by the internal surface area (inner circumference time's height). The average loading for the September testing was $2239.90 \pm 1276.73 \mathrm{lbf}$ and the average for the November + outlier testing was $3024.75 \pm 469.39 \mathrm{lbf}$. The internal surface and volume were computed to be $50.28 \mathrm{in}^{2}$ and $50.27 \mathrm{in}^{3}$, respectively, for the 4-inch inner diameter and 4 inch tall stainless steel pipes. The percent number above each bar represents the relative error (standard deviation divided by the average). The fabrication technique provided promising results as the relative error went from $57.7 \%$ to $15.5 \%$.

Once the average for the I-R2 sample was determined, shear adhesion was done on the non-intumescent R2 foam. Figure 49 also shows the stresses of both foams. The R1 foam experienced a lesser average breaking load of $2239.90 \pm 1276.73 \mathrm{lbfs}$ compared to the $3024.75 \pm 469.39 \mathrm{lbf}$ loading the I-R2 experienced. All the R1 foams experienced adhesive failure and did not leave material on the inner pipe's surface. This demonstrates 
that the I-R2's primary adhesion mechanism is mechanical interlocking and will be more suited to be used in an operational environment where internal contamination would be high.

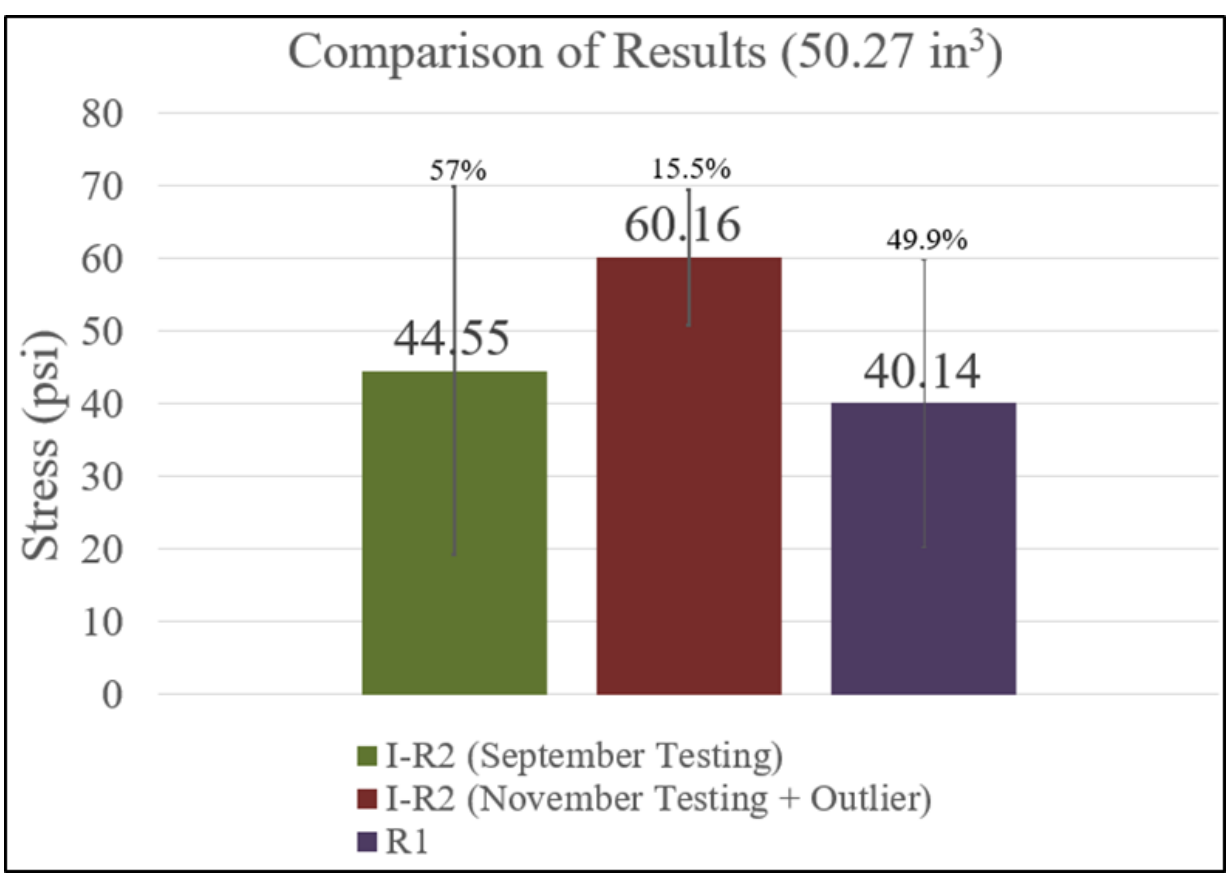

Figure 49: Comparison of adhesion testing

Due to the sample set of I-R2 having a large standard deviation, the shear adhesion testing was downscaled to accommodate stainless steel pipes having an inner diameter of 2 inches. A bucket piece was 3D printed and is showcased in Figure 50. The samples tested had the same aspect ratio of 1 in order to be consistent with previous shear adhesion testing. The samples had an inner diameter 2 inches with a height of 2 inches. The same sample fabrication was done as with the bigger samples. 


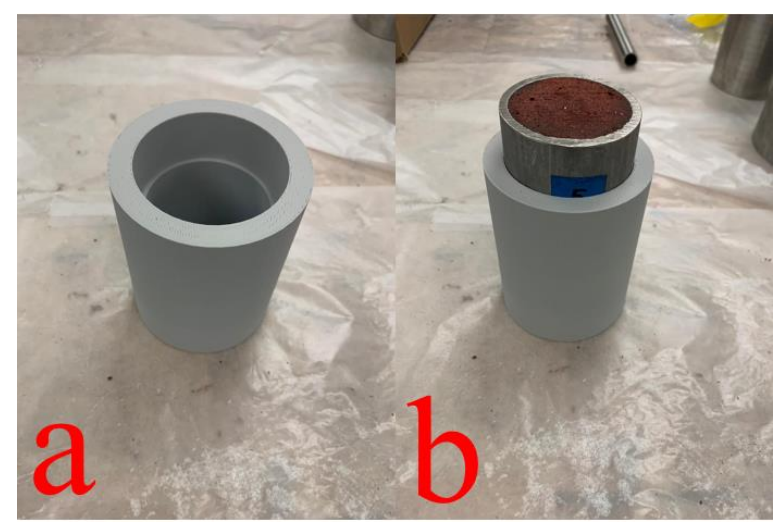

Figure 50: (a) 3D bucket piece, (b) sample inside of bucket piece

Figure 51 highlights the findings of the 2-inch samples. The data appears to be consistent as the majority of the samples appeared to be in $1300 \mathrm{lbf}$. range. The average loading was $1302 \pm$ $9.32 \mathrm{lbf}$. The sample that took $331.47 \mathrm{lbf}$ to fail was compressed from the bottom while the rest were compressed from the top. It also experienced adhesive failure while the other samples failed in a cohesive manner [83].

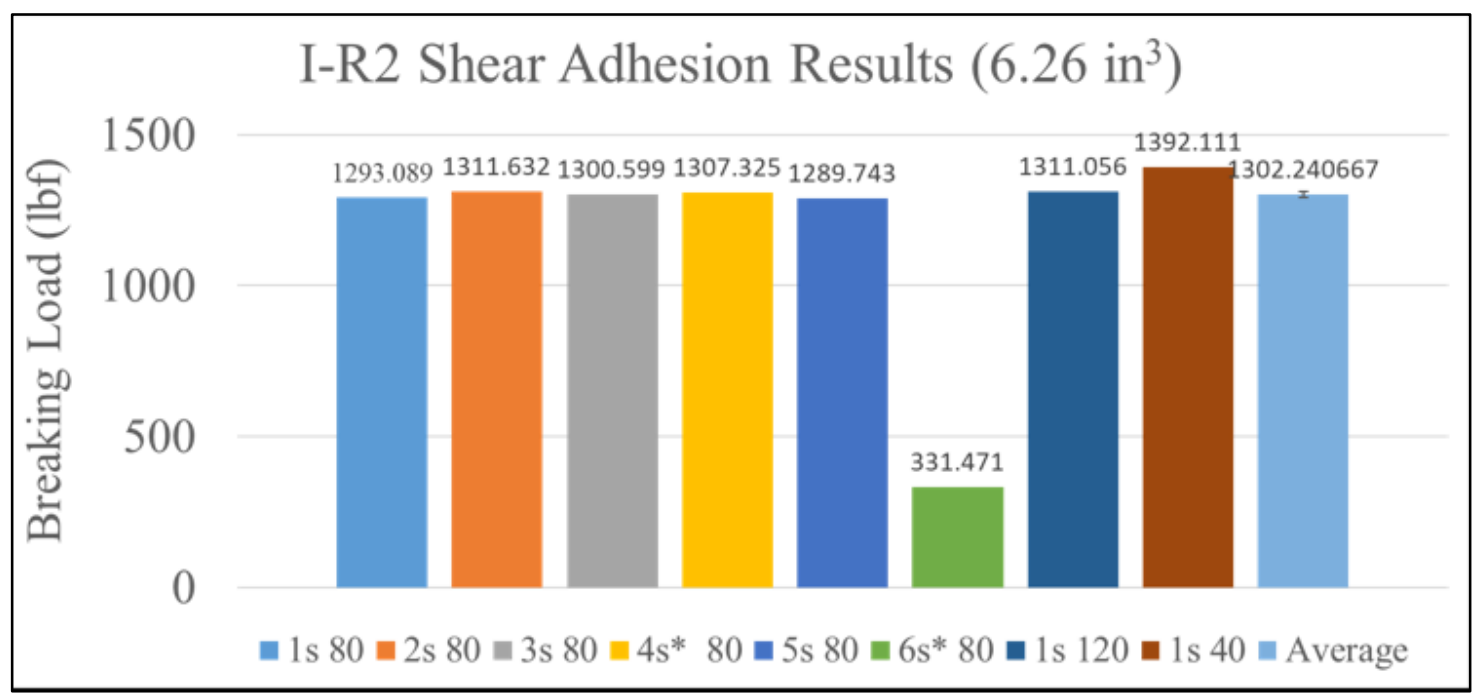

Figure 51: Shear adhesion results of 2-inch samples

The average breaking load for the 4-inch-tall 4-inch inner diameter samples was $3024.75 \pm 469.39 \mathrm{lbf}$ while the average breaking load for the 2-inch-tall 2-inch diameter 
sample set was $1302 \pm 9.32 \mathrm{lbf}$. It is almost a 1:2 ratio due to the diameters being multiples of each other. This demonstrates that shear adhesion potentially can be a function of crosssectional area if the aspect ratios are the same. The 2-inch sample had a smaller standard deviation compared to the 4-inch set due to more pressure from the foam being exerted on the walls since the cross-sectional area was smaller. The I-R2 foam expands and cures faster due to catalysts and surfactants like polyamine amide, allowing it to have more intimate and uniform contact with the smaller sample set [61]. Figure 52 shows the comparison between the two sample sets. The smaller sample set's stress was computed by dividing the average breaking load by the internal surface area of $12.56 \mathrm{in}^{2}$. The samples are labeled by their respective internal volumes with $6.28 \mathrm{in}^{3}$ representing the 2 -inch tall and 2-inch diameter samples and $50.27 \mathrm{in}^{3}$ being the 4-inch tall and4-inch diameter samples.

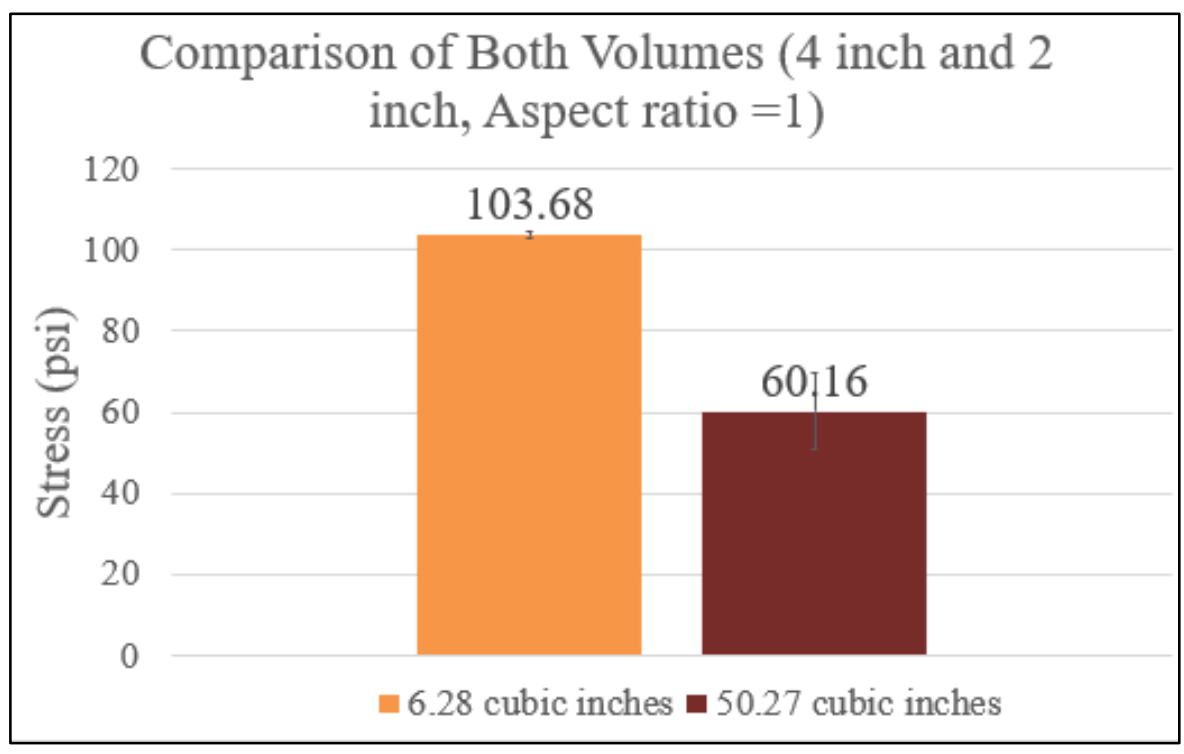

Figure 52: Comparison of both volumes 


\subsection{Effects of Volume}

Adhesion testing was done on pipes that were double the length of the previous test samples in order to determine a relationship of volume and breaking loads. The 8 -inch-tall 4-inch diameter samples' volume was computed to be $100.54 \mathrm{in}^{3}$ and surface area was $100.56 \mathrm{in}^{2}$. The average failure loading for the 8-inch-tall 4-inch diameter samples were $5305.53 \pm 421.27 \mathrm{lbf}$ compared to the $3024.75 \pm 469.39 \mathrm{lbf}$. for the 4-inch-tall 4-inch diameter samples. The 4-inch-tall 2-inch diameter samples' volume was computed to be $12.56 \mathrm{in}^{3}$ and surface area was $25.13 \mathrm{in}^{2}$. The average loading for the 4-inch-tall 2-inch diameter samples were $1406.79 \pm 281.32 \mathrm{lbf}$ compared to the $1302.24 \pm 9.32 \mathrm{lbf}$. for the 2-inch-tall 2-inch diameter samples. The computed stresses of the four volumes are shown in Figure 53. Three of the volumes' stresses were similar and average 56.25 psi. The 2inch tall 2-inch diameter pipe had the smallest volume and largest stress of 103.68 psi. This high stress can be due to compressive stress occurring towards the center of the foam during the curing process since the curing space is smaller compared to the other volumes.

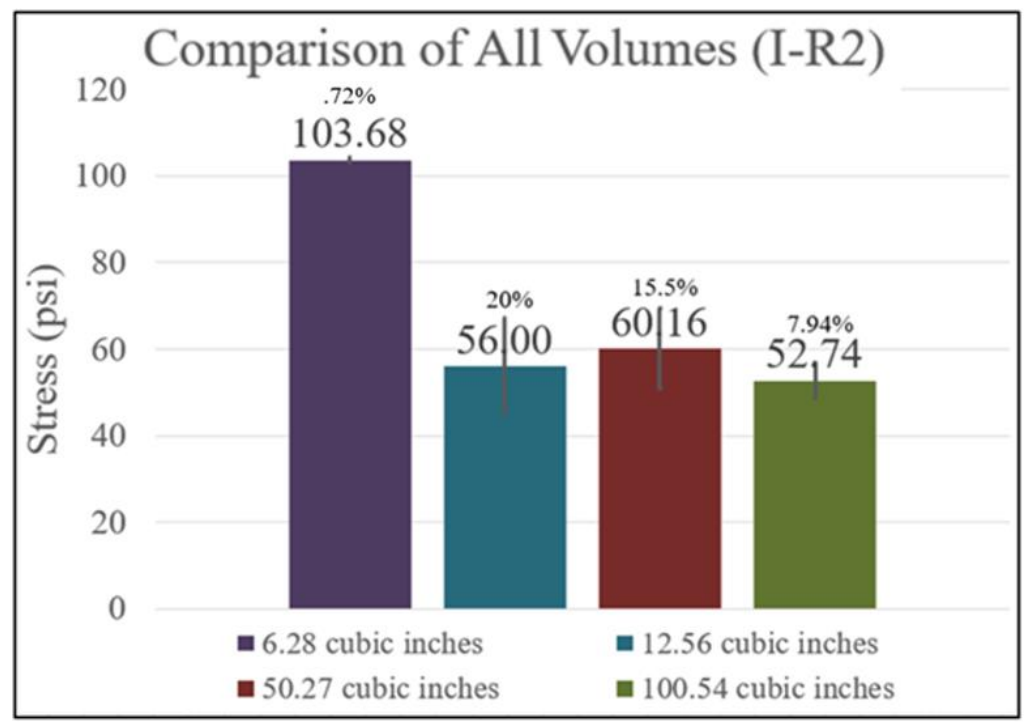

Figure 53: Comparison of both 4-inch diameter volumes 
All the four volumes equated to four different surface areas. Adhesion is ultimately a function of inner surface area of the pipe, since this is where all the shear stresses are located. One foam cartridge of I-R2 yields $100 \mathrm{in}^{3}$ of foam material. Dispensing this amount in a 4-inch inner diameter pipe will fill up to 8 inches of height while filling a 2 inch diameter pipe will fill up 31 inches worth. The surface area for the 4-inch inner diameter pipe is $100 \mathrm{in}^{2}$ while the 2-inch pipe creates $200 \mathrm{in}^{2}$. Different volumes will yield different surface areas. Plotting the surface areas of all the volumes tested and the breaking loads yielded Figure 54. The graph appears nearly linear and a linear trend line was made to develop a relationship of surface area and breaking loads. This can be helpful in predicting failures in PFFs. The slope of the linear trend line is $50.79 \mathrm{psi}$, which represents the minimum stress the PFF shall withstand.

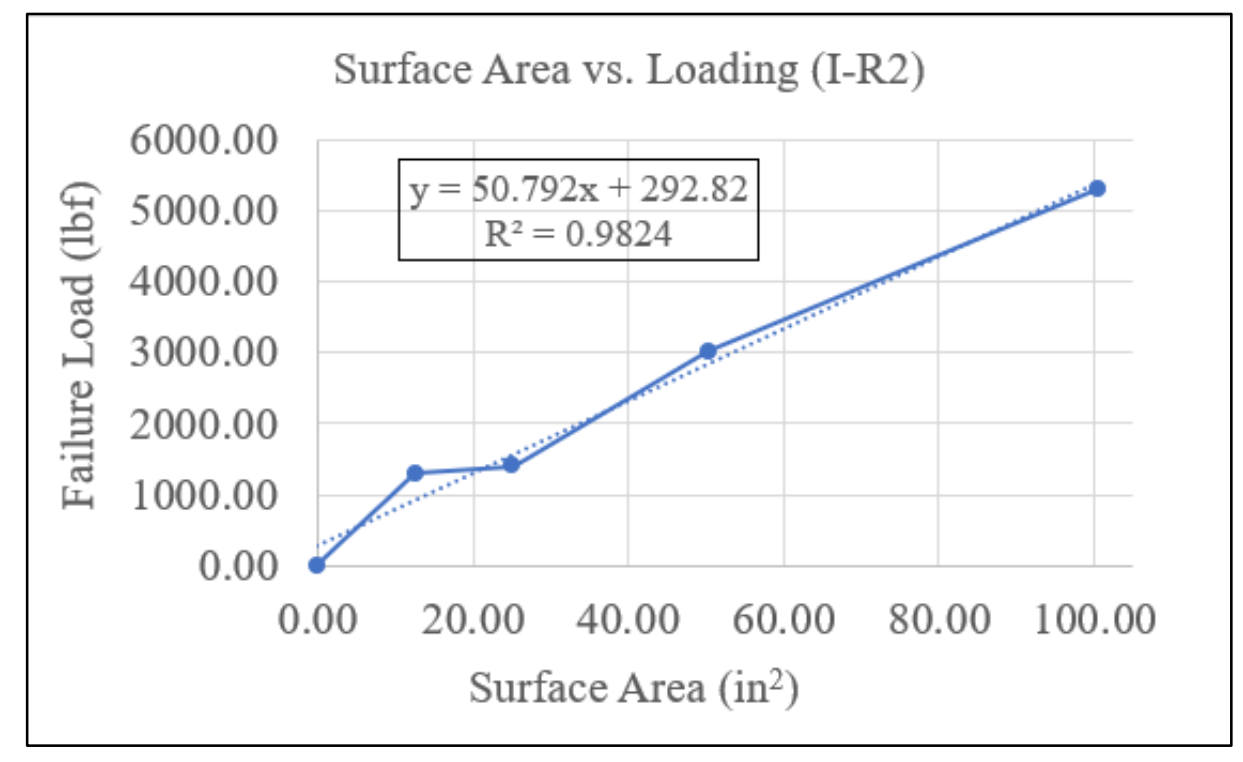

Figure 54: Surface area vs. loading graph

\subsection{Effects of Physical Stressors}

Evaluating the effects of physical stressors on adhesion was lastly executed. Figure 56 highlights the process of executing the three events that SBIO documents postulate [5]. 
Figure 55a shows the water submersion testing that was done at a depth of $3 \mathrm{ft}$. at 8, 12 and 24 hours. Figure 55b shows how the samples were dropped at heights of 4, 8, and $12 \mathrm{ft}$. onto a steel plate. Figure $55 \mathrm{c}$ demonstrates the foam being place in a muffle furnace at $1400^{\circ} \mathrm{F}$.

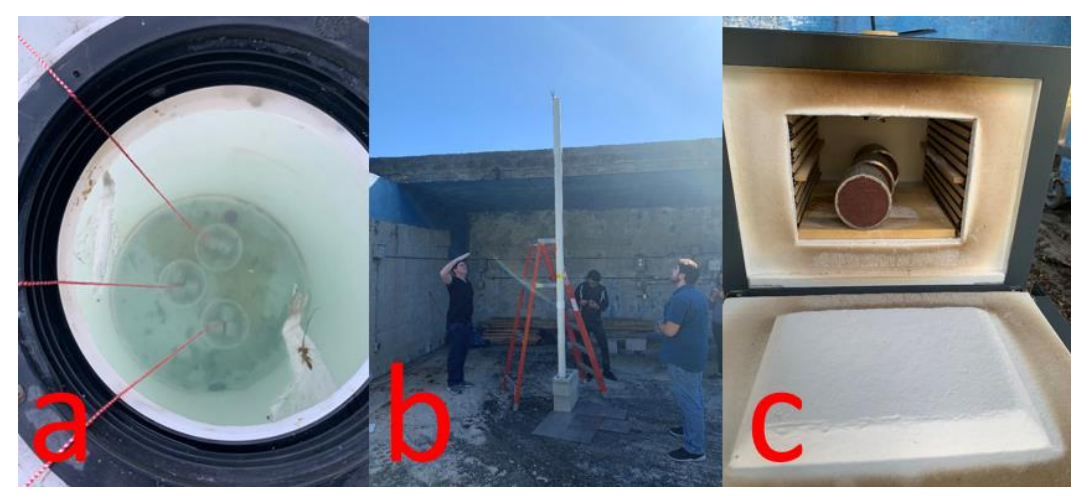

Figure 55: (a) Water submersion; (b) drop Test; (c) muffle furnace

The findings are displayed in Figure 56. The water submersion samples' stresses ranged from 91.10 to 106.3 psi. This was computed by dividing the breaking loads by the surface areas. The samples that had longer exposure to water failed worse and one of the samples of the 24-hr. collection had water inside of it. These foams are closed celled foams so they should block the transport of water but water still permeated the sample [37]. The fire testing proved to be the worst due to the I-R2 completely intumescing and delaminating off the substrate. The muffle furnace's temperature did not reach $1400^{\circ} \mathrm{F}$ because of safety reasons but instead achieved $1000^{\circ} \mathrm{F}$ for 30 minutes. This presents an issue if a fire ever occurs for a long period and in this test, smoke was observed to be coming out of the muffle furnace. This smoke can be another hazard due to contamination being transported by the smoke. The drop test values ranged from 79.60 to 112.96 psi. A few of the sample sets experienced adhesive failure for the 8 and $12 \mathrm{ft}$. drop. The collision impact may have negatively affected the adhesion interface. A few other samples were compressed from the 
bottom and none of them failed in an adhesive manner. The sample failed at $102.03 \mathrm{psi}$ compared to the default value of 103.68 psi. This implies that adhesive failure could potentially occur if compressed from the bottom.

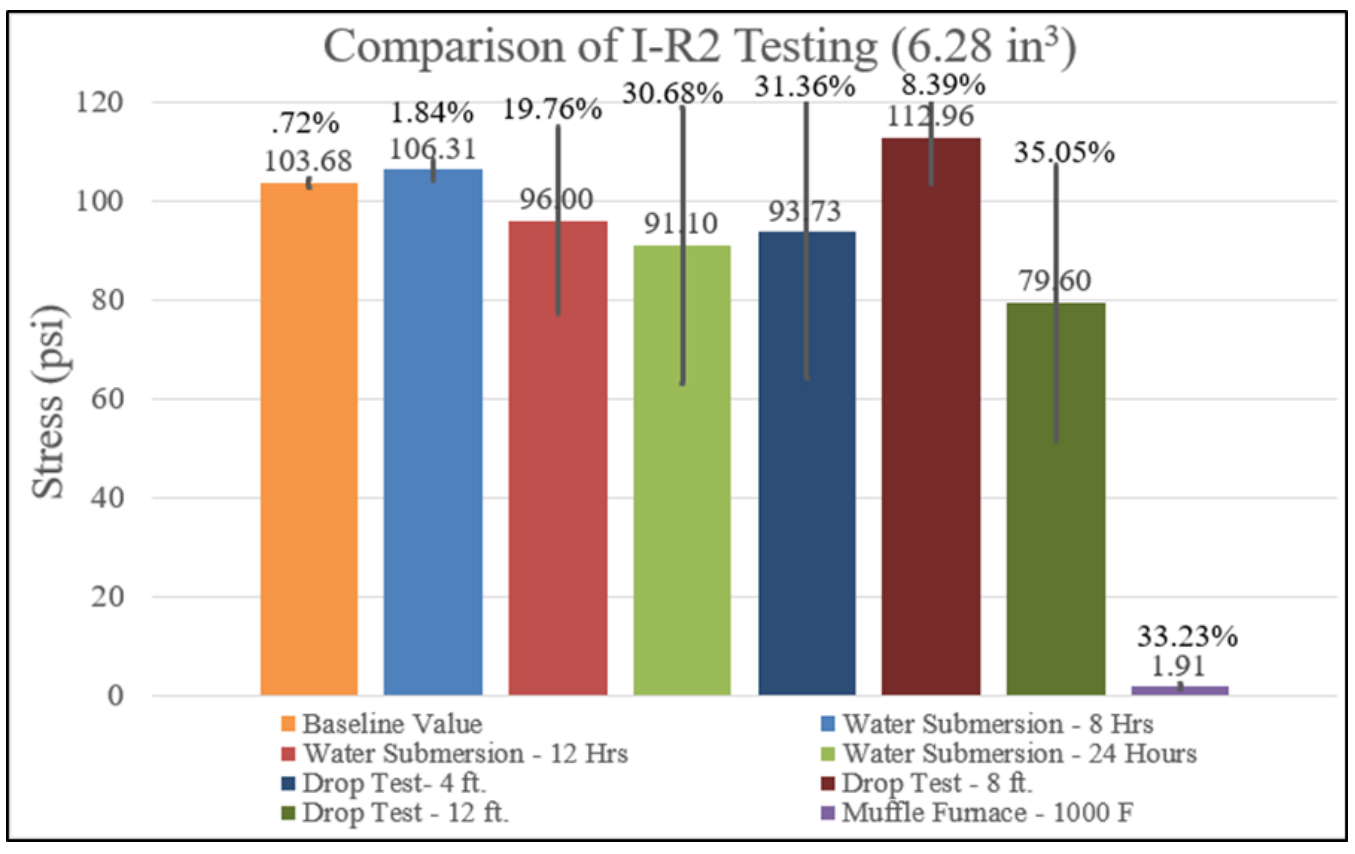

Figure 56: Physical stressors findings 


\section{CHAPTER V - CONCLUSION}

In conclusion, both hypotheses were proven over the course of this thesis. The intumescent foam, I-R2, had the best mechanical properties and limits compared to the other non-intumescent foams. SEM imaging confirmed this by showing that the I-R2 foam had the most consistent spherical cell sizes $(0.019$ in). This feature relates to the macroscopic properties since the relative density dictates mechanical performance and is a function of cell size. The rigid foams had the best adhesion properties compared to the flexible foams due to its higher crosslinking and isocyanate content. SEM images also confirmed that the rigid foams had the best adhesion interface compared to the flexible foams with lesser voids and cell collapse caused by shearing from the pipe walls. The I-R2 foam adhesion mechanism was proven to be mechanical interlocking and outperformed the $\mathrm{R} 1$ foam during adhesion testing in operational volumes. The I-R2 foam also experienced adhesive failure more often than the $\mathrm{R} 1$ foam which is an advantage in an operational environment. The I-R2's shear adhesion testing findings showed to a near-fit linear relationship with surface area and did not show a dependency with amount of volume.

These findings will allow for future recommendations for future balloting of ASTM E3191: Standard Specification for Permanent Foaming Fixatives Used to Mitigate Spread of Radioactive Contamination. Intumescent technology will have additional benefits that aid in D\&D efforts that non-intumescent technologies do not offer. For Section 5.1 of ASTM E3191, which describes sufficient mechanical properties PFFs shall have, the I-R2 foam had a compressive strength of $2.00 \mathrm{kpsi}$ ( $83 \%$ deflection) and a tensile strength of 289 psi. Concrete and grout, which are materials that are used in D\&D activities, have average compressive strengths of $3.25 \mathrm{kpsi}$ and $2.00 \mathrm{kpsi}$, respectively. Some concretes 
have tensile strengths that are as low as 300 psi [98]. Concrete, however, is brittle unlike I-R2 and will be challenging to apply in pipes. Using a PFF that has similar or better properties to materials already being used in the workforce will ensure quality performance and workers' trust. The PFF shall also have consistent spherical cell sizes to optimum mechanical performance (ex: 0.019 in). For Section 5.4 of ASTM E3191, which details mechanical properties to withstand physical or seismic activity, the I-R2 exhibited high stresses and loading before failure occurred. On average, the I-R2 had an averaged 68.14 psi amongst the four volumes tested. The average stresses the I-R2 experienced from the physical stressor testing was 83.09 psi compared to the baselined value of $103.68 \mathrm{psi}$. This is a $19.8 \%$ decrease in performance when subjected to stressors. The recommendation is to have a foam that can either withstand 50 psi or more (Figures 53 and 54), in addition to being closed celled to prevent fluid transport. These findings will be subjected to the sites' discretion. Due to all the types of adhesion failure that occurred, the I-R2 is best suited to be used as a mechanical plug. ASTM C1892: Nominal Joint Strength of End-Plug Joints in Advanced Ceramic Tubes at Ambient and Elevated Temperatures states the adhesion testing done was testing the push out force and nominal joint strength when failure happened [99].

Future work will need to be done to ensure quality performance in PFFs. Applying additional seismic activity like an earthquake activity can ensure this technology can withstand multiple seismic events. Due to the I-R2 underperforming during the muffle furnace test, additional measures must be taken. Either combining an insulated material like concrete or configuring the expandable graphite content can help ensure adhesion performance in extreme heat conditions. The smaller volumes had a tighter data spread 
than the larger volumes due to more internal pressure being exerted on the inner walls. This can be a means of improving the pressure-carrying capabilities and failure mechanisms by confining the foam, so it can build compressive stress as in the case of the 2-inch-tall 2inch diameter sample set $\left(6.28 \mathrm{in}^{3}\right)$ in Figure 53. Aging and radioactive material exposure studies should be considered to determine effects on adhesion and immobilization capabilities. All these findings and considerations are promising and can push forward the implementation of this technology in the future. 


\section{REFERENCES}

1. Cary, A. Plutonium-contaminated Hanford 'canyon' is deteriorating. Environment is at risk. study says. 2019; Available from: https://www.tricityherald.com/news/local/hanford/article232328877.html.

2. Falconer, F.L., Idaho National Engineering Laboratory (INEL) Environmental Restoration (ER) Program Baseline Safety Analysis File. 1995.

3. Abitz, R., Duncan, A., Kane, M., Dewberry, R., and Santos, J., Planning for the Decontamination of the Plutonium Fuel (PuFF) Facility Savannah River Site (SRS), South Carolina. 2010.

4. Renovations Extend Life of Savannah River National Laboratory Facility. 2017; Available from: https://www.energy.gov/em/articles/renovations-extend-lifesavannah-river-national-laboratory-facility.

5. $\quad$ Foppe, L.T., Comparison of Risk-Dominant Scenario Assumptions for Several TRU Waste Facilities in the DOE Complex. 1999. p. 6-7.

6. $\quad$ Backgrounder on Decommissioning Nuclear Power Plants. 2018.

7. Administration, O.S.a.H. Decontamination. 1985.

8. Demmer, R., Fox, D., Reese, S., and Banford, A., Fixatives Used for Decommissioning and Maintenance of Radiological Facilities. 2017. p. 1-3.

9. Vartbedian, R., Must Reads: Hidden danger: Radioactive dust is found in communities around nuclear weapons sites. 2018, Los Angeles Times.

10. Vertabedian, R., Nation's most ambitious project to clean up nuclear weapons waste has stalled at Hanford. 2019, Los Angeles Times.

11. Vartabedian, R. Nuclear accident in New Mexico ranks among the costliest in U.S. history. 2016 [cited 2019; Available from:

https://www.latimes.com/nation/la-na-new-mexico-nuclear-dump-20160819snap-story.html.

12. ASTM E3191-18: Standard Specification for Permanent Foaming Fixatives Used to Mitigate Spread of Radioactive Contamination. p. 1-2.

13. Ionescu, M., Chemistry and Technology of Polyols for Polyurethanes. 2005, Rapra Technology Limited: Shawbury, UK. 
14. Zia, K.M., Anjum, S., Zuber, M., Mujahid, M., and Jamil, T., Synthesis and molecular characterization of chitosan based polyurethane elastomers sing aromatic diisocyanate. 2014, Int. J. Biol. Macromol. p. 26-32, 66.

15. Akindoyo, O.J., et al., Polyurethane types, synthesis and appications- a review. 2016. p. 2-3, 5-7.

16. Taheri, N. and S. Sayyahi, Effect of clay loading on the structural and mechanical properties of organoclay/HDI- based thermoplastic polyurethane nanocomposites. 2016, e-Polym. p. 65-73.

17. Rafiee, Z. and V. Keshavarz, Synthesis and characterization of polyurethane/microcrystalline cellulose bionanocomposites. 2015, Prog. Org. Coat. p. 190-193.

18. Zia, K.M., H.N. Bhatti, and I.A. Bhatti, Methods for polyurethane and polyurethane composites, recycling and recovery: A review. 2007, React. Funct. Polym. p. 675-692.

19. Chattopadhay, D. and K. Raju, Structural engineering of polyurethane coatings for high performance applicatons. 2007, Prog. Polym. Sci. p. 352-418.

20. Szycher, M., Handbook of polyurethanes. 1999, CRC Press: Boca Raton, Fl.

21. Silvertsen, K., Polymer foams. 2007. p. 1-10.

22. Anisur, M.R., Kibria, M., Mahfuz, M., Saidur, R., and Metselaar, I., Energy Sustainability Through Green Energy. 2015, Latent Heat Thermal Storage (LHTS) for Energy Sustainability. p. 76-86.

23. Gama, N., A. Ferrerira, and A. Barros-Timmons, Polyurethane Foams: Past, Present, and Future. 2018. p. 1-5, 9,11-12.

24. Ashida, K., Polyurethane and Related Foams Chemistry and Technology. 2007, Taylor \& Francis Group: Boca Raton, Fl. USA.

25. Elwell, M., Ryan, A., Grunbauer, H., and Van Leishout, H., Studies of Structure Development during the Reactive Processing of Model Flexible Foam Systems Using FT-IR Spectroscopy, Synchroton SAXS, and Rheology. 1996, American Chemical Society. p. 2960-2968.

26. DeBell, J.M., W.C. Goggin, and W.E. Gloor, German plastic practice. 1946, DeBell and Richardson: Cambridge, Mass. 
27. Lee, S.-T. and N.S. Ramesh, Polymeric Foams: Mechanisms and Materials. 2004, CRC Press: New York, NY, USA.

28. Titow, W.V., PVC Technology. 2001: Shawbury, UK. p. 146.

29. Szycher, M., Szycher's Handbook of Polyurethanes;. 2006: New York, NY.

30. Buist, J.M. and Lowe, A., The Chemistry of Polyurethanes and Their Applications. 1965, Annals of Work Exposures and Health. p. 143-145.

31. Defonseka, C., Practical Guide to Flexible Polyurethane Foams. 2013, Smithers Rapra: Shawbury, UK.

32. Krol, P., Linear Polyurethanes: Synthesis Methods, Chemical Structures, Properties and Applications. 2008, VSP: Leiden, The Netherlands.

33. Javni, I., W. Zhang, and Z.S. Petrovickansaspetrovic, Effect of different isocyanates on the properties of soy-based polyurethanes. 2003, J. Appl. Sci. p. 2912-2916.

34. Motokucho, S., Nakayama, Y., Morikama, H., and Nakatani, H., Environmentalfriendly chemical recycling of aliphatic polyurethanes by hydrolysis in a CO2/water system. 2018, J. Appl. Polym. Sci. p. 135.

35. Shufen, L., Zhi, J., Kaijun, Y., Shuqin, Y., and Chow, W., Studies on the thermal behavior of polyurethanes. 2006, Polym. Plast. Techno. Eng. p. 95-108.

36. Gibson, J.L. and F.M. Ashby, Cellular solids- Structural Properties. 2 ed. 1999.

37. Klempner, D. and V. Sendijarevic, Polymeric foams and Foam Technology. 2004, Hanser.

38. Throne, J., Thermoplastic Foam Extrusion. 2004, Hanser.

39. de Vries, D.V.W.M., Characterization of polymeric foams. 2009. p. 5.

40. Roberts, A.P. and E.J. Garboczi, Elastic moduli of model random threedimensional closed-cell cellular solids. 2001, Acta Mater. p. 49, 189-197.

41. Roberts, A.P. and E.J. Garboczi, Elastic properties of model random threedimensional open-cell solids. 2002, J Mech Phys Solids. p. 33-55.

42. Vries, D.V.W.M.d., Characterization of polymeric foams. 2009: Eindhoven University of Technology. p. 4-9. 
43. Hamilton, A.R., Evaluation of the anisotropic mechanical properties of reinforced polyurethane foams. 2013, Queen's University Belfast. p. 6-9.

44. Istrate, O.M. and B. Chen, Relative modulus-relative density relationships in low density polymer-clay nanocomposite foams. 2011, Soft Matter. p. 1840-1848.

45. Sorrentino, L., Aurilia, M., Forte, G., and Iannace, S., Anisotropic mechanical behavior of magnetically oriented iron particle reinforced foams. 2011, J Appl Polym Sci. p. 1239-1247.

46. MIT, Constitutive Equations. 2013: MIT. p. 40-59.

47. DOE-EM, Contamination Control Fixative List. 2011. p. 5.

48. Hoikkanen, M., Injection Moulded Thermoplastic Elastomer - Metal Hybrids. 2012: Tampere University of Technology.

49. Amancio-Filho, S.T. and J.F.d. Santos, Joining of Polymers and Polymer - Metal Hybrid Structures: Recent Developments and Trends. 2009. p. 1461-1476.

50. Comyn, J. and A.J. Kinloch, Durability of Structural Adhesive Technology. 1983, Applied Science: London. p. 85.

51. Amacio-Filho, S.T. and J.F. dos Sanots, Joining of Polymers and Poler - Metal Hybrid Structures: Recent Developments and Trends, . 2009, Polym. Eng. Sci. p. 1461-1476.

52. Boutar, Y. and S. Naimi, Effect of adhesive thickness and surface roughness on the shear strength of aluminum one-component polyurethane adhesive single lap joints for automotive appllcations. 2016. p. 17.

53. Marshall, S.J., Bayne, S., Baier, R., Tomsia, A., and Marshall, G., A review of adhesion science. 2010, Dent. Mater.

54. Petrie, E.M., Handbook of adhesives and sealants. 2000, Mc Graw-Hill: New York, N.Y.

55. Couvrat, P.L., The modern structural bonding: theory and practice. 1992, Paris: Tec \& Doc-Lavoiser.

56. Chemimi, M.M. and J.F. Watts, An XPS study of the steel-aromatic moisturecured urethane interface. 1992, J. Adhes. p. 377-393.

57. Gaehde, J., Friedrich, J., Gehrke, R., and Sachse, J., Adhesion of Polyurethane to Surface-modified Steel. 2012, J. Adhes. p. 569-586. 
58. Baldan, A., Adhesively-bonded joints and repairs in metallic allots, polymers and composite materials: Adhesives, adhesion theories and surface pretreatment. 2004, J. Mater Sci. p. 1-49.

59. Ramarathnam, G., Joining of Polymers to Metal. 1992, Weld. Res. Suppl. p. 483490.

60. Hopmann, C., Wunderle, J., Neus, A., Ochotta, P., Bobzin, K., and Schultz, C., Influence of surface treatment on the bond strength of plastics/metal hybrids. 2015, Zeitschrift Kuntstofftechnik.

61. Puentes-Parodi, J., Adhesion of Polyurethane-Steel Hybrids and Influence of Annealing on its Durability and Lifetime. 2018. p. 1-40.

62. Dillingham, G. and C. Moriarty, The Adhesion of Isocyanate-based Polymers to Steel. 2003, J. Adhes. p. 269-285.

63. Chattopadhyay, D.K. and D.C. Webster, Thermal stability and flame retardancy of polyurethanes. 2009, Prog. Polym. Sci. p. 1068-1133.

64. Ullah, S., A study of bonding mechanism of expandable graphine intumescent catings on steel substrates. 2011. p. 2-3.

65. Wang, J. and Y. Chen, Flame-retardant mechanism resulting from an intumescent system. 2005: Journal of Fire Sciences. p. 23, 55-74.

66. Mesquita, L.M.R., P.A.G. Piloto, and M.A.P. Vaz, An experimental study of intumescent fire protection coatings. Polytechnic Institute of Braganca: Branganca, Portugal. p. 1.

67. Zhang, L., Zhang, M., Zhou, Y., and Hu, L., The study of mechanical behavior and flame retardancy of castor oil phosphate-based rigid polyurethane foam containing expanded graphite and triethyl phosphate. 2013: ScienceDirect. 98 p. 2784-2794.

68. Nasir, K. and R. Sulong, An investigation into waterborne intumescent coatings with different fillers for steel application. 2016. p. 10.

69. Pagni, A., Pour in Place Polyurethane Foam as an impact Mitigation and Flame Retardant Material Used in Nuclear Material Transportation Containers - The Mechanism of Intumescence. 2014, General Plastics. p. 1-4.

70. Caplugs LLC. 
71. FR-3700 Last-A-Foam. General Plastics Manufacturing Company: Tacoma, Washington.

72. Technology, S.R.P. and S.R.N. Laboratory, Safety Analysis Report for Packaging Model 9977. 2007. p. 0, 2-i, 2-10, 2-18, 2-28, 2-48-73.

73. Packaging Transportation of Radioactive. 2004, DOE Order 460.1B:

Washington, DC.

74. Traeger, R.K., Physical Properties of Rigid Polyurethane Foams. 1967: Sandia Laboratory. p. 2-5, 10-12.

75. Lu, W.-Y., Mechanical Characterization of Rigid Polyurethane Foams. 2014, Sandia National Laboratory: Albuqyeque, New Mexico. p. 11-12, 14, 38, 54, 60, 68.

76. Lu, W.-Y., Korellis, J., Lee, K., and Grishaber, R., Hydrostatic and uniaxial behavior of a high density polyrurethane foam (FR-3720) at various temperatures. 1993.

77. Nicholas, L. and G.T. Gmitter, Cellular plastics. 1965. p. 85.

78. Neilsen, K.M., Lu, W.Y., Werner, T., Scherzinger, M., and Lo, S.C., Flexible Foam Model. 2018, Sandia National Laboratories. p. 10-16, 39.

79. Goods, S.H., Neuschwanger, C.L, Henderson, C., and Skala, D.M., Mechanical Properties and Energy Absorption Characteristics of a Polyurethane Foam. 1997. p. 20-25.

80. Timoshenko, S. and D.H. Young, Elements of Strength of Materials. 1962, Nostrand \& Co. Inc: New York, NY.

81. Zaretsky, E., Asaf, Z., Ran, E., and Aizik, F., Impact response of high density flexible polyurethane foam. 2012, Department of Mechanical University, Ben Gurion University: Israel. p. 2-6.

82. Dattelbaum, D.M., Robbins, D.L., Gustavsen, R.L., Sheffield, S., and Stahl, D.B., Shock compression of polyurethane foams. 2012, Los Alamos National Laboratory: Los Alamos, NM. p. 1-4.

83. Mahmood, N., Investigations on the Adhesion of Polyurethane Foams on Thermoplastic Material Systems. 2005. p. 30-31. 
84. Nicholson, J.C., Peters, B., Wilson, J., and Washington, A.L., Fabrication and Evaluation of Radiation Hardened Polyurethane Foams for D\&D Activities. 2016. p. 10-20.

85. Wiyono, P., P. Suprobo, and H. Kristijanto, Characterization of Physical and Mechanical Properties of Rigid Polyurethane Foam. 2016, Institut Teknologi Sepuluh Nopember: Indonesia. p. 1-8.

86. ASTM D3574: Standard Test Methods for Flexible Cellular Materials-Slab, Bonded, and Molded Urethane Foams. p. 4-5, 7-8.

87. ASTM D1623: Standard Test Method for Tensile and Tensile Properties of Rigid Cellular Plastics. ASTM. p. 4-7.

88. ASTM D1621: Standard Test Method for Compressive Properties of Rigid Cellular Plastics. p. 3-5.

89. Schiller, C. and M. Glos, Aesthetics and adhesion behavior of PU foam based composites with rigid facer materials. p. 1-5.

90. Commission, U.S.N.R., 71.73 Hypothetical accident conditions. 2017.

91. Ridha, M., Mechanical and failure properties of rigid polyurethane foam under tension. 2007: National University of Singapore. p. 7-9.

92. Day, K.W., Concrete Mix Design, Quality Control and Specification. 2006, Taylor \& Francis e-Library.

93. Azad, M., R. Serwan, and K. Taghreed, Relationship between cube and cylinder compressive strengths of mortar used for ferrocement. 2015. p. 249-250.

94. Al-Sanhawneh, E.I., Size effect and strength correction factors for normal weight concrete specimens under uniaxial compression stress. 2013, Contempt. Eng. Sci. p. 57-68.

95. Celik, A.O., Kiline, K., Tuncan, M., and Tuncan, A., Distributions of compressive strength obtained from various diameter cores. 2012: ACI Mater J. p. 597-606.

96. Jihad Hamad, A., Size and shape effect of specimen on the compressive strength of HPLWFC reinforced with glass fibers. 2015. p. 6.

97. Marinzuli, G., R. Surace, and A.D. Ludovico, A preliminary study on adhesion on steel cylinder filled with aluminum foam. 2013. p. 6. 
98. Langton, C., Cementitious grout for high level waste tank closure. 2018, Savannah River National Laboratory.

99. Materials, A.S.f.T.a., C1892: Nominal Joint Strength of End-Plug Joints in Advanced Ceramic Tubes at Ambient and Elevated Temperatures. 